\title{
GeoVision Analysis Supporting Task Force Report: Thermal Applications- Geothermal Heat Pumps
}

Approved for public release. Distribution is unlimited.
Xiaobing Liu

Patrick Hughes (Oak Ridge National Laboratory)

Kevin McCabe (National Renewable Energy Laboratory)

Jeffrey Spitler Laura Southard (Oklahoma State University)

April 2019 


\section{DOCUMENT AVAILABILITY}

Reports produced after January 1, 1996, are generally available free via US Department of Energy (DOE) SciTech Connect.

Website http://www.osti.gov/scitech/

Reports produced before January 1, 1996, may be purchased by members of the public from the following source:

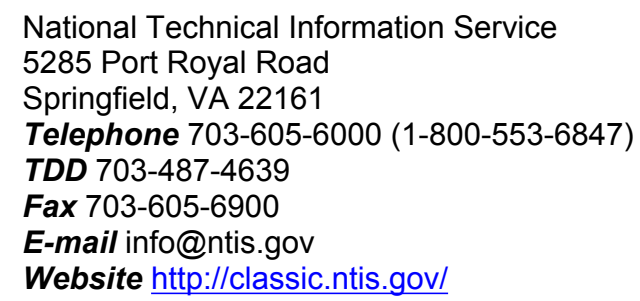

Reports are available to DOE employees, DOE contractors, Energy Technology Data Exchange representatives, and International Nuclear Information System representatives from the following source:

Office of Scientific and Technical Information

PO Box 62

Oak Ridge, TN 37831

Telephone 865-576-8401

Fax 865-576-5728

E-mail reports@osti.gov

Website http://www.osti.gov/contact.html

This report was prepared as an account of work sponsored by an agency of the United States Government. Neither the United States Government nor any agency thereof, nor any of their employees, makes any warranty, express or implied, or assumes any legal liability or responsibility for the accuracy, completeness, or usefulness of any information, apparatus, product, or process disclosed, or represents that its use would not infringe privately owned rights. Reference herein to any specific commercial product, process, or service by trade name, trademark, manufacturer, or otherwise, does not necessarily constitute or imply its endorsement, recommendation, or favoring by the United States Government or any agency thereof. The views and opinions of authors expressed herein do not necessarily state or reflect those of the United States Government or any agency thereof. 


\title{
Energy \& Environmental Sciences Directorate Building Equipment Research Group
}

\section{GeoVision Analysis Supporting Task Force Report: Thermal Applications-Geothermal Heat Pumps}

\author{
Xiaobing Liu, Patrick Hughes \\ (Oak Ridge National Laboratory) \\ Kevin McCabe \\ (National Renewable Energy Laboratory) \\ Jeffrey Spitler, Laura Southard \\ (Oklahoma State University)
}

April 2019

Prepared by

OAK RIDGE NATIONAL LABORATORY

Oak Ridge, TN 37831-6283

managed by

UT-BATTELLE, LLC

for the

US DEPARTMENT OF ENERGY

under contract DE-AC05-00OR22725 



\section{Acknowledgement}

This work was sponsored by the U.S. Department of Energy's (DOE's) Geothermal Technologies Offices (GTO) within the Office of Energy Efficiency and Renewable Energy. Special thanks to GTO's Director, Dr. Susan Hamm, for her leadership, Arlene Anderson for her technical oversight, and Jeff Winick for his management and coordination.

The analysis, conclusions, and recommendations in this report are solely those of the authors. Nevertheless, the author wishes to thank the following (listed in alphabetical order) for their valuable inputs:

Allan Jelacic, Independent Consultant (formerly U.S. Department of Energy)

Bob Wyman, Founder and Consultant, Dandelion (Home Geothermal)

Carrie Cobb, Research Lead, Bonneville Power Administration

Daniel Ellis, Chairman, Comfortworks, Inc.

Douglas Dougherty, President and CEO, GEO (The Geothermal Exchange Organization)

Garen N. Ewbank, CEM, BEP, CSDP, Ewbank Geo Testing, L.L.C.

John (Jack) P. DiEnna Jr., Executive Director, Geothermal National \& International Initiative

Joseph K. Warner, University of Tennessee

Katherine Young, Program Manager for Geothermal Energy, National Renewable Energy Laboratory

Kevin Madison, Energy Engineering Project Manager \& Principal, Madison Engineering, P.S.

Michael Albertson, Senior Vice President, WaterFurnace International

Michael Kennedy, Energy Sims

Paul Bony, Senior Program Manager, CLEAResult

Robert R. Brown, Vice President of Engineering, WaterFurnace International 


\section{CONTENTS}

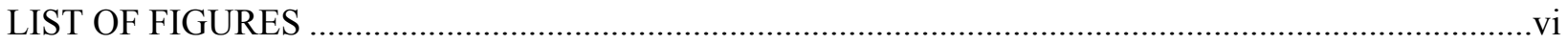

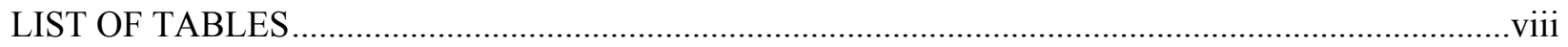

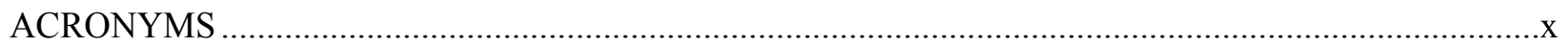

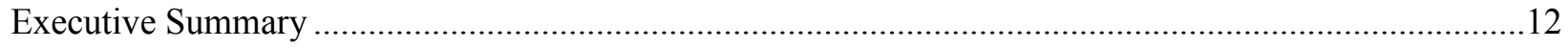

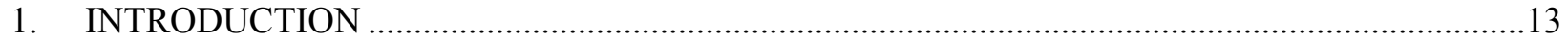

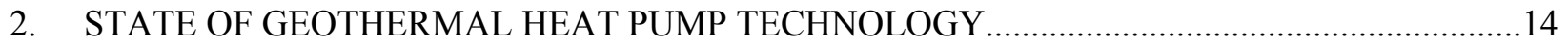

2.1 OVERVIEW OF GEOTHERMAL HEAT PUMP TECHNOLOGY ....................................14

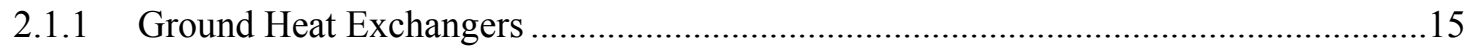

2.1.2 System Configurations and Heat Pump Equipment...................................................16

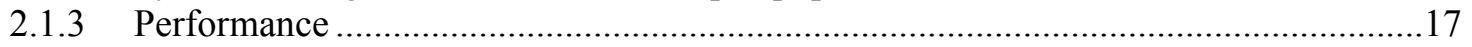

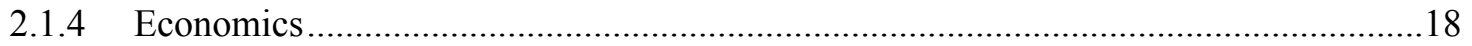

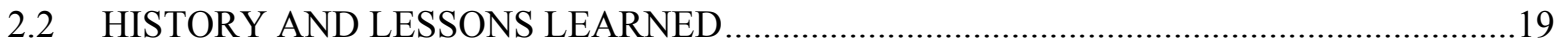

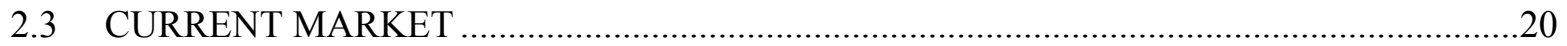

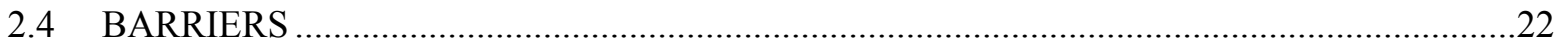

2.5 RESEARCH AND DEVELOPMENT FOR GEOTHERMAL HEAT PUMPS ......................24

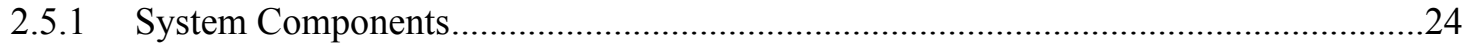

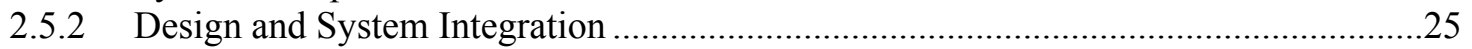

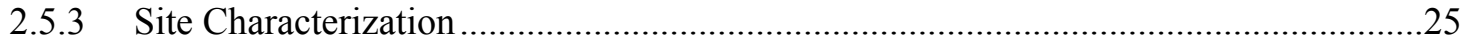

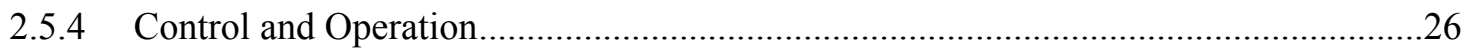

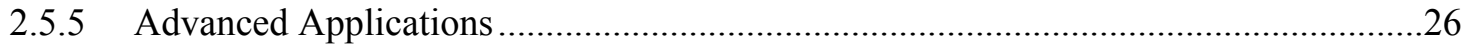

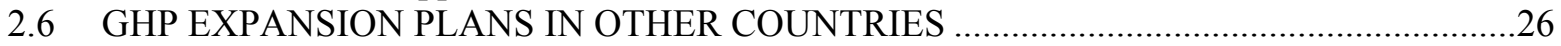

3. GEOTHERMAL HEAT PUMP APPLICATION GROWTH SCENARIO STUDY .......................28

3.1 PROCEDURE FOR ASSESSING GEOTHERMAL HEAT PUMP GROWTH

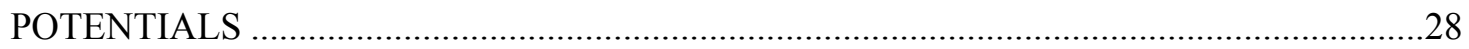

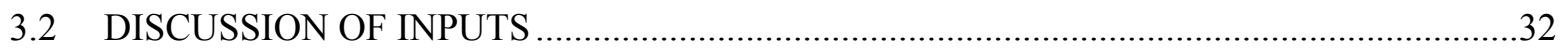

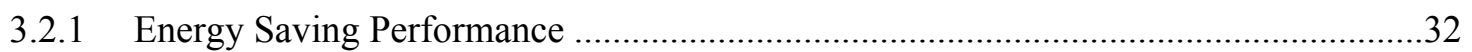

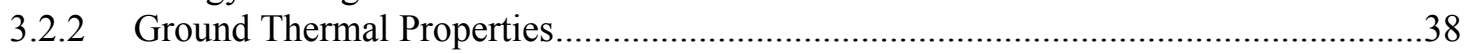

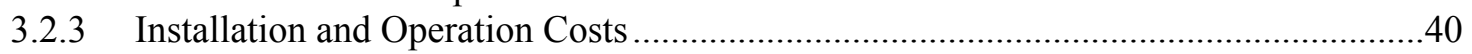

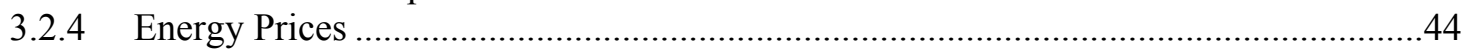

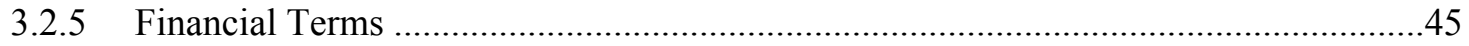

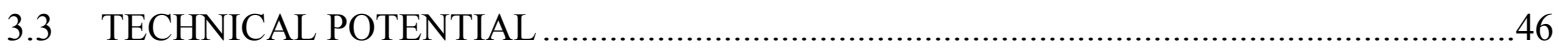

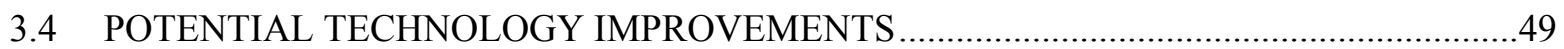

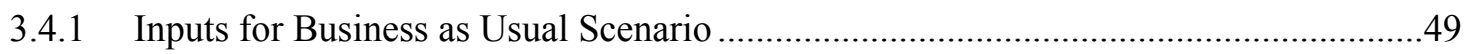

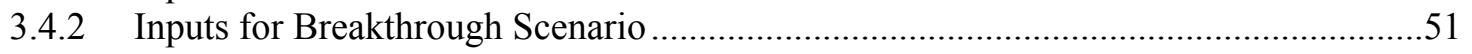

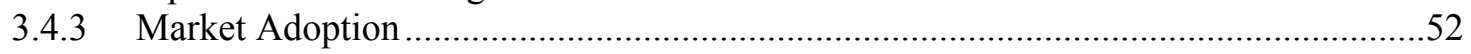

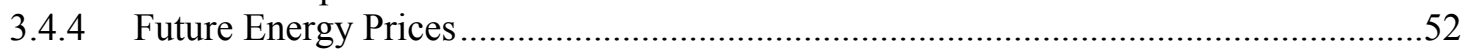

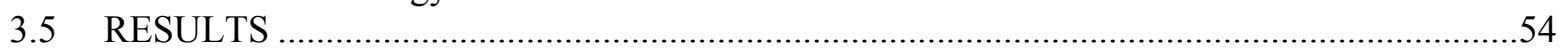

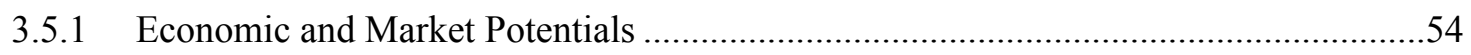

3.5.2 Projected Installed Capacity and Market Share of Geothermal Heat Pumps ...............56

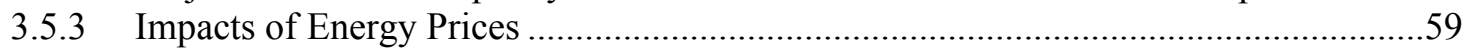

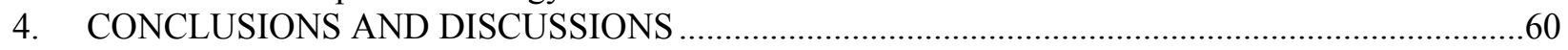

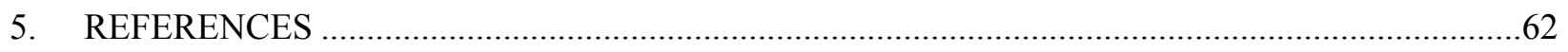





\section{LIST OF FIGURES}

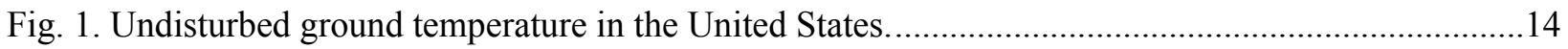

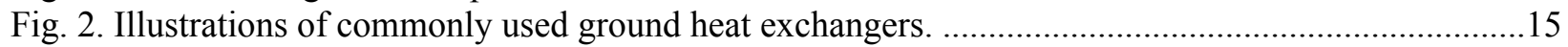

Fig. 3. Configuration of a typical distributed geothermal heat pump system.........................................16

Fig. 4. Case study results for 10 ARRA-funded GHP demonstration projects........................................18

Fig. 5. Distribution of GHP unit shipments in the United States in 2009............................................21

Fig. 6. Historic prices of natural gas (Source: EIA 2016c) ................................................................22

Fig. 7. Cumulative building floor space conditioned by geothermal heat pump systems in the

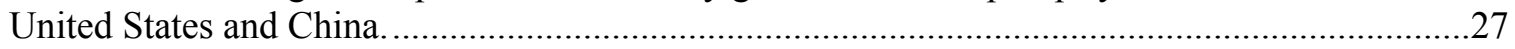

Fig. 8. A bottom-up procedure for assessing the growth potentials of GHP applications.........................29

Fig. 9. Data flow among various geothermal heat pump-related task forces working on the GeoVision Study.

Fig.10. Annual source energy saving percentages by building principal activities and climate zones.

Fig. 11. Annual carbon emission reduction percentages by building principal activities and climate zones.

Fig. 12. Annual energy cost savings percentages by building principal activities and climate zones.

Fig. 13. Annual peak electricity demand reduction percentages by building principal activities and climate zones.

Fig. 14. Location and value of available rock thermal conductivity data (data are adapted from SMU 2016)

Fig. 15. A comparison between rock thermal conductivity values and ground thermal conductivity values measured with in-situ thermal response tests.

Fig. 16. Statistical distribution of available rock thermal conductivity data in each climate zone..............40

Fig. 17. Installed costs of 1-, 2-, and 5-ton geothermal heat pump equipment (RSMeans 2016). ..............42

Fig. 18. Installed costs of typical residential space cooling equipment (RSMeans 2016).........................43

Fig. 19. Installed costs of typical residential space heating equipment (RSMeans 2016)........................43

Fig. 20. Installed costs of typical packaged VAV equipment (RSMeans 2016). .......................................44

Fig. 21. Projected residential energy prices (EIA 2016a) ......................................................................45

Fig. 22. The process for evaluating the technical potential of energy savings by GHPs in a county..........47

Fig. 23. Source energy savings potential (in trillions of British thermal units) in each county (excluding Alaska and Hawaii) from retrofitting existing HVAC systems in residential

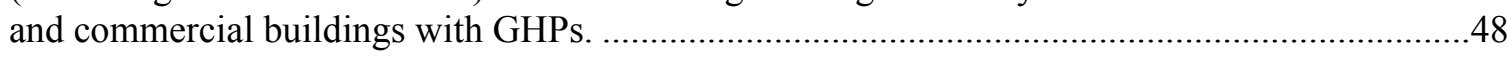

Fig. 24. EIA projected increase of GHP efficiencies from 2015 through 2050 (EIA 2017a)....................50

Fig. 25. EIA projected increase in efficiencies of natural gas furnace and central air conditioners

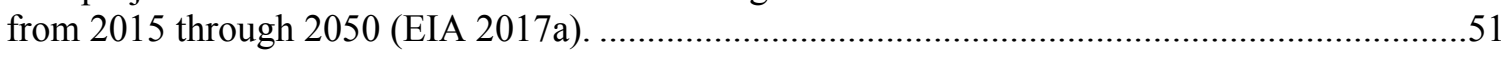

Fig. 26. Two different market adoption curves used in the scenario study ............................................52

Fig. 27. Projected energy prices under various scenarios in the 2016 Annual Energy Outlook (EIA

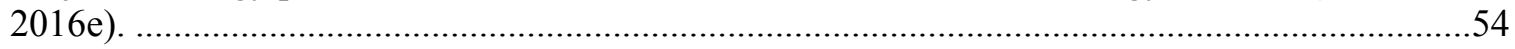

Fig. 28. Projected economic and maximum market potential of GHPs from 2014 through 2050 ............55

Fig. 29. Economic potential of GHPs in 2050: (a) conservative case; (b) optimistic case.........................56

Fig. 30. Projected cumulative installed GHP capacity from 2014 through 2050 ...................................57

Fig. 31. Projected market share of GHPs in the commercial and residential sectors from 2014

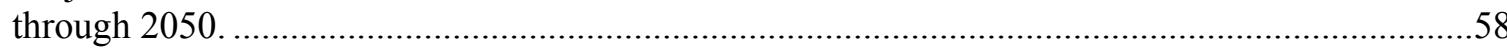

Fig. 32. Installed GHP capacities in 2050: (a) conservative case; (b) optimistic case. ............................59

Fig. 33. Impacts of technology development and energy prices on the installed GHP capacity................60 



\section{LIST OF TABLES}

Table 1. Energy Star minimum efficiency requirements for residential geothermal heat pump units for various applications (effective January 1, 2012).

Table 2. Costs of typical commercial geothermal heat pump systems in the United States......................17

Table 3. Categories and representatives of commercial buildings........................................................32

Table 4. Energy sources of existing heating, ventilation, and air-conditioning systems ${ }^{\text {a }}$...........................33

Table 5. Average prices of vertical closed-loop ground heat exchangers by dominant geology in each census region

Table 6. Technical potential of geothermal heat pump retrofits in the United States................................47

Table 7. Key inputs for the business as usual and breakthrough scenarios 



\section{ACRONYMS}

AEO

AFUE

ARRA

BOS

BT

CAGR

CBECS

COP

CRB

DER

dGen

dGeo

DOE

DU

DWH

EER

EIA

FEMP

GHP

GHPC

GHX

GS-IHP

GSHP

GTC

HVAC

NG

NPV

NREL

NZEB

O\&M

PV

RECS

$\mathrm{SC}$

$\mathrm{SH}$

SMU

TPF

TPO

TRT

VAV

WAHP
Annual Energy Outlook (EIA)

annual fuel utilization efficiency

American Recovery and Reinvestment Act

balance of the system

breakthrough

compound annual growth rate

commercial buildings energy consumption survey (EIA)

coefficient of performance

Commercial Reference Building (DOE)

distributed energy resource

Distributed Generation Market Demand Model (NREL)

Distributed Geothermal Market Demand Model (NREL)

US Department of Energy

direct use

domestic water heating

energy efficiency ratio

US Energy Information Administration

Federal Energy Management Program (DOE)

geothermal heat pump

Geothermal Heat Pump Consortium, Inc.

ground heat exchanger

ground-source integrated heat pump

ground-source heat pump

ground thermal conductivity

heating, ventilation, and air-conditioning

natural gas

net present value

National Renewable Energy Laboratory

near-zero-energy-building

operation and maintenance

photovoltaics

residential energy consumption survey (EIA)

space cooling

space heating

Southern Methodist University

third-party financing

third-party ownership

thermal response test

variable air volume

water-to-air heat pump 



\section{EXECUTIVE SUMMARY}

Geothermal heat pumps (GHPs), also referred to as ground-source heat pumps or Geo-exchange, have been proven capable of producing large reductions in energy use and associated carbon emissions for space conditioning and water heating in buildings. However, the current adoption rate of GHPs in the United States is still low, and GHPs receive little attention from either the public or policy makers. This report gives an overview of the status of GHP technology and its application in the United States, cost and performance of the state-of-the art GHP systems, barriers preventing wider adoption, and technologies under development that have potential to help overcome these barriers.

This report also presents an assessment of the technical potential of applying GHP systems in businesses and homes in the United States. The assessed technical potential includes energy savings, carbon emissions reductions, and consumer energy cost savings. This assessment is based on energy consumption data obtained from the latest residential and commercial buildings energy consumption surveys conducted by the US Department of Energy's Energy Information Administration (EIA). It uses the energy savings data of GHP systems compared with existing conventional heating, ventilation, and air-conditioning (HVAC) systems, which were obtained from numerous published case studies and validated computer simulations. The impacts of various climate and geological conditions, as well as the efficiency and market share of existing conventional HVAC systems, have also been considered in the assessment. The analysis results indicate that if all the existing HVAC systems in the residential and commercial sectors were retrofitted with GHPs (i.e., the technical potential of GHPs), in each year, primary energy consumption could be reduced by 5.7 quadrillion Btus (quads), $\mathrm{CO}_{2}$ emissions could be reduced by 356.3 million Mt, and energy costs could be reduced by $\$ 49.8$ billion. The 5.7 quad of primary energy savings from GHP retrofits could reduce national primary energy consumption for space heating and space cooling by $46 \%$ (based on 2010 U.S. building energy end-use data).

Furthermore, the economic and market potentials of GHP applications are assessed under several different scenarios of technological advancement and energy prices. The economic potential of GHPs, which is the sum of the potential GHP applications that result in positive net present value (NPV) of the investment, will reach $448 \mathrm{GW}_{\text {th }}$ by 2050 with the 2016 EIA Annual Energy Outlook (AEO) predicted reference case energy prices and low technology development. The economic potential could be increased by $30 \%$ to $582 \mathrm{GW}_{\text {th }}$ in 2050 through technology breakthroughs (i.e., reducing the installed costs of ground heat exchangers by $30 \%$ and improving the operational system efficiency of GHPs by $50 \%$ ).

The maximum market potential, which is the total installed capacity of GHPs that have payback periods acceptable to customers, would be $104 \mathrm{GW}_{\text {th }}$ by 2050, assuming a conservative customer adoption rate and with low technology development. However, with technology breakthroughs and an optimistic customer adoption rate, the maximum market potential of GHPs would be $231 \mathrm{GW}_{\text {th }}$ by 2050 .

Given the projected low energy prices throughout 2050, this analysis predicts that GHP installed capacity will grow at a low rate $(4.3 \%-5.4 \%$ CAGR) in the business as usual (BAU) scenario. This growth rate is about half that experienced globally from 2010 through 2015 (8.69\% CAGR) as reported by Lund and Boyd (2016). With this low CAGR, the total installed GHP capacity would be $77 \mathrm{GW}_{\text {th }}$ by 2050 , which is only about $5 \%$ of the predicted total HVAC market in 2050 .

To further increase the deployment of GHPs, substantial investment in R\&D is needed to significantly reduce costs and improve performance of GHPs. With the expected technology breakthroughs, the GHP installed capacity could be increased by $25 \%$ compared with the BAU scenario. The potential technology developments to reduce the cost of GHPs include development of lower cost and performance neutral GHXs (as well as associated techniques/equipment for installation), more cost effective GHP equipment and system configurations, and automated processes for installation and performance evaluation. Non- 
technology-related developments could also reduce the cost of GHPs, including volume manufacturing of GHP equipment (e.g., by merging small heat pump manufacturers), large scale GHP applications (e.g., district GHP systems) to take advantage of economies of scale, and a vertically integrated business model - from design, to build, to operate - to improve the efficacy and quality of GHP installations. The energy saving performance of GHPs could be increased though optimal design and integration of GHP systems. The accuracy, flexibility, and accessibility of GHP system design tools (e.g., computer models for various GHXs) and supporting data (e.g., geological characteristics and thermal properties of the shallow ground subsurface) need to be improved to enable optimal design and integration. Currently, ground thermal properties data, which are essential for sizing GHXs, are scarce and in situ measurements of these data are often too expensive for residential GHP projects. More cost-effective testing methods and a national database of high resolution ground thermal property data are highly desirable.

Increasing public awareness of and trust in GHPs is crucial to improve consumer acceptance. The results of this study indicate that the customer adoption rate could have a bigger impact than the technology advancement. Improved customer acceptance has potential to increase the installed GHP capacity in 2050 by $56 \%-58 \%$ depending on different levels of technology development. Individual system design is usually needed for each GHP application and the installation process of a GHP system often involves multiple contractors. Furthermore, it takes more effort to quantify the energy savings benefits of GHPs than just metering the kilowatt-hours generated with a Photovoltaics (PV) system. Streamlining deployment and performance verification are important and should be an integral part of programs for increasing public awareness and trust in GHPs.

To realize the economic potential of GHPs, which is 2.5 to 4.3 times higher than the maximum market potential, innovative financing (such as third-party-ownership or TPO) and associated business models are needed to overcome the high initial cost barrier by monetizing the energy savings, as well as other environmental and social benefits, over the lifetime of GHPs. However, TPO for GHPs was not investigated in this study due to the lack of supporting data to reliably model customer adoption for this innovative (early stage) business model. Further study is recommended to understand the challenges and potentials for implementing GHPs with TPO.

Energy prices affect the economics of the GHP investment. If the natural gas price increases by $35 \%$ as predicted in the 2016 AEO for the "Low Oil and Gas Resource and Technology" scenario, the GHP installed capacity could be increased by $26 \%$, which has about the same impact as technology breakthroughs. However, because energy prices are beyond the control of the GHP industry, technology development perhaps is the only certain way to make GHPs more economically competitive in this era of cheap energy.

\section{INTRODUCTION}

Geothermal heat pumps (GHPs) have been proven capable of producing large reductions in energy use, $\mathrm{CO}_{2}$ emissions, and peak electricity demand in buildings while satisfying the demands for space heating (SH), space cooling (SC), and domestic water heating (DWH). Thus, GHP technologies are among the most widespread green technologies for heating and cooling buildings. This report summarizes the results of a GHP study including the following: (1) a review of the status of GHP applications, (2) an assessment of the technical potential of GHP applications, (3) an analysis of the economic and market potential of GHP applications under different scenarios, and (4) recommended solutions to realize the potential of GHPs. 


\section{STATE OF GEOTHERMAL HEAT PUMP TECHNOLOGY}

This section covers the status of GHP technology; its applications, cost and performance, and market penetration; and the barriers preventing its wider adoption.

\subsection{OVERVIEW OF GEOTHERMAL HEAT PUMP TECHNOLOGY}

A GHP system is composed of a ground heat exchanger (GHX), one or multiple water-source heat pumps with extended operation range, and systems for air and water distribution. GHPs use the thermal mass in the shallow subsurface of the ground as the heat sink/source for heat pump operation. The ground temperature at about $30 \mathrm{ft}$ below the surface at a given location is constant all year long. This undisturbed ground temperature differs by location, but it typically ranges from $40^{\circ} \mathrm{F}$ to $70^{\circ} \mathrm{F}$ in most parts of the United States (Fig. 1). The small difference between the ground temperature and the desired room temperature (around $70^{\circ} \mathrm{F}$ ) makes GHPs very energy efficient for providing SC and SH. GHPs can also provide DWH. GHPs eliminate on-site combustion of natural gas (NG) or other fossil fuels for space and water heating and the associated emissions. Commercial GHPs can also reduce water use because they can work without using a cooling tower. According to an Office of the Assistant Secretary of Defense Memorandum dated October 14, 2015, GHPs have the longest estimated useful life of all energy efficiency, renewable energy, and water conservation technologies potentially used for Department of Defense Energy Conservation Investment Program Projects (DOD 2015).

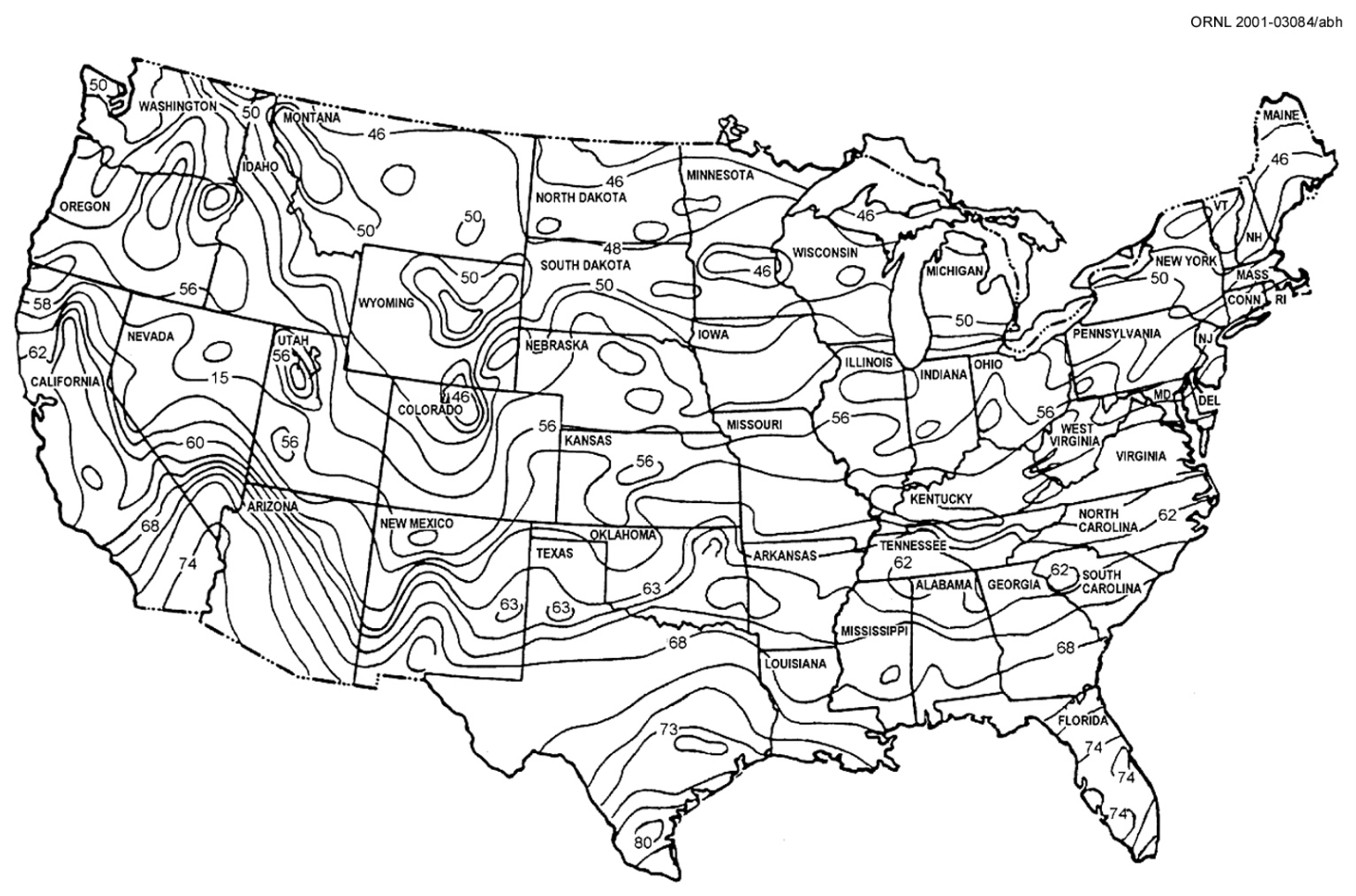

Fig. 1. Undisturbed ground temperature in the United States.

\subsubsection{Ground Heat Exchangers}

There are several different types of GHXs, including closed-loop ground-coupled heat exchangers, openloop or semi-closed-loop groundwater water wells, and open- or closed-loop surface water (e.g., pond or lake) heat exchangers. Figure 2 shows a few commonly used GHXs. The clear majority of GHP systems 
in the United States use closed-loop GHXs. It was estimated that $46 \%$ of the existing GHP systems use vertical closed-loop GHXs and 38\% of GHP systems use horizontal closed-loop GHXs. Numerous designs for vertical closed-loop GHXs exist, including single pipe, multiple pipes, coiled pipes, or coaxial pipes. The remaining $16 \%$ of GHP systems use groundwater or surface water in an open- or closed-loop configuration (Lund 2001).

Truck-mounted rotary or sonic drilling equipment, which is usually designed for water well or oil drilling, is most commonly used to drill the boreholes for vertical closed-loop GHXs (Sachs 2002). Directional drilling technology, which is primarily used in the oil and natural gas industry, has been adapted recently to drill angled or horizontal boreholes to reduce land requirements and disturbance of the ground surface (Remund and Carda 2009). The most commonly used equipment for installing horizontal loops includes bulldozers, backhoes, vibratory plows, chain trenchers, or directional borers.
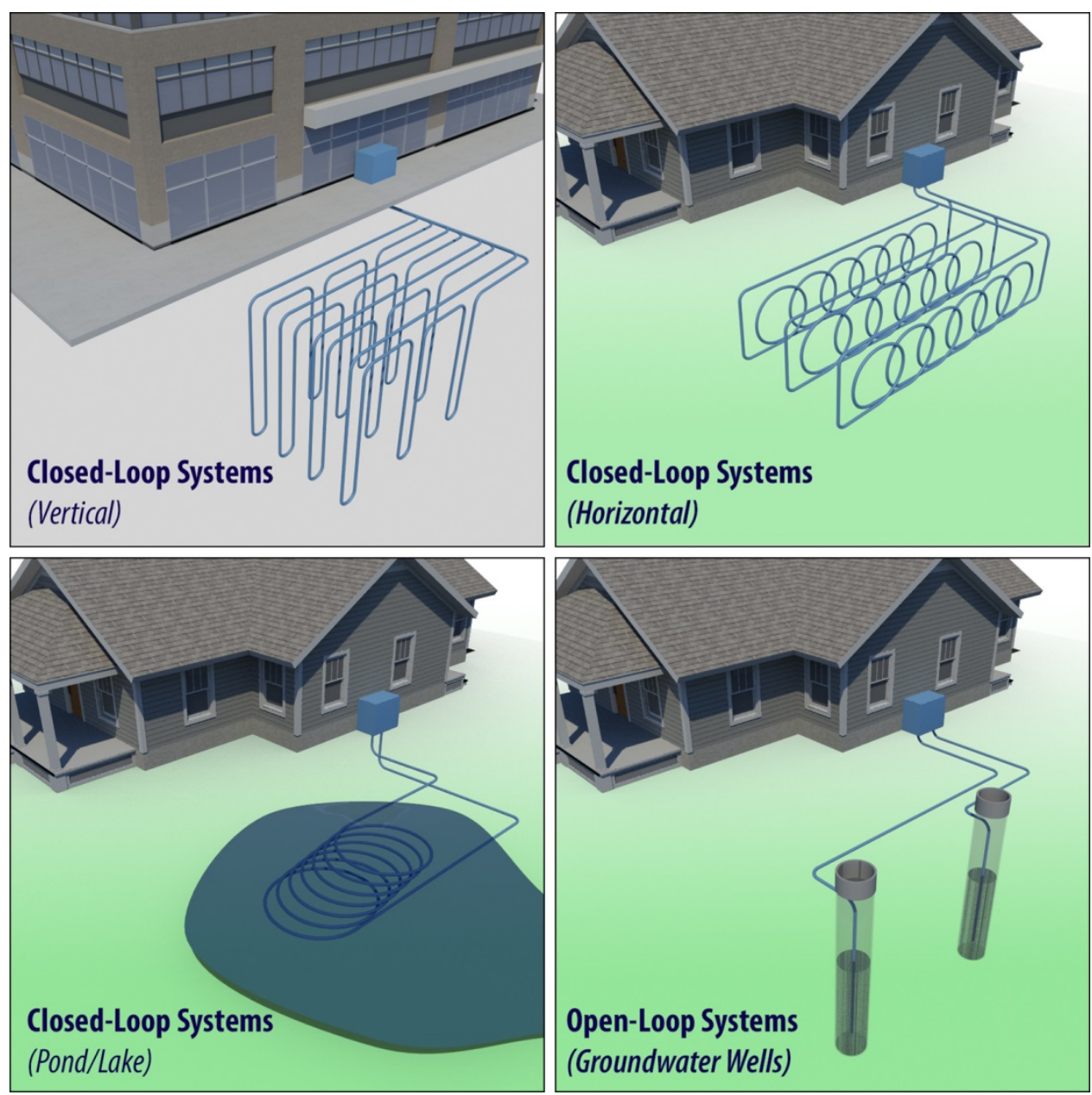

Fig. 2. Illustrations of commonly used ground heat exchangers.

\subsubsection{System Configurations and Heat Pump Equipment}

The most common GHP system configuration used in US homes consists of a packaged or split water-toair heat pump (WAHP) with a centrally ducted forced-air distribution system that conditions one floor of a multistory home or the entire house. 
For commercial buildings (e.g., offices, schools, hotels, or large residential buildings with multiple dwelling units), distributed GHP systems are predominantly used in the United States (Liu 2012). With a distributed GHP system, each zone of the building is conditioned with an individual WAHP, and the multiple WAHPs are connected to a common water loop (Fig. 3). Traditionally, a two-pipe water loop is used with a variable speed central pumping station. The cooling capacities of the WAHP units usually range from 0.5 to 20 ton $(1.74-70 \mathrm{~kW})$.

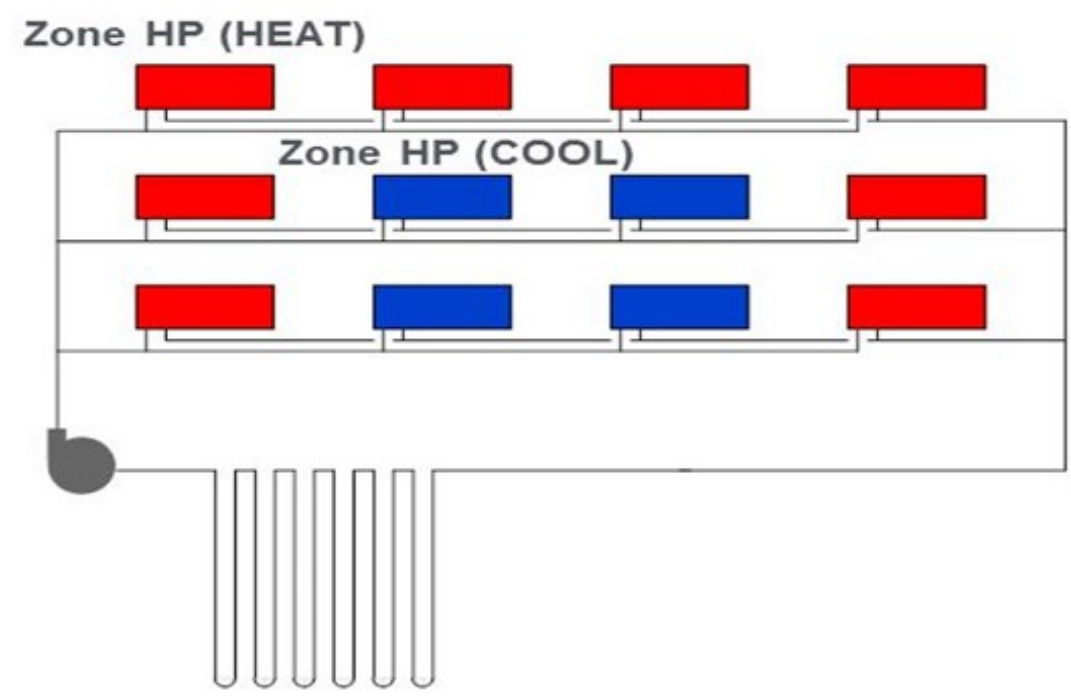

Fig. 3. Configuration of a typical distributed geothermal heat pump system.

Central GHP systems, which use large heat pumps or modular water-to-water heat pumps to generate hot and/or chilled water for delivery to the conditioned space, have also been used in the United States, especially for retrofitting existing central chiller and boiler systems. To satisfy the simultaneous demands for heating and cooling in different zones of a building, central GHP systems in the United States usually have four-pipe distribution systems: two pipes for supply and return of chilled water and another two pipes for supply and return of hot water.

The currently allowed minimum efficiency for GHP equipment is an energy efficiency ratio (EER) of 14.1 and a coefficient of performance (COP) of 3.2 (ASHRAE 2016). Energy Star has higher minimum efficiency requirements (Table 1) for GHP equipment (DOE 2012a), which is a prerequisite for obtaining the available federal tax credits (DOE 2013) and other existing financial incentives. Currently more than 3,600 GHP models have been certified by Energy Star. Many currently available two-stage or variable speed GHP equipment has higher energy efficiency than the Energy Star requirement at part-load conditions (e.g., when the heat pump compressor is running at low stage).

Table 1. Energy Star minimum efficiency requirements for residential geothermal heat pump units for various applications (effective January 1, 2012)

\begin{tabular}{|c|c|c|c|}
\hline \multicolumn{2}{|c|}{ Product type } & $\begin{array}{c}\text { EER } \\
(\mathrm{Btu} / \mathbf{W})\end{array}$ & $\begin{array}{c}\text { COP } \\
(W / W)\end{array}$ \\
\hline \multirow{2}{*}{ Water-to-air } & Closed-loop & 17.1 & 3.6 \\
\hline & Open-loop & 21.1 & 4.1 \\
\hline \multirow{2}{*}{ Water-to-water } & Closed-loop & 16.1 & 3.1 \\
\hline & Open-loop & 20.1 & 3.5 \\
\hline
\end{tabular}


Notes:

- The "closed-loop" and "open-loop" applications refer to "ground loop" and "groundwater" applications as defined in ISO/AHRI/ASHRAE Standard 13256, respectively.

- $\quad E E R=$ energy efficiency ratio; used to indicate the cooling efficiency of heat pump equipment.

- $\quad \mathrm{COP}=$ coefficient of performance; used to indicate the heating efficiency of heat pump equipment.

The efficiency and applicability of GHP equipment has been improved significantly in recent years because of several technological advancements, including inverter-compressor technology with communicating controls and improvements and refinements to refrigerant coils and to all aspects of variable-speed motors (Horwitz-Bennet 2014). These GHP equipment can vary their heating or cooling outputs in a wide range-from $20 \%$ to $130 \%$ - provide good humidity control and even eliminate the need for auxiliary heat in cold climates. The latest GHP models launched by a few manufactures have EERs for cooling higher than $40^{1}$ and COPs of up to 5.3 for heating. At least one of these new GHP models can provide not only SH and SC, but also $100 \% \mathrm{DWH}$ (it is usually referred as the ground-source integrated heat pump or GS-IHP) ${ }^{2}$. A recent field study (Baxter et al. 2016) indicated that the GS-IHP provided $54.6 \%$ total source energy savings compared to a baseline electric heat pump and electric water heater at Knoxville, Tennessee for the 2015-2016 test year. In addition to the source energy savings, the GS-IHP also resulted in a peak demand savings ranging from $54 \%$ to $78 \%$ per month and an energy cost savings of $\sim 64 \%$. More and more GHP manufacturers offer online control and monitoring capabilities to provide homeowners with key data on their energy use and tools to control it. These features also help contractors diagnose and fix problems more efficiently (Horwitz-Bennet 2014).

\subsubsection{Performance}

Numerous previous studies confirmed that properly designed, installed, and operated GHP systems use significantly less energy than conventional heating, ventilation, and air-conditioning (HVAC) systems (Hughes and Shonder 1998, Southard et al. 2014, Liu et al. 2017). Recent case studies of 10 GHP demonstration projects that were funded in part by 2009 American Recovery and Reinvestment Act (ARRA) grants indicate significant savings in energy and associated costs and reductions in carbon emissions (Fig. 4). On an annual basis, these GHP systems have avoided 27\%-66\% source energy consumption, reduced carbon emissions by $21 \%-66 \%$, and saved $18 \%-65 \%$ of the energy costs for conditioning the host buildings. In addition, significant water savings have also been achieved in some cases. Case studies also found that more benefits can be achieved if design/control is improved, including optimal system integration to maximize heat recovery and smarter control to avoid excessive pumping power (Liu et al. 2017).

\footnotetext{
${ }^{1}$ Equivalent to a cooling COP of 11.7 .

${ }^{2}$ ClimateMaster launched the Trilogy ${ }^{\mathrm{TM}} 40$ Q-Mode ${ }^{\mathrm{TM}}$ series GS-IHP in 2014, now known as the Trilogy 45® Q-Mode ${ }^{\circledR}$ (http://www.climatemaster.com/residential/trilogy). The AHRI (Air-Conditioning, Heating, and Refrigeration Institute) certified efficiency of one of the commercially available Trilogy $45 \AA$ units is 45.1 EER (Btuh/Watt) and 5.1 COP.
} 


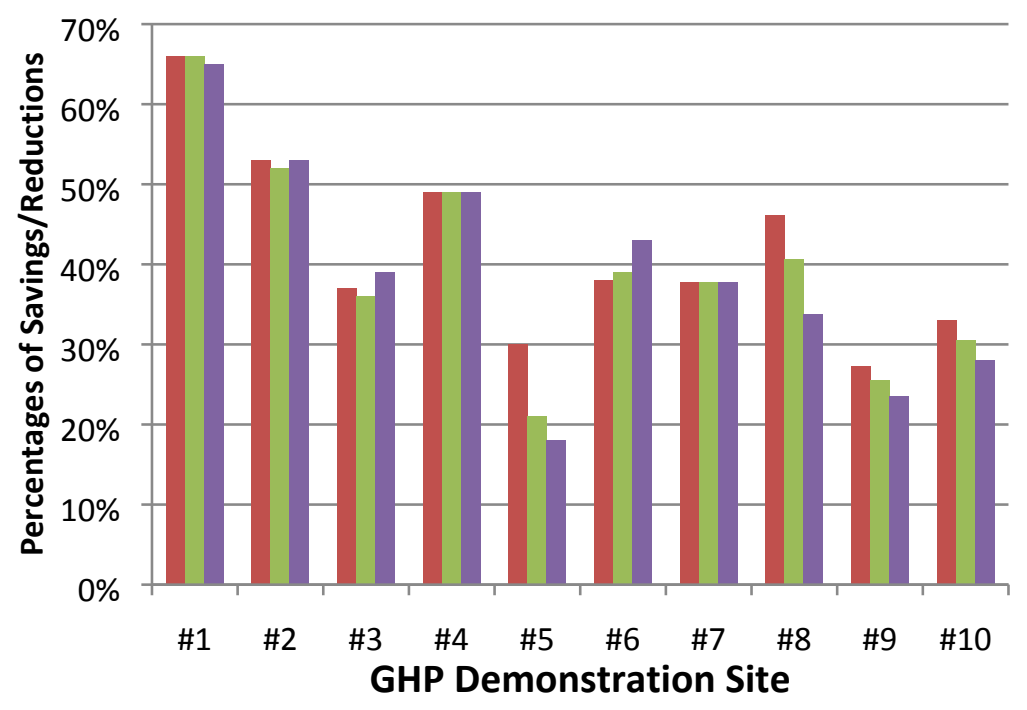

Source energy savings (HVAC)

Carbon reductions (HVAC)

Energy cost savings (HVAC)

Fig. 4. Case study results for 10 ARRA-funded GHP demonstration projects.

\subsubsection{Economics}

The cost of GHP systems varies widely depending on geological conditions, building loads, system designs, and heat pump equipment. The typical price of a GHP system installed in a new home is in the range of $\$ 3,000-\$ 5,000$ per ton (Ellis 2008); the average price for large-scale housing retrofits is $\$ 4,600$ per ton in 2006 dollars (DOD 2007).

A few recent surveys have been conducted in the United States to collect cost information for commercial GHP systems. According to these surveys, the average cost of a commercial GHP system increased by $129 \%$, from $\$ 9.07 / \mathrm{ft}^{2}$ in 1995 to $\$ 20.75 / \mathrm{ft}^{2}$ in 2012 , or about $5 \%$ annually over the 17 -year period (Kavanaugh et al. 2012). This study determined that the cost increase (177\%) for the interior portion of the GHP system (including the heat pump and other major equipment, controls, piping, and duct work) exceeded the cost increase for the closed-loop GHX portion (52\%) over the 17-year period. In other words, costs for the indoor components, for which the technology is relatively mature, rose at a higher annual rate (6\%) than the inflation rate (about 3\% per year), whereas the annual increase rate of the GHX cost $(2.5 \%)$ was slower than the inflation rate, presumably because of innovations in cost reduction and increased competition in the market. Table 2 presents the costs of components of typical commercial GHP systems that use closed-loop vertical GHXs. Most of these cost data are from the survey conducted by Kavanaugh et al. (2012), except the cost of water-source heat pumps, which was estimated based on data from a recent US Energy Information Administration (EIA) report (EIA 2010).

Table 2. Costs of typical commercial geothermal heat pump systems in the United States

\begin{tabular}{lc}
\hline \multicolumn{1}{c}{ Item } & $\begin{array}{c}\text { Cost } \\
(\mathbf{\$})\end{array}$ \\
\hline Water-source heat pump & $2.5-4 / \mathrm{ft}^{2}$ \\
\hline Closed-loop vertical GHX & $6.76-15 / \mathrm{ft}^{-}$ \\
\hline Total system & $13-26 / \mathrm{ft}^{2}$ \\
\hline
\end{tabular}


The simple payback period for a GHP retrofit project in the United States is usually $8-14$ years; and for new construction, the simple payback period is shorter, but a payback period of more than 5 years is still common (Hughes 2008).

\subsection{HISTORY AND LESSONS LEARNED}

In October 1993, the Clinton administration launched the Climate Change Action Plan and the voluntary Climate Challenge, a partnership between the US Department of Energy (DOE) and major electric utilities that pledged to reduce their greenhouse gas emissions. The Climate Challenge attracted more than 50 utilities, whose chief executive officers sent letters to the Secretary of Energy stating their intent to either stabilize their greenhouse gas emissions at or below their 1990 levels or reduce their emissions to a different measurable performance level (DOE 1993). The electric utility industry selected GHP technology as one of its five initiatives under the President's Climate Change Action Plan. The GHP market mobilization and technology demonstration initiative became known as the National Earth Comfort Program, and the Geothermal Heat Pump Consortium, Inc. (GHPC) was formed to implement it (GHPC 2001).

At about the same time, DOE's Federal Energy Management Program (FEMP) was formed to reduce the cost and environmental impact of the government by advancing energy efficiency and water conservation, promoting the use of renewable energy, and improving utility management decisions at federal sites. Aggressive US federal energy goals, expressed in terms of energy intensity (site usage in British thermal units per building area), were established by Executive Order (EOP 1999). The goals for 2005 and 2010 were $30 \%$ and $35 \%$ reductions, respectively, in energy intensity in all federal agencies (excluding industrial and laboratory facilities) compared with energy consumption in 1985. To assist agencies in meeting these goals, FEMP established a comprehensive GHP program including technical assistance and use of energy savings performance contracts to privately finance GHP retrofit projects in federal buildings.

The GHP programs implemented by GHPC for privately owned buildings and by FEMP for federally owned buildings clearly accelerated the growth of the GHP industry. Annual sales of GHPs nearly doubled from 1994 to 1999, and GHP shipments to the federal market increased more than 10-fold from FYs 1999 to 2001 (Hughes and Pratsch 2002).

Although this authority has seldom been used because of administrative challenges, federal legislation in 2007 authorized the US Department of Agriculture Rural Utilities Service to provide 35-year loans from government funds to rural electric cooperatives for installing GHXs for customers. The rural electric cooperatives recovered the cost of repaying the funds through a tariff on customer electricity bills (DOA 2007).

In 2009 the US economy was faltering, and federal legislation was passed to create jobs and stimulate the economy (ARRA 2009). Congress directed that $\$ 400$ million of DOE funds be committed for geothermal energy, and DOE used its discretionary powers to allocate $\$ 67$ million to GHP programs. Almost all this funding was used for GHP demonstration projects (Hughes et al. 2011).

As a result of a sequence of pieces of federal legislation, tax credits were provided for GHP systems installed between December 1, 2009, and December 31, 2016, so long as the heat pump met Energy Star requirements. The residential tax credit was for 30\% of the entire installed cost of the GHP system with no maximum cap; the commercial tax credit was for $10 \%$ of the entire installed system, and the GHP system was subject to a 5-year depreciation period (DOE 2013). The tax credits were reinstated retroactively to include GHPs installed after Jan. 1, 2017 and extended to Jan. 1, 2022 (GEO 2018). 
Unfortunately, since EIA discontinued its survey of US GSHP unit shipments in 2010, sufficient data are not available to analyze the impacts of these incentives/programs for promoting GHP applications in the United States.

\subsection{CURRENT MARKET}

A recent Navigant Research report (2013) indicates that the United States represented 29\% of global GHP installations by capacity with $13.5 \mathrm{GWt}$ (3.9 million cooling tons, ${ }^{3}$ or 1.1 million GHP equipment given the typical GHP unit size is about $12 \mathrm{kWt}$ ) installed by 2012. This report also indicated that the split between the cumulative residential and commercial GHP applications is $3.5: 1$. According to Lund and Boyd (2016), the installed capacity of GHPs in the United States had increased to $16.8 \mathrm{GWt}$ (or about 5 million cooling tons) by 2016 . About $75 \%$ of residential applications are in new construction and $25 \%$ in retrofits of existing homes (Ellis 2008). It is estimated that these GHP systems have provided space conditioning to roughly 199 million $\mathrm{m}^{2}\left(2.14\right.$ billion $\left.\mathrm{ft}^{2}\right)$ of residential and commercial buildings in the United States. ${ }^{4}$ The current market share of GHPs in the US HVAC market is about 1\% (EIA 2016a).

\footnotetext{
${ }^{3}$ A cooling ton is equal to $3.5 \mathrm{~kW}$ cooling capacity.

${ }^{4}$ The total floor space conditioned by GSHP systems is estimated based on the typical floor space per ton ratio in the United States $-400 \mathrm{ft}^{2}$ per ton for commercial buildings and $600 \mathrm{ft}^{2}$ per ton for residential buildings.
} 


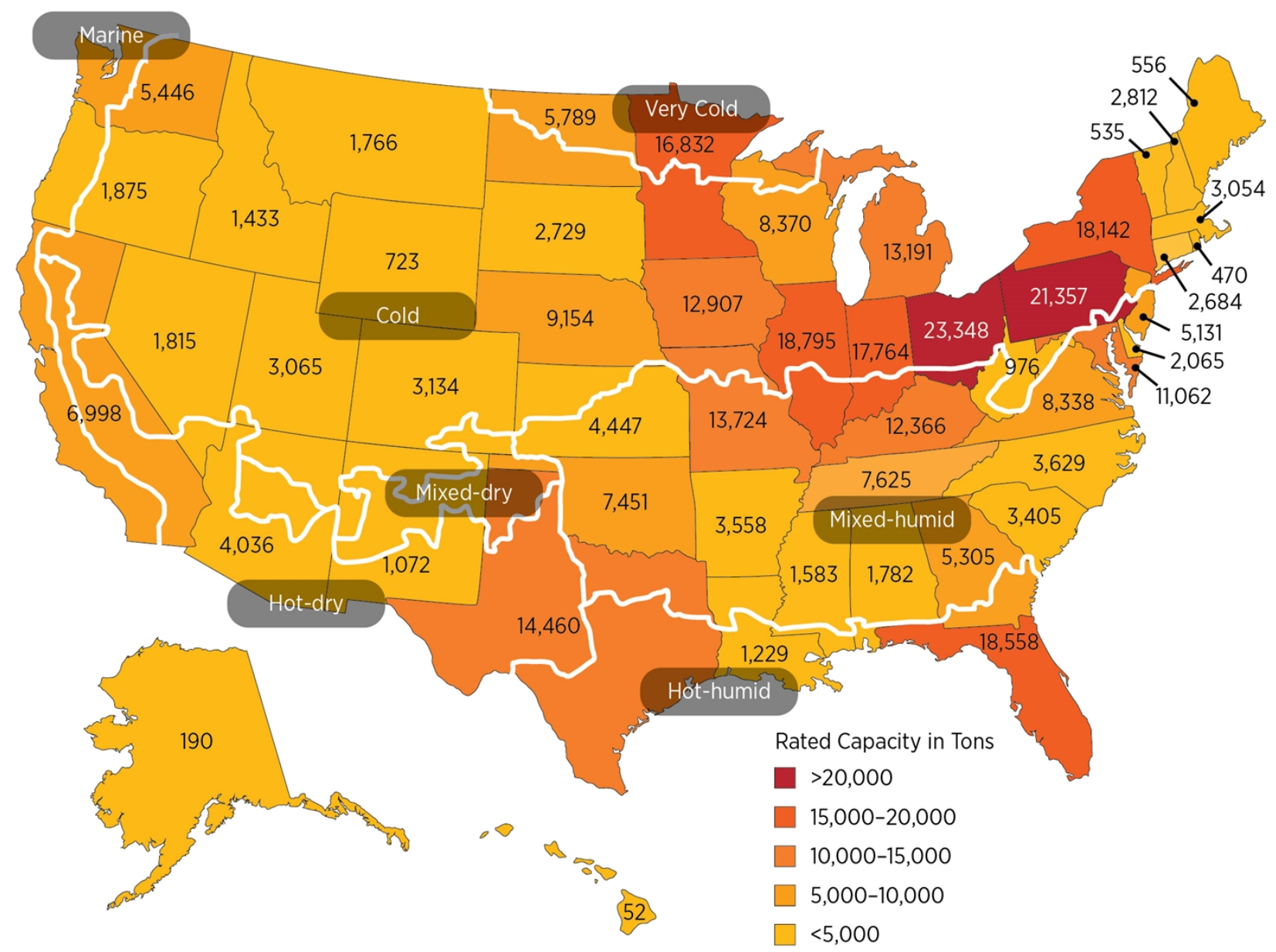

Fig. 5. Distribution of GHP unit shipments in the United States in 2009.

(Data source: EIA 2010.) (Note: The number shown in each state indicates the total capacity of GHP shipments in 2009 in the state; the white lines indicate climate zones.)

GHPs have been used in all 50 states and the District of Columbia in the United States. Figure 5, which is based on the 2009 data on the destinations of GHP unit shipments in the United States (EIA 2010) and is color-coded based on the total rated capacity (in cooling tons) shipped in that year, graphically shows the distribution of GHP applications in the United States. Various climate zones in the United States are indicated by solid lines in this figure. About $52 \%$ of domestic GHP shipments went to 10 states: Florida, Illinois, Indiana, Michigan, Minnesota, Missouri, New York, Ohio, Pennsylvania, and Texas. It appears GHP applications are more concentrated in areas with a cold climate and high population density. Total GHP shipments were 118,818 units in 2009, which was the last year EIA tracked GHP shipments.

Although the housing market has been showing signs of growth since the bottom of the recession in 2009, the US Census Bureau reports that GHP installed capacity in the United States faced declines of 11\% between 2010 and 2011 and 5\% between 2011 and 2012 (Navigant Research 2013). 
A report issued by Priority Metrics Group (2009) estimated that the GHP market in the US was about $\$ 3.7$ billion in 2009, including design, equipment, and installation. It is estimated that the total revenue from sales of domestic GHP equipment was about $\$ 319.5$ million in $2009^{5}$ (EIA 2010).

\subsection{BARRIERS}

High initial upfront costs and low returns, poor public awareness and confidence, lukewarm governmental support, and a lack of new technologies to improve GHP system cost or performance are believed to be the major barriers preventing rapid adoption of GHPs in the United States (Hughes 2008, NYSERDA 2017). GHXs are a major, but not the only, reason for the high initial cost of GHPs. The extra selling costs (e.g., effort for educating customers and providing technical assistance), a lack of competition in the design and installation, and oversizing or excessive backup resulting from inexperienced designers also contribute to high initial costs. The recent low fossil fuel prices (Fig. 6) reduce the monetary value of energy savings. Unfortunately, the other environmental and social benefits of GHPs, including reduced carbon emissions and benefits to electric grids (e.g., reduced summer electricity demand and improved load factor), are not properly valued in the current marketplace.

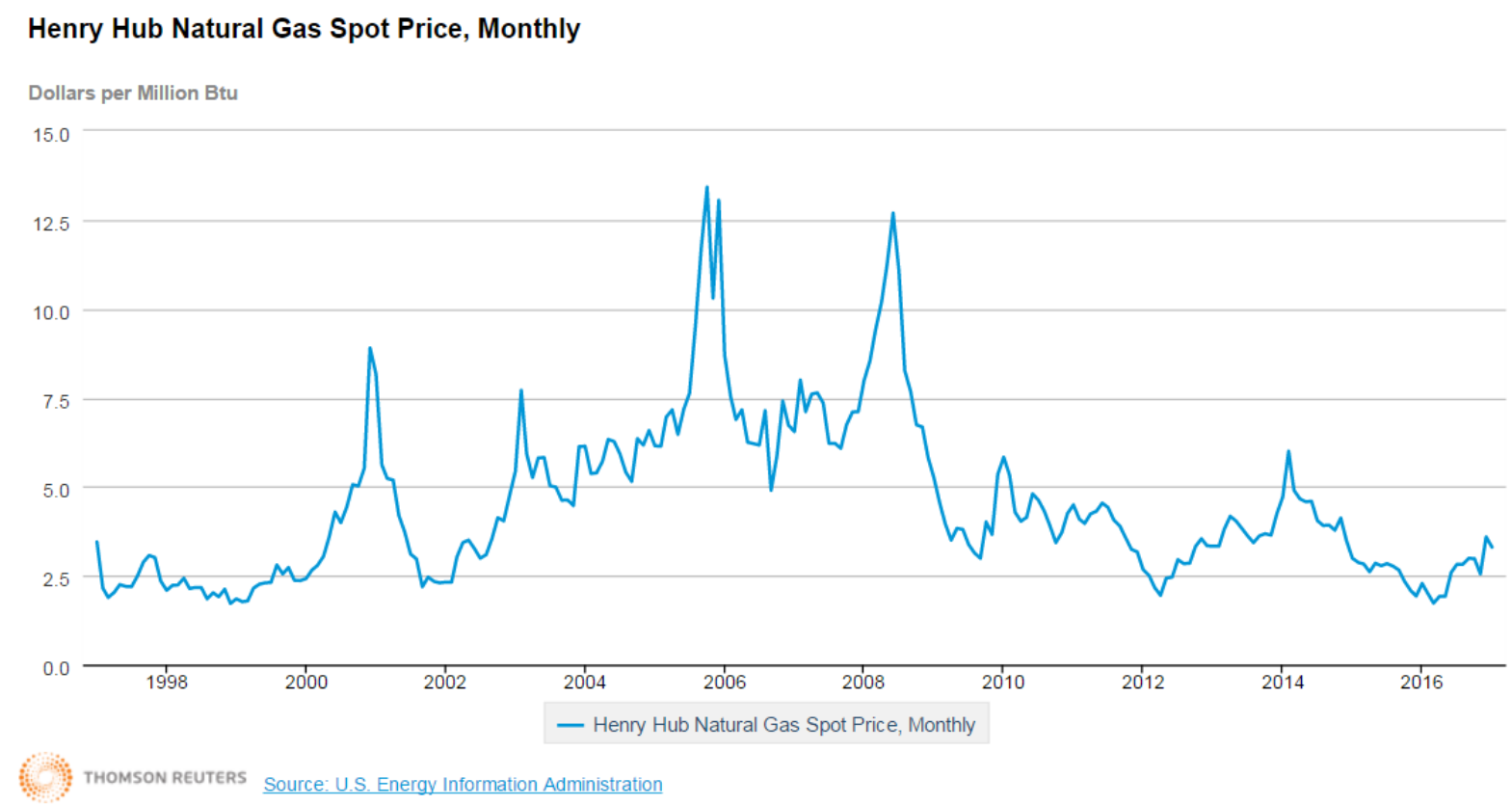

Fig. 6. Historic prices of natural gas (Source: EIA 2016c).

Third-party financing (TPF), which has been very successful in breaking the high initial cost barrier for other products, has not been widely used for GHP applications because of several hurdles. These hurdles include (1) a lack of standardization for contracts and measurements of energy savings performance, (2) a lack of appreciation for GHP value in real estate appraisals, and (3) the complexity involved with transferring loans associated with GHPs when homeownership is changed. These hurdles increase the risks and thus the capital cost of GHP loans. With current energy prices, the capital cost for financing GHPs is too high to make business sense except in some niche markets (e.g., replacing heating-oil-fired furnaces with GHPs).

\footnotetext{
${ }^{5}$ Revenue includes charges for cooperative advertising and warranties but does not include excise taxes and the cost of freight or transportation.
} 
Third-party ownership (TPO) is considered as a better solution than loan-based financing for GHPs. The ideal business mode of the TPOs is that third parties invest and own GHPs, and home or business owners use the GHPs without any initial cost. Both the third parties and home or business owners share the energy cost savings over the life span of the GHPs. TPO providers may be able to reduce the cost of GHPs by monetizing any available tax credits and using economies of scale. They are also motivated to improve energy saving performance (e.g., through proactive maintenance based on the monitoring data) of GHPs.

However, to make TPOs economically viable in a broad market, the cost and performance of GHPs need to be improved through substantial technology development, especially as the federal tax credits for GHPs expired at the end of 2016 (DOE 2017a and 2017b) and energy prices are at historically low levels. The tax credits were reinstated retroactively to include GHPs installed after Jan. 1, 2017 and extended to Jan. 1, 2022 (GEO 2018).

Possible solutions for overcoming the above barriers include the following.

- Reduce costs across all elements of GHP projects, including development of lower cost and performance neutral GHXs (as well as associated techniques/equipment for installation), more cost effective GHP equipment and system configurations, and automated processes for installation and performance evaluation. Non-technology-related developments could also reduce the cost of GHPs, including volume manufacturing of GHP equipment (e.g., by merging small heat pump manufacturers), large scale GHP applications (e.g., district GHP systems) to take advantage of economies of scale, and a vertically integrated business model - from design, build, to operate - to improve the efficacy and quality of GHP installations.

- Maximize energy saving performance though optimal design and integration of GHP systems. The accuracy, flexibility, and accessibility of GHP system design tools (e.g., computer models for various GHXs) and supporting data (e.g., geological characteristics and thermal properties of shallow subsurface of the ground) need to be improved to enable optimal design and integration. Currently, ground thermal properties data, which are essential for sizing GHXs, are scarce, and in situ measurements of these data are often too expensive for residential GHP projects. More cost-effective testing methods and a national database of high resolution ground thermal property data are highly desirable.

- Enable innovative financing and ownership mechanisms (e.g., TPO) for reducing the initial cost impacts of GHPs. The cost and benefit analysis of GHPs should be standardized, as well as the contracts for GHP financing. For new construction, including GHPs as standard builds in home designs could standardize the design and installation of GHPs. This standardization will make GHP financing easier to manage.

- Value other environmental and social benefits of GHPs in addition to the energy cost savings. These benefits include reduced carbon emissions, peak electric demands (thus improved stability of the electric grid), and on-site combustion of fossil fuels (thus lowering risks of fire hazards and health issues associated with the emissions and particles resulting from combustion). The value of GHPs should also be accounted for in the sale prices of real estate.

- Increase public awareness of and confidence in GHPs. Stakeholders in the GHP industry, including governments, utilities, communities, manufacturers, contractors, etc., could create outreach programs and tools (e.g., publicly available and easy-to-use websites or apps) to educate potential customers about the costs and benefits of GHPs. In addition, more case studies of installed GHPs would show the real-world difference between GHPs and conventional HVAC systems. 


\subsection{RESEARCH AND DEVELOPMENT FOR GEOTHERMAL HEAT PUMPS}

Recent research and development (R\&D) for GHPs in the United States includes (1) modeling and performance characterization of GHXs that use building foundation structures in lieu of vertical boreholes or horizontal trenches (Im et al. 2012); (2) evaluating alternative GHX designs, including coaxial and double U-tube (Liu and Munk, 2013); (3) developing GS-IHPs (Rice et al. 2013, Baxter et al. 2016);

(4) developing modeling tools for hybrid GHP systems (Hackel 2009, Wang et al. 2015); and

(5) performing case studies of commercial GHP demonstration projects funded in part by ARRA grants (Liu et al. 2017).

A worldwide review of recent and ongoing R\&D related to GHPs found that almost all the research is related directly or indirectly to either reducing the initial cost of GHPs or improving their performance (Spitler et al. 2017). Below is a summary of these R\&Ds, which is organized in six categories including system components, design and system integration, site characterization, control and operation, and advanced applications. Notably, R\&D for GHPs is more active in European and East Asia.

\subsubsection{System Components}

This section covers improving the performance of individual components of GHP systems, most commonly GHXs but also including heat pumps and antifreeze mixtures.

\section{Ground Heat Exchangers}

Recent studies have focused on development of improved GHXs that offer lower borehole thermal resistance, can be quickly installed, and do not have significant pumping power penalties.

- Characterization of GHXs in deep boreholes. Deep boreholes are of interest for applications where available land is limited. In addition, under some geologic conditions drilling a deep borehole can be less expensive than drilling a few shallower boreholes for the same heat transfer capacity. There are several issues that complicate design of GHXs for deep boreholes, including grouting procedures for avoiding pipe collapse, maintaining satisfactorily low pressure drop, limiting short-circuiting effects, and the advantages vs. the disadvantages of ground temperatures at deeper depths. Projects looking at these issues include an Effsys Expand project (Acuña 2016, Gehlin et al. 2015).

- Development and performance evaluation of alternative GHX designs. A recently funded EU project (Cheap GSHPs 2015) is investigating helical GHXs (also referred to as "heat baskets") and coaxial steel borehole heat exchangers, which will be installed to depths as shallow as $15 \mathrm{~m}(50 \mathrm{ft})$ below the grade. This project has a goal to reduce the installed cost of GHXs by $25 \%-30 \%$. Another EU-funded project (GEOTeCH Project 2016) is investigating spiral GHXs, thermal piles, and thermally activated diaphragm walls. One desirable direction for future research would be to develop a standard testing method for GHXs that would allow accurate measurements of the borehole thermal resistance and the pressure drop resulting from alternative designs.

- Use of foundations piles as GHXs to reduce drilling costs. Recent research has been primarily aimed at establishing the suitability of using piles as heat exchangers from a structural standpoint and on thermal performance of individual piles (Cecinato and Loveridge 2015, Loveridge et al. 2015). Because the pile configuration is determined solely by structural considerations and may be unevenly placed and of different depths, pile heat exchangers may not be sufficient for all the building loads, and therefore additional GHXs or supplementary heat sinks or heat sources may be needed. 


\section{Heat Pumps}

Madani (2016) and colleagues at KTH Royal Institute of Technology in Stockholm are working on improving controls for heating-only GHP equipment with variable-speed compressors and variable-speed circulating pumps to minimize the total electricity consumption and cost. Possible approaches include use of weather forecasting, spot electricity pricing, and occupant-behavior-learning. Another project of interest (Andersson 2016) is development of a propane GHP unit with very low charge mass (less than 150 grams or 5 ounces). Corberan (2016) suggests that dual-source (ground and air) heat pumps have strong potential for reducing required GHX size while offering excellent performance.

\section{Antifreeze}

Palm and Ignatowicz (2016) studied the effects of corrosion inhibitors and other additives on the fluid and thermal properties of antifreeze mixtures. They are also investigating possible alternative additives such as nanoparticles and possible alternative water-antifreeze mixtures.

\subsubsection{Design and System Integration}

GHP system performance depends not only on the performance of each individual component but also on how the components are integrated into a system. If system integration is not handled properly, it can either increase system initial costs or decrease performance, or both. Current R\&D projects in this area are focused on (1) increasing flexibility and reliability of design tools to evaluate various GHX designs (Cimmino and Bernier 2014, Monzó et al. 2015, Spitler et al. 2016, Cullin et al. 2015, Javed 2016) and (2) optimizing thermal energy storage in the borehole field to enable directly cooling (or heating) without running heat pumps (Gehlin 2016). Further R\&D is needed to develop tools that can improve and optimize designs of GHPs, including the following.

- Better calculation procedures and tools for borehole thermal resistance to treat double U-tubes, coaxial heat exchangers, and other innovative GHX designs.

- Improved prediction of long-term performance of GHXs.

- Expanded simulation capabilities for modeling district GHP systems that can recover heat among various buildings and use various ground sources (e.g., wastewater), as well as other conventional heat addition and rejection devices.

\subsubsection{Site Characterization}

Identification and characterization of important ground parameters (e.g., thermal, hydrogeological, environmental, and engineering properties) of the subsurface $(<1,000 \mathrm{ft}$ below the grade) is critical to GHX designs. Currently, data on ground thermal conductivity (GTC) is scarce (Section 3.2.2). Recent research has focused on improving the testing methods for GTC by (1) estimating the convective effects of groundwater movements due to temperature-gradient-dependent buoyancy (Choi and Ooka 2016),

(2) characterizing the ground response for standing column well design (Rouleau et al. 2016),

(3) providing additional information about the distribution of thermal conductivity and groundwater flow (Acuña 2013), and (4) developing lower cost testing approaches and devices (Raymond et al. 2015, Verdecchia et al. 2016, Su et al. 2017). Methods for predicting undisturbed ground temperatures (Ouzzane et al. 2015, Xing 2014) have recently been published. These methods can reasonably predict ground temperatures where the surface conditions are undisturbed by buildings and pavement. New research is needed to develop methods for predicting ground temperatures in urban areas in addition to collecting field measurements. 


\subsubsection{Control and Operation}

Performance of commercial GHP systems, particularly with hybrid GHP systems including auxiliary heat sinks or sources, can be improved by optimizing the system designs, controls, and operations. Current research is focused on (1) optimizing controls for hybrid GHP systems (Atam and Helsen 2016a and 2016b, Hamstra 2014); (2) optimizing GHP systems with load-side storage such as thermally active building systems, as reviewed by Helsen (2016); and (3) improving pumping controls to reduce pumping energy, which has the potential to reduce electricity consumption of GHP systems by $10 \%$ (Niu et al. 2016). In addition, research aimed at reducing the standby losses may be particularly useful for increasing off-peak-season performance, as suggested by Corberan (2016).

\subsubsection{Advanced Applications}

GHPs are highly desirable for near-zero-energy buildings (NZEBs) as the electricity generated with the intermittent renewable energy (e.g., photovoltaic or wind) can readily be consumed on-site with a very high efficiency heating/cooling system. The excess electricity generated with the renewable energy can be stored as heat in the ground, which is a better (more cost-effective) option than battery storage of electricity (Thygesen 2016). Several ongoing projects are looking at use of GHPs in NZEBs in Switzerland (Wemhoener 2016) and Sweden (Stignor 2016). There are also some advantages of combining photovoltaic-thermal collectors - solar collectors that produce electricity and thermal energy - with GHPs. Besides recharging the ground in cold climates, cooling photovoltaic panels improves the efficiency of electricity production (Brischoux and Bernier 2016).

\subsection{GHP EXPANSION PLANS IN OTHER COUNTRIES}

Navigant Research (2013) predicts that global installed GHP capacity will grow from 46,748 MWt (13.3 million tons) in 2012 to $127,392 \mathrm{MWt}$ (36.2 million tons) in 2020 at a compound annual growth rate (CAGR) of $13.4 \%$ between 2013 and 2020. The renewable energy policies and associated incentives implemented in many countries are the main force behind the growth of the GHP market.

The EU 20-20-20 goals (meet 20\% of energy needs from renewable energy sources by 2020) adopted by member countries have led those countries to develop mandates and incentives to move homeowners and building operators away from fossil fuel heating to GHPs and other renewable sources. As reported by Navigant Research (2013), the installed GHP capacity in Europe was nearly 23,966 MWt (6.8 million tons) in 2012, representing more than 51\% of the world's total installed GHP capacity that year. While most European GHP capacity was in Western Europe (91\%) as of 2012, capacity in the Eastern European market showed the strongest growth with a CAGR of 37.1\% between 2010 and 2012. Per the Common Vision for the Renewable Heating and Cooling Sector in Europe (RHC-Platform 2011), more than $25 \%$ of heat consumed in the EU could be generated with renewable energy technologies (including GHPs) in 2020, and more than half of the heat used in Europe could be supplied with renewable energy technologies by 2030 . However, to realize this potential, the cost and performance of the renewable energy technologies need to be significantly improved through substantial investment in research, development, and demonstration activities. It is estimated that 4,032 million Euro is needed for the successful implementation of the Strategic Research and Innovation Agenda for Renewable Heating and Cooling in Europe (RHC-Platform 2013).

In China, the government has a goal to satisfy the $15 \%$ energy demands in the building sector with renewable energy (including GSHP, solar thermal, and solar photovoltaic) by 2020. Because of strong promotion and financial incentives offered by the Chinese government (MoHUD 2008, 2012), the GSHP industry has experienced explosive growth since 2005. The average annual growth rate of GHP applications was nearly $46 \%$ between 2000 and 2013, which is much greater than the growth rate 
worldwide in the same interval (Xu 2013). As can be seen in Fig. 7, the cumulative building floor space conditioned by GSHP systems in China has grown from zero to 400 million $\mathrm{m}^{2}\left(4.3\right.$ billion $\left.\mathrm{ft}^{2}\right)$ in just one decade, surpassing that in the United States in 2010 (Liu et al. 2015).

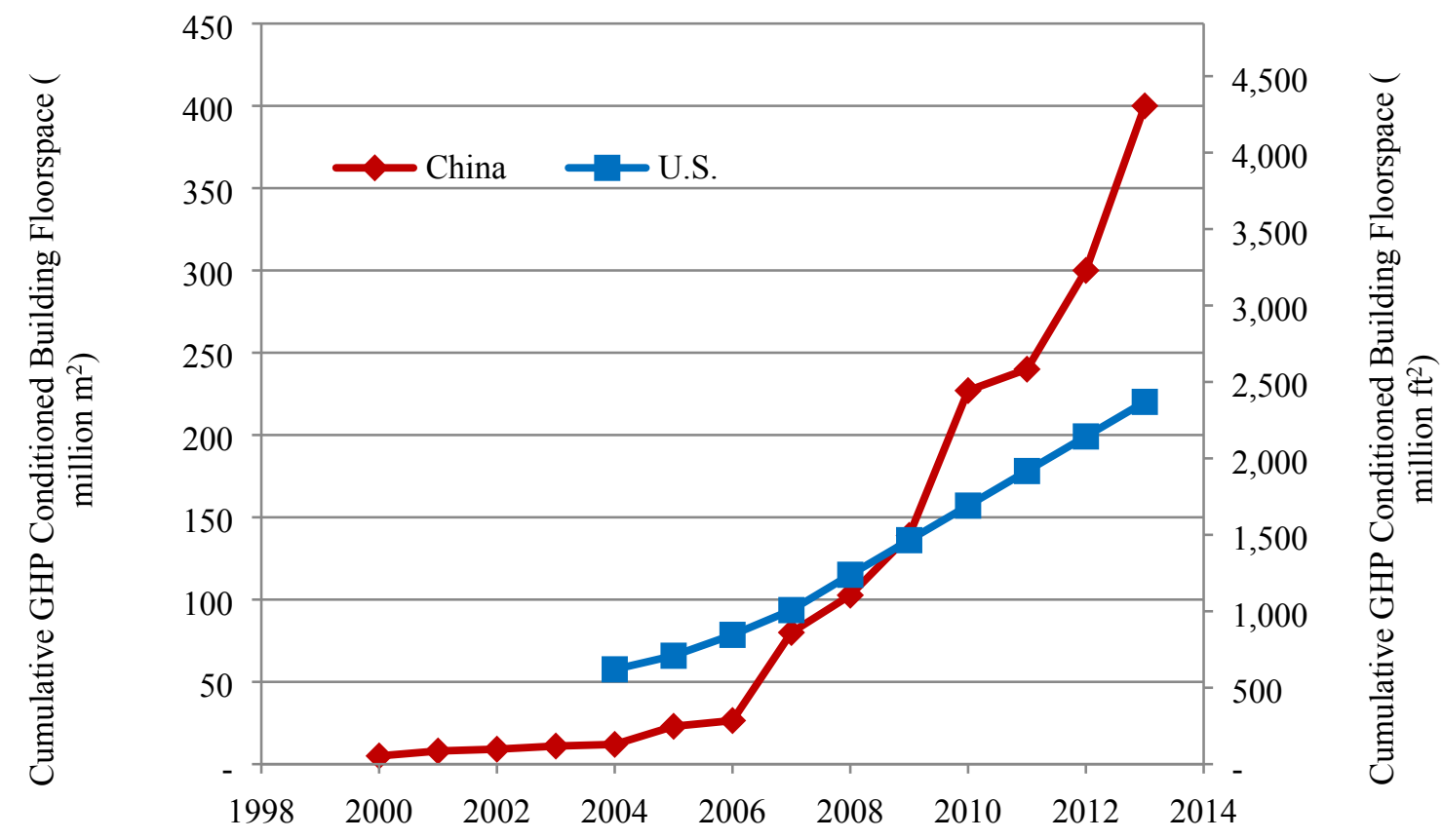

Fig. 7. Cumulative building floor space conditioned by geothermal heat pump systems in the United States and China.

In its $13^{\text {th }}$ Five-Year Period for Economic and Social Development (2016 through 2020), the Chinese government revealed a plan for geothermal energy development and utilization. ${ }^{6}$ This plan sets the following goals:

- 1.1 billion $\mathrm{m}^{2}$ (12 billion $\mathrm{ft}^{2}$ ) of additional building floorspace will be heated and cooled with geothermal heating (cooling); $500 \mathrm{MW}$ new geothermal power will be installed.

- By 2020, 1.6 billion $\mathrm{m}^{2}$ (17 billion $\mathrm{ft}^{2}$ ) in total will be served by geothermal heating (cooling), and there will be $530 \mathrm{MW}$ cumulative geothermal power generation capacity.

- In 2020, annual use of geothermal energy will be equal to 70 million tons of standard coal, and 40 million tons of standard coal will be replaced with geothermal heating.

In addition, the plan stated that during the $13^{\text {th }}$ Five-Year period, China would (1) complete an effective management and policy system for the development and use of geothermal energy; (2) master the core technology of the geothermal industry; and (3) establish a more complete industry chain for geothermal energy development and use, including equipment manufacturing and monitoring systems.

\footnotetext{
${ }^{6}$ The $13^{\text {th }}$ Five-Year Period for Economic and Social Development was jointly developed by the National Development and Reform Commission, the Ministry of Land and Resources, and the National Energy Bureau (http://www.mlr.gov.cn/xwdt/jrxw/201702/t20170207_1439676.htm).
} 
It is estimated that the development of geothermal energy will bring a total of 260 billion Chinese yuan (US\$38 billion) in investments. In this process, the geothermal energy development franchise bidding system and the public-private partnership model will be explored, restrictions on urban heating market access will be lifted, and geothermal energy development enterprises will be encouraged to enter the urban heating market.

\section{GEOTHERMAL HEAT PUMP APPLICATION GROWTH SCENARIO STUDY}

In this section, the growth of GHP applications in the continental United States through 2050 is assessed under various scenarios, including a "business as usual" (BAU) scenario and a "breakthrough" (BT) scenario that assumes significant cost reductions and performance improvements through technology developments. This section also introduces the assessment method and the main results.

\subsection{PROCEDURE FOR ASSESSING GEOTHERMAL HEAT PUMP GROWTH POTENTIALS}

The projected customer adoption of GHPs is a function of many different parameters, including cost and performance variables in addition to exogenous variables such as fuel costs and projected building and thermal load growth in the United States. To quantify the potential opportunity for GHP system adoption, three key metrics are calculated - technical potential, economic potential, and market potentialfollowing a bottom-up procedure depicted in Fig. 8 and discussed below.

To aid in the assessment of GHP growth potential, the National Renewable Energy Laboratory (NREL) developed the Distributed Geothermal Market Demand Model (dGeo) as a tool to explore the potential role of geothermal distributed energy resources (DERs) in meeting current and future thermal energy demands in the United States. dGeo simulates the potential for deployment of geothermal DERs in the residential and commercial sectors of the continental United States at a sub-county resolution, with a focus on two specific technologies: GHPs and geothermal direct use (DU) for district heating. To quantify the opportunity space for these technologies, dGeo leverages a highly resolved geospatial database and robust bottom-up, agent-based modeling framework. The model incorporates detailed spatial data to understand siting suitability and thermal demands (e.g., for SH and SC) in existing buildings. It also considers regional geological conditions (e.g., ground temperature and thermal properties) and energy prices (for NG, propane, fuel oil, and electricity). The dGeo design is consistent with other models in the dGen (Distributed Generation Market Demand) family of market demand models, including dSolar and dWind (Sigrin et al. 2016). dSolar has been used extensively in previous analyses for distributed solar deployment, and dWind was used recently in projections for future distributed wind deployment (Lantz et al. 2016). 


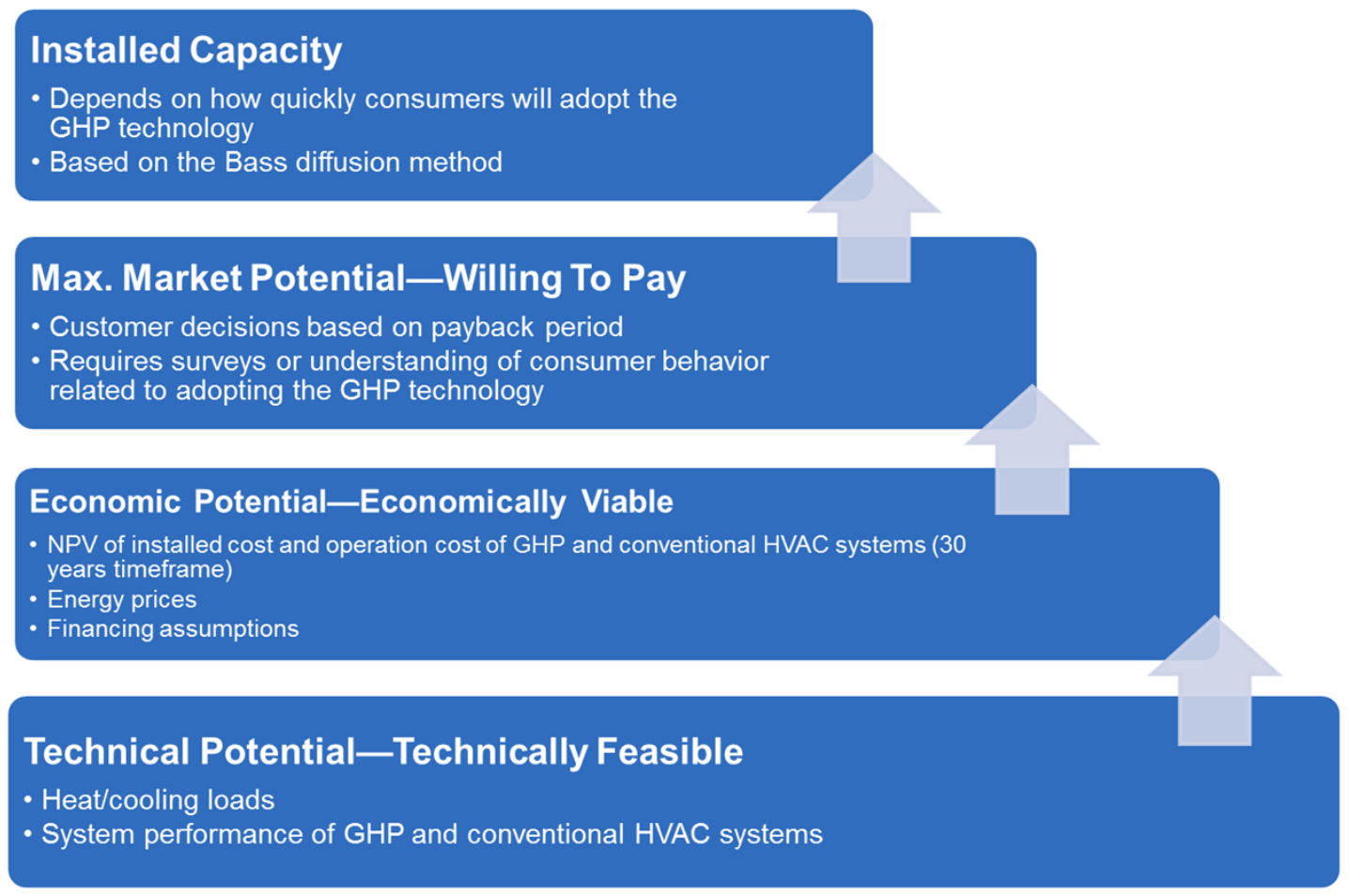

Fig. 8. A bottom-up procedure for assessing the growth potentials of GHP applications.

To simulate the potential market for GHPs, the dGeo model follows a framework that shares several key traits with classical agent-based models. The model framework involves six main components:

1. Agent generation: During agent generation, which occurs at model initialization, dGeo creates a synthetic population of agents within each region, where each agent represents a type of commercial or residential building, complete with several key attributes.

2. Agent mutation: At each time step, agents are updated to inherit new time-dependent attributes (or change existing ones) that may affect their evaluation of the opportunity for technology adoption.

3. Assessment of technical potential: Based on the current status of agents at each time step, dGeo assesses the quantity of GHP applications that are technically feasible, given proximity to end-use thermal demand and siting constraints.

4. Assessment of economic potential: At each time step, dGeo evaluates the economics of an investment in GHP for each agent using discounted cashflow analysis. This analysis produces financial metrics that can be used to assess how economically attractive a GHP application is to each agent, as well as the overall number of agents for whom the GHP adoption would be economically rational.

5. Assessment of market potential: Based on empirical data that relates financial metrics to the number of customers who would be willing to adopt a technology, dGeo translates economic potential into market potential at each time step.

6. Simulation of technology deployment: Finally, at each time step, dGeo simulates technology deployment based on current economic evaluations of each agent, as well as population-level interaction effects from other agents. 
Following the technical potential calculation (see Section 3.3 for more details), dGeo calculates a new estimate of economic potential for GHPs based on the current state of the modeled agents. These estimates leverage several agent attributes updated or inherited during the agent mutation process, such as the SH and SC system ages, energy costs specific to these system types, and other user-defined inputs related to the cost and performance of the systems. dGeo defines the economic potential for GHPs as the installable capacity of systems with a positive return on investment, determined based on a positive net present value (NPV) over a 30-year time frame.

To derive this estimate, dGeo begins by performing a series of calculations that determine the cash flows associated with installation and operation of a GHP system for each agent. These calculations are too detailed to describe exhaustively here; however, they account for six primary components.

1. System Payment. For host-owned systems, the annual costs of servicing loans (principal repayment and interest) are based on the amount borrowed, loan term, and annual percentage rate. Costs associated with future replacement of the heat pump component of the GHP system are simply amortized over the expected heat pump lifetime.

2. Fixed O\&M Costs. These costs consist of fixed costs of servicing and maintaining the system over the analysis period and are calculated based on agent attributes for GHP operation and maintenance (O\&M) costs and building size.

3. Annual Energy Costs. Agents evaluate the current and anticipated future expenditures associated with the energy to operate their GHP systems for heating and cooling. These costs are based on the agents' attributes for current and future costs of energy and GHP site space conditioning energy consumption.

4. Revenue from Incentives. Agents can receive revenue from applicable energy investment tax credit.

5. Revenue from Depreciation. Commercial sector agents may deduct asset depreciation over the lifetime of the GHP system. This depreciation decreases the tax burden of each applicable agent.

6. Revenue from Interest Deductions: All agents using the host-owned business model may deduct the interest paid on systems from their taxable burden. ${ }^{7}$ These deductions provide a source of revenue at the specified taxable rate of each agent. The model assumes that the agent has a sufficient taxable burden to monetize interest deductions fully.

Using these six components, dGeo calculates the cash flows of a GHP installation for each eligible agent, assuming an analysis period of 30 years. To account for the value of a GHP installation relative to continued use of a conventional HVAC system, dGeo also calculates the cash flows associated with the conventional HVAC system of each agent. These cash flow calculations incorporate all the components used in the GHP calculations except for revenue from incentives, which the model assumes do not apply to conventional HVAC systems. Furthermore, dGeo assumes that the system payments for a new HVAC system will not begin until some future year, as determined by each agent's expected years to equipment replacement. Subsequent system replacements are simply amortized over the expected lifetime of a new HVAC system.

To calculate the net cash flows of a GHP system relative to a conventional HVAC system, dGeo simply subtracts the HVAC cash flows from the GHP cash flows. The resulting net cash flows are then evaluated to determine a series of financial metrics, including: payback period, percent monthly bill savings, timeto-doubling, and NPV. Payback period is determined as the first year with a net-positive cumulative cash flow, while percent monthly bill savings is calculated as the mean annual cash flow divided by the mean

\footnotetext{
${ }^{7}$ Residential customers may not deduct interest from an unsecured loan but may do so when financing via a home equity line of
} credit. 
annual energy costs associated with the conventional HVAC system. Time-to-doubling is derived following the methods described by Denholm et al. (2009). NPV is calculated per Eq. (1):

$$
N P V=\sum_{t=0}^{30}\left(\frac{1}{1+D}\right)^{t} * C_{t},
$$

where $\mathrm{D}$ is the agent's discount rate, $\mathrm{t}$ is the year since initial investment, and $C_{t}$ is the net cash flow at year t.

Using the derived NPV values for all eligible agents, dGeo is able to determine the overall economic potential for GHPs. To do so, it identifies all agents with a positive NPV, calculates the product of the GHP capacity and the number of buildings associated with each agent, and sums across all agents to determine the total installable capacity with a positive return on investment.

Whereas economic potential considers the portion of potential GHP applications that is economically viable, market potential considers the portion that is likely to be deployed, given the reaction of consumers in the market to economic factors. To quantify the market potential for GHP, dGeo uses the same method used by other models in the dGen family (Sigrin et al. 2016). This approach determines the maximum market share for each agent, which is defined as the portion of the potential market that would eventually adopt the technology given its level of economic attractiveness.

To quantify the maximum market share, dGeo relies on a series of empirically derived curves that relate the economic attractiveness of technology adoption and maximum market share. Several studies have sought to quantify this relationship based on the payback period of a given technology (Sigrin and Drury 2014; Paidipati et al. 2008; EIA 2004; R.W. Beck 2009; and Kastovich et al. 1982).

dGeo uses these maximum market share curves to translate the results of the economic potential analyses into an assessment of market potential. For GHPs, dGeo's method for calculating market potential is relatively straightforward. Using the output financial metrics from the economic potential calculations, including payback period, time-to-doubling, and percent monthly bill savings, dGeo determines the maximum market share associated with each agent. Following the conventions of Sigrin et al. (2016), dGeo's residential agents evaluate host-owned GHP systems based on the payback period. Commercial agents evaluate host-owned GHP systems similarly, using the payback period metric to determine market potential.

After the translation of economic to market potential using each agent's calculated payback period, dGeo can calculate the aggregate market potential of GHP $\left(V_{m, r}\right)$ in tons of capacity for region $r$, containing $n$ agents, per Eq. (2):

$$
V_{m, r}=\sum_{i=0}^{n}\left(Q_{i} * C_{i} * M_{i}\right)
$$

where $Q_{i}$ is the building count associated with agent $i ; C_{i}$ is the GHP cooling capacity (in tons) associated with agent $i$; and $M_{i}$ is the maximum market share for agent $i$, as determined by the relevant financial metric and maximum market share curve.

The installed capacity, which is the sum of the GHP systems expected to be deployed over time, is estimated based on the maximum market potential with the Bass diffusion process (S-curve) to approximately account for how quickly consumers will adopt the GHP technology (Bass 1969, Rogers 2003). 
This assessment was conducted through a multi-lab, multi-task force effort, as depicted in Fig. 9. The Thermal Applications task force at ORNL collected information on ground thermal properties, assessed the technical potential of GHPs, calculated energy savings performance of GHPs at various residential and commercial applications, developed generic cost models for GHPs and comparable baseline HVAC systems, and identified potential growth scenarios for GHPs. The dGeo team at NREL conducted subcounty-level analyses with all the inputs provided by the ORNL team to assess the economic and market potential of GHPs. These results were then used to evaluate the impacts of GHP deployment on carbon emissions and job creation on a national level by the Impact task force at Lawrence Berkeley National Laboratory and NREL (Millstein, et al. 2017).

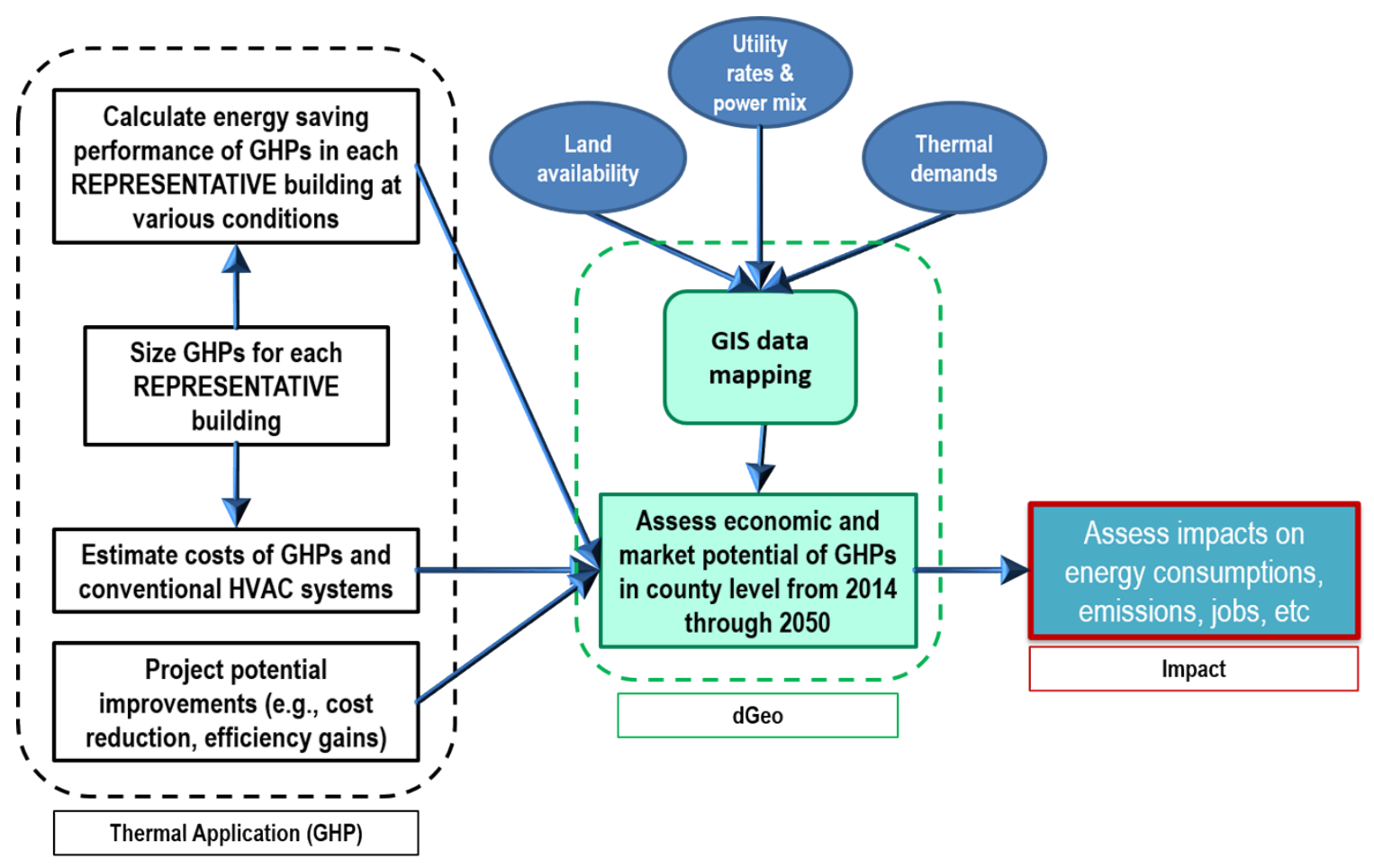

Fig. 9. Data flow among various geothermal heat pump-related task forces working on the GeoVision Study.

\subsection{DISCUSSION OF INPUTS}

Needed inputs for assessing the various potentials of GHPs are organized in the following categories: (1) energy saving performance; (2) ground thermal properties; (3) installed and operation costs;

(4) energy prices; and (5) financing terms. These inputs reflect competition of GHPs with baseline HVAC systems, which represent conventional systems typically used in residential and commercial buildings. Key inputs in each category that have significant impacts on the economic competitiveness of GHPs are discussed below.

\subsubsection{Energy Saving Performance}

The energy saving performance is indicated by the ratio of the difference between the energy consumption of a GHP system and that of a baseline HVAC system to the energy consumption of the baseline HVAC system for conditioning the same building. The energy consumption of the GHP and that 
of the baseline HVAC system are predicted with eQUEST (Hirsch et al. 2016), a widely used building energy modeling program including a module for simulating GHPs (Liu and Hellstrom 2006). The simulated baseline HVAC systems and the GHPs are sized to meet the SH and SC demands of each building, and they are operated with typical controls of these systems.

\subsubsection{Representative Buildings}

According to the 2015 Residential Energy Consumption Survey (RECS, EIA 2017b), there were 118.2 million housing units in the United States and the predominant type of housing units is single-family house, which accounts for approximately 85 percent of the floor space in residential sector. A 1,644 $\mathrm{ft}^{2}$ one-story, slab-on-grade, wood-frame single-family house is simulated to represent typical US homes. Commercial buildings are categorized into six groups based on the similarity of building's principal activities, and each group is represented with one of DOE's Commercial Reference Buildings (CRBs; DOE 2012b). Table 3 lists the six groups and the corresponding CRB models. Thirteen locations (cities) were selected to represent the major climate zones (IECC 2009) in the continental United States.

Table 3. Categories and representatives of commercial buildings

\begin{tabular}{ccl}
\hline Categories & $\begin{array}{c}\text { Commercial reference } \\
\text { building model }\end{array}$ & \multicolumn{1}{c}{ Description } \\
\hline Office & Medium office & $\begin{array}{l}3 \text { stories; 53,620 } \mathrm{ft}^{2} ; \text { direct expansion (DX) cooling and gas-fired } \\
\text { furnace with electric reheat }\end{array}$ \\
\hline Lodging & Small hotel & $\begin{array}{l}4 \text { stories; 40,095 } \mathrm{ft}^{2} ; \mathrm{DX} \text { cooling and gas furnace for common area; } \\
\text { DX cooling and electric resistance heating for guest rooms }\end{array}$ \\
\hline Education & Secondary school & $\begin{array}{l}2 \text { stories; } 210,954 \mathrm{ft}^{2} ; \text { chilled water and hot water (from gas-fired } \\
\text { boiler) }\end{array}$ \\
\hline Retail & Small retail & 1 story; 22,500 $\mathrm{ft}^{2} ; \mathrm{DX}$ cooling and gas furnace \\
\hline $\begin{array}{c}\text { Food } \\
\text { service }\end{array}$ & Restaurant & 1 story; 5,505 $\mathrm{ft}^{2} ; \mathrm{DX}$ cooling and gas furnace \\
\hline Warehouse & Nonrefrigerated warehouse & 1 story; 52,050 $\mathrm{ft}^{2} ; \mathrm{DX}$ cooling and gas furnace \\
\hline
\end{tabular}

Simulations of the reference buildings were used to evaluate the energy saving performances of GHPs serving each representative building in each climate zone. It is assumed that the energy saving performance for buildings in the same group is identical and is independent of building size. The characteristics of the existing conventional HVAC systems (e.g., efficiency of cooling equipment or energy source for $\mathrm{SH}$ ) are considered when evaluating energy saving performance.

\subsubsection{Baseline Heating, Ventilation, and Air-Conditioning Systems}

Each CRB model includes a conventional HVAC system that is commonly used in the represented commercial buildings (Table 3), and thus is considered as the primary baseline HVAC system for the represented commercial buildings. Efficiencies of the simulated commercial space heating and space cooling equipment are adopted from the minimum code-compliant efficiencies specified in ASHRAE 90.1-2004 (ASHRAE 2004). The primary baseline HVAC system for single-family house is comprised of an electric air conditioner and a gas furnace. Efficiencies of the simulated baseline HVAC equipment are from the latest survey of the existing space heating and space cooling equipment by EIA (2017 a).

EIA's commercial buildings energy consumption survey (CBECS) and residential energy consumption survey (RECS) data indicate that there are other existing HVAC systems serving each group of commercial and residential buildings in addition to the primary baseline HVAC systems. The existing 
HVAC systems are categorized based on the energy source for SH and SC. Table 4 lists different energy sources and their shares in the national site energy consumption for SH and SC of each group of buildings. These national-level contributions were determined based on the microdata of the most recent CBECS (EIA 2016b) and RECS (EIA 2013). As can be seen in this table, electricity is the predominant energy source for SC in both residential and commercial sectors (with a share of more than 98\%). NG, heating oil, and propane are the predominant energy sources for $\mathrm{SH}$ in commercial buildings (with more than $80 \%$ combined share). For single-family homes, the combined share of NG, heating oil, and propane is relatively lower $(66.5 \%$ ), and electricity contributes $28.1 \%$ to the total site energy consumption for $\mathrm{SH}$, of which two-thirds is from heat pumps (mostly air-source heat pumps) and the rest from electric resistance heaters.

Table 4. Energy sources of existing heating, ventilation, and air-conditioning systems ${ }^{a}$

\begin{tabular}{|c|c|c|c|c|}
\hline Reference building & $\begin{array}{c}\text { Energy source for space } \\
\text { heating }\end{array}$ & Contribution & $\begin{array}{c}\text { Energy source for space } \\
\text { cooling }\end{array}$ & Contribution \\
\hline \multirow{2}{*}{ Office } & Electricity & $9.5 \%$ & Electricity & $99.4 \%$ \\
\hline & natural gas (NG)/oil/propane & $90.5 \%$ & Other & $0.6 \%$ \\
\hline \multirow{2}{*}{ Lodging } & Electricity & $17.8 \%$ & Electricity & $99.2 \%$ \\
\hline & NG/oil/propane & $82.6 \%$ & Other & $0.8 \%$ \\
\hline \multirow{2}{*}{ Education } & Electricity & $3.8 \%$ & Electricity & $98.6 \%$ \\
\hline & NG/oil/propane & $96.1 \%$ & Other & $1.4 \%$ \\
\hline \multirow{2}{*}{ Retail } & Electricity & $9.5 \%$ & Electricity & $100 \%$ \\
\hline & NG/oil/propane & $90.1 \%$ & Other & $0.0 \%$ \\
\hline \multirow{2}{*}{ Inpatient } & Electricity & $0.5 \%$ & Electricity & $99.6 \%$ \\
\hline & NG/oil/propane & $99.4 \%$ & Other & $0.4 \%$ \\
\hline \multirow{3}{*}{ Single family home } & Electricity (resistance) & $9.4 \%$ & \multirow{3}{*}{ Electricity } & \multirow{3}{*}{$100 \%$} \\
\hline & NG/oil/propane & $66.5 \%$ & & \\
\hline & $\begin{array}{l}\text { Electricity (air-source heat } \\
\text { pump) }\end{array}$ & $18.7 \%$ & & \\
\hline
\end{tabular}

${ }^{a}$ from commercial and residential buildings energy consumption survey data: CBECS (EIA 2016b) and RECS (EIA 2013).

As the minimum code-compliant efficiencies of boilers or furnaces that use NG, oil, or propane are very similar [around 80\% annual fuel utilization efficiency (AFUE) per ASHRAE 90.1-2004], the non-electric SH equipment was modeled with the same heating efficiency ( $80 \%$ AFUE). In addition to the primary baseline HVAC system used in each original CRB model, a secondary baseline HVAC system, which uses non-electric SH equipment or electric resistance heaters, were simulated for each representative commercial building. For residential buildings, in addition to the primary SH equipment (i.e., gas furnace), two other baseline SH equipment - electric resistance heater and air-source heat pump-were simulated for the representative residential building.

\subsubsection{Modeled Geothermal Heat Pump Systems}

The modeled GHP systems are those typically used in the United States - central forced air systems with two-stage GHP equipment for residential applications and distributed systems with multiple single-stage GHP equipment for commercial applications. The typical nominal cooling efficiency of the two-stage 
GHP unit is $18.2 \mathrm{EER}^{8}$ at full capacity and $27 \mathrm{EER}$ at $76 \%$ of full capacity. The typical nominal heating efficiency of the two-stage GHP unit is $4 \mathrm{COP}$ at full capacity and $4.5 \mathrm{COP}$ at $76 \%$ of full capacity. ${ }^{9}$ The typical nominal efficiencies of the state-of-the-art single-stage GHP equipment are 20 EER and 4.2 COP. The GHX is sized to maintain the fluid temperature from the ground loop (the entering fluid temperature to the GHP unit) within the range of $30^{\circ} \mathrm{F}-95^{\circ} \mathrm{F}$ for given building load and ground thermal properties.

The modeled GHX could be a vertical or horizontal closed-loop system depending on the land availability and associated installation cost. Both residential and commercial GHP systems can also provide water heating either partially (with a desuperheater) or fully (with GS-IHP). However, the contribution of water heating was not accounted for when assessing the technical potential of GHPs due to limited applications in current practice.

\subsubsection{Predicted Performance of Geothermal Heat Pump Systems}

Figure 10 shows the primary (source) energy saving performance resulting from retrofitting the existing HVAC systems (i.e., the primary baselines) with GHPs in several types of commercial buildings and single-family houses at various locations (representing different climate zones). As shown in this figure, the range and magnitude of source energy saving percentages vary widely by building type: $32 \%-59 \%$ for single-family houses, $-4 \%-50 \%$ for offices, $18 \%-41 \%$ for lodgings, $17 \%-33 \%$ for schools (education), and $-2 \%-33 \%$ for retails. In general, more energy savings can be achieved at locations with cooler weather (indicated by larger index number of climate zones).

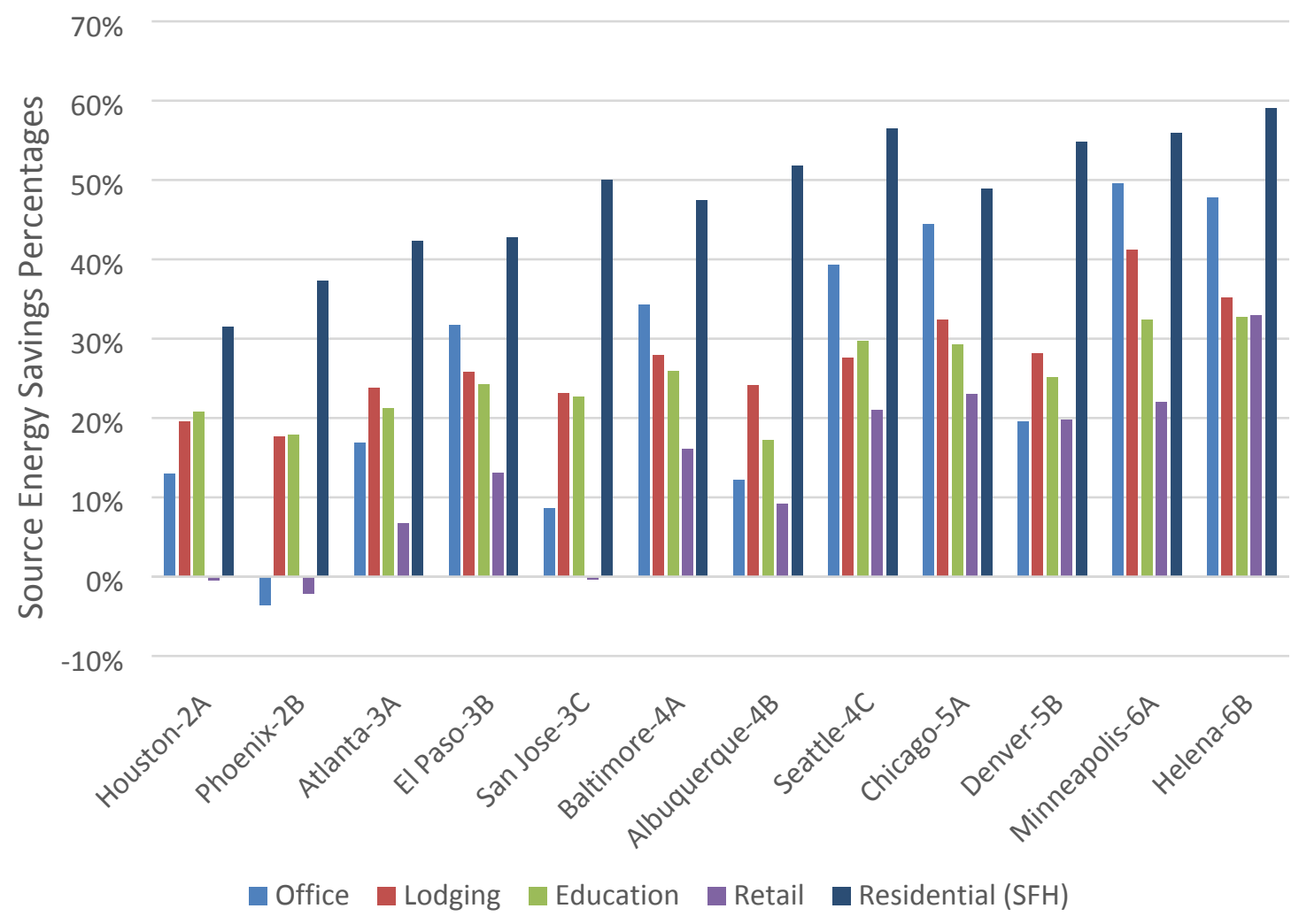

Fig.10. Annual source energy saving percentages by building principal activities and climate zones.

\footnotetext{
${ }^{8}$ The EER is the cooling capacity [in British thermal units (Btu) per hour) of the unit divided by its electrical input (in watts) at standard conditions.

${ }^{9}$ The COP and EER are measured at AHRI/ISO/ASHRAE/ANSI 13256-1 rating conditions: for cooling at full capacity, entering fluid temperature is $77^{\circ} \mathrm{F}$; for heating at full capacity, entering fluid temperature is $32^{\circ} \mathrm{F}$.
} 
The above results indicate that the source energy saving percentages resulting from residential GHP applications are higher than those from commercial GHP applications. It is because that the simulated residential GHP systems use the more energy efficient two-staged GHP equipment and single-family houses have higher space heating demand than commercial buildings (due to longer operation period during nights and less internal heat gains from lighting and computers). For some commercial buildings (e.g., offices and retails) in hot climates (e.g., climate zones 2A and 2B), the energy savings in SH are little and the moderate energy savings in SC are offset by the consumed pumping energy associated with GHP operations. This resulted in the negative source energy saving percentages shown in Fig. 10.

Associated with the above source energy savings, GHP retrofits also reduce carbon emissions and energy costs with percentages similar to the source energy savings (Figs. 11 and 12). Source to site energy conversion factors and emission factors of electricity and fossil fuels are all adopted from a report developed by NREL (2007). Energy cost savings are based on 2014 energy prices for electricity and NG in the states where the representative cities are located (EIA 2016c, 2016d). With more renewable power in the mix of electricity production in the future - a trend that has already begun - the emission factor of electricity will decrease, which in turn will further reduce the carbon emissions of GHPs.

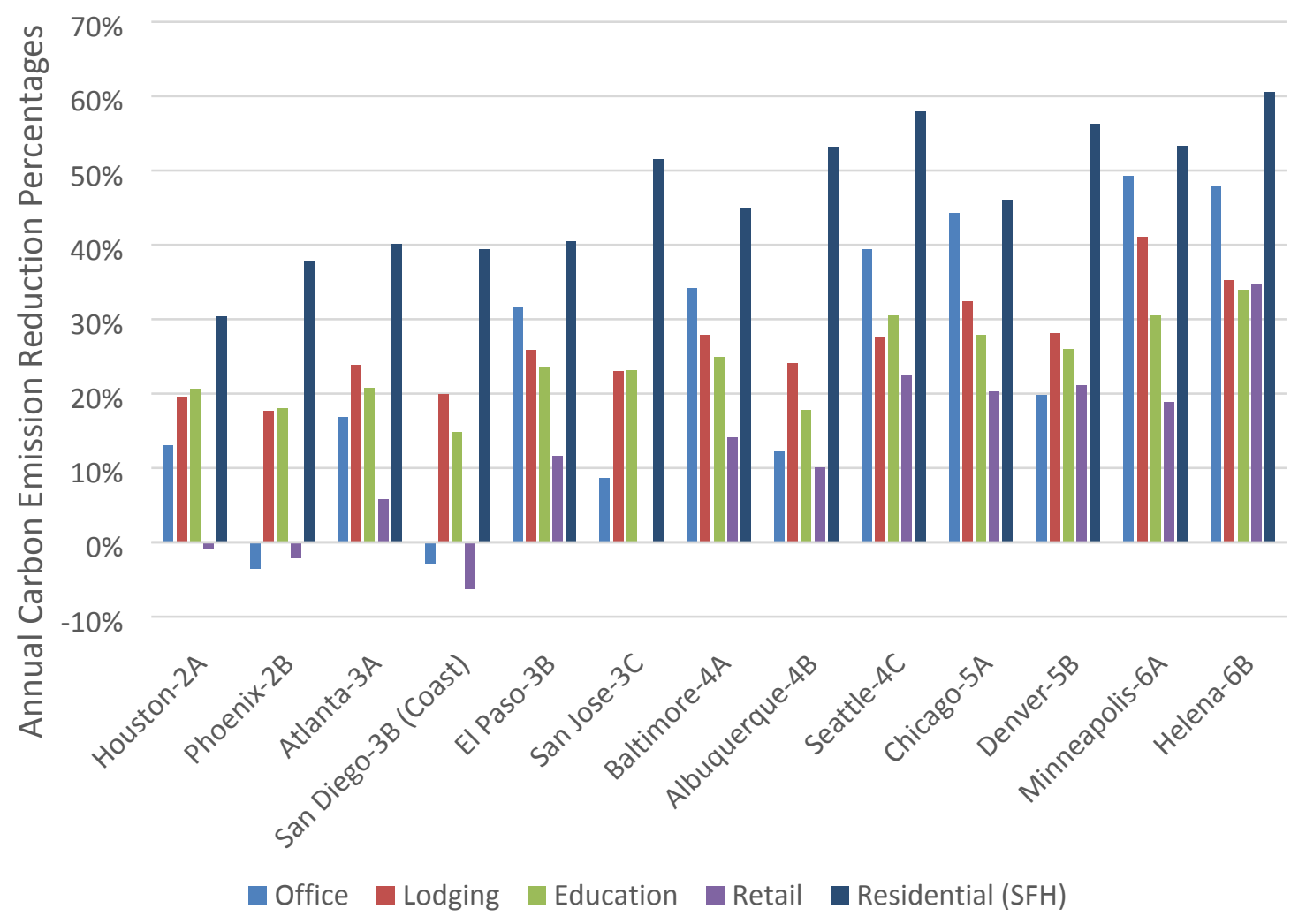

Fig. 11. Annual carbon emission reduction percentages by building principal activities and climate zones. 


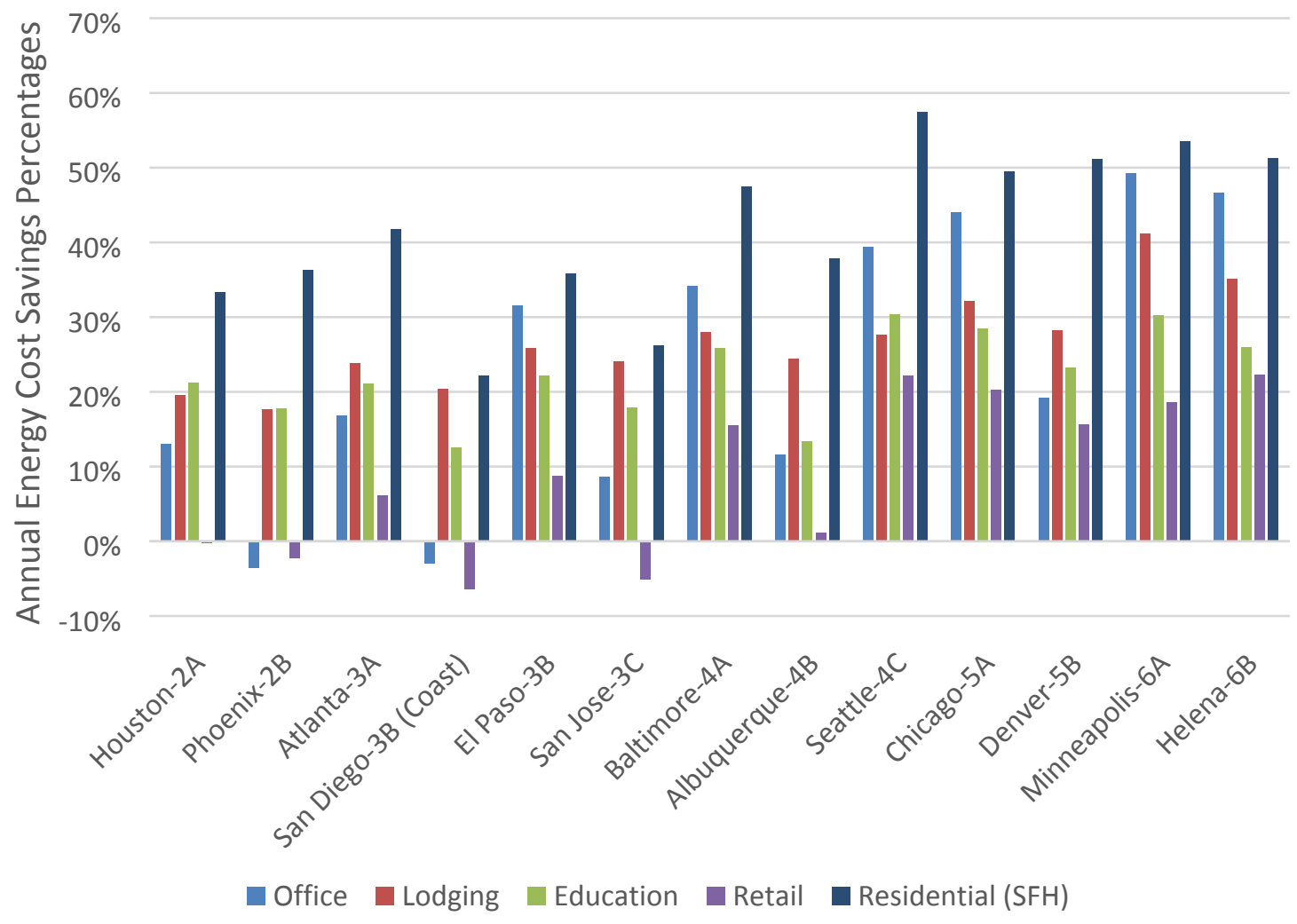

Fig. 12. Annual energy cost savings percentages by building principal activities and climate zones.

The simulation results also indicate that GHP retrofits can reduce annual peak electricity demand for all the investigated buildings except those either in very hot climates (e.g., climate zone 2B) or in very cold climates (e.g., climate zone 6B) and the existing SH systems are non-electric (Fig. 13). Although GHPs could result in more electricity consumption (kilowatt-hours) if they displace fossil fuels for $\mathrm{SH}$, they reduce summer peak electricity demand in most cases because of their higher cooling efficiencies than those of the conventional SC systems. 


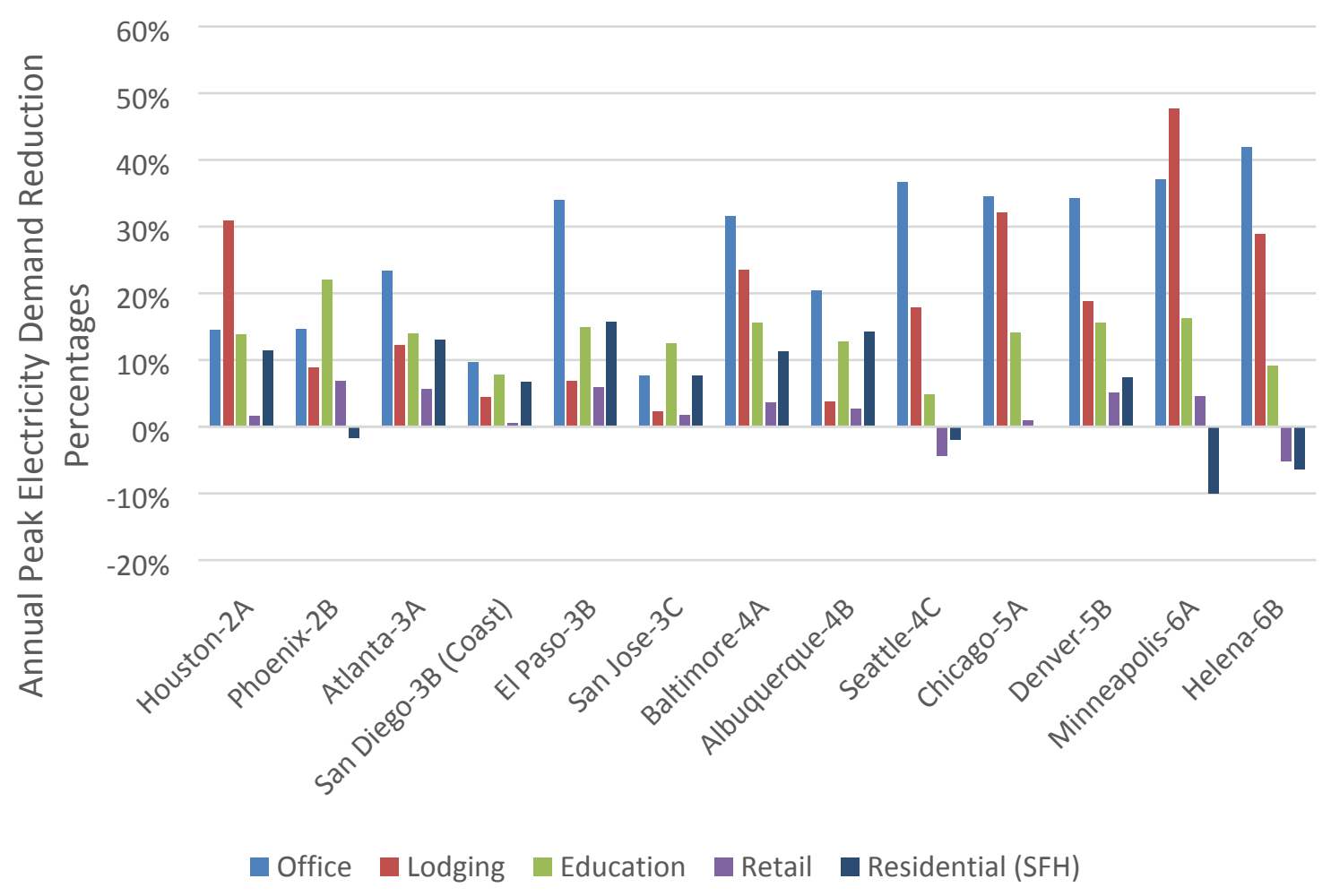

Fig. 13. Annual peak electricity demand reduction percentages by building principal activities and climate zones.

\subsubsection{Ground Thermal Properties}

Ground thermal properties, including undisturbed ground temperature and effective GTC, are critical parameters for sizing GHXs. The undisturbed ground temperature at a location can be estimated based on local historical weather data (Xing 2014) or by looking up the national map of undisturbed ground temperature (Fig. 1). The effective GTC values account for the complicated geological conditions ${ }^{10}$ along the depth of a borehole and the possible underground water movement. They are usually measured through in-situ thermal response tests (TRTs) following standard procedures (IGSHPA 2015, ASHRAE 2015, ANSI/CSA 2016). At the time of this study, there was no comprehensive national database of GTC results. The geological surveys of some states, including New Jersey, Connecticut, and Tennessee, collected GTC data measured with TRTs and submitted these data ${ }^{11}$ to the National Geothermal Data System (NGDS 2016). More GTC data measured with TRTs were collected in this study from several contractors in a few states. The final compilation of GTC data that was assembled during this study included 157 entries. The GTC data gathered for this study show that even when sites are located less

${ }^{10}$ The thermal conductivity of saturated soils ranges from $1.64 \mathrm{~W} / \mathrm{m}-\mathrm{K}\left(0.95 \mathrm{Btu} / \mathrm{hr}-\mathrm{ft}-{ }^{\circ} \mathrm{F}\right)$ for very fine soil to

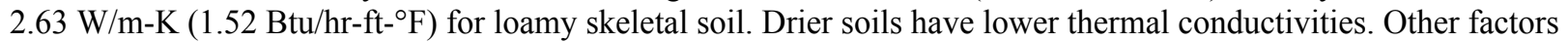
that affect soil thermal conductivity include soil texture (sand, silt, clay, or loam), organic content, mineralogy, and compaction. Rock thermal conductivity is affected by mineral composition, porosity, water content, mineral grain size, amorphous phase (glass) content, and fracturing. The range of thermal conductivity for rocks varies from 0.38

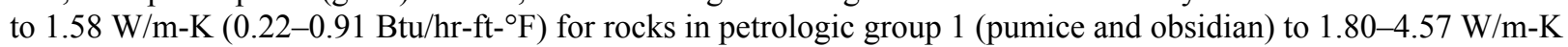
$\left(1.04-2.64 \mathrm{Btu} / \mathrm{hr}_{-} \mathrm{ft}-{ }^{\circ} \mathrm{F}\right)$ for rocks in petrologic group 5 (including granite) to $0.81-7.77 \mathrm{~W} / \mathrm{m}-\mathrm{K}(0.47-4.49 \mathrm{Btu} / \mathrm{hr}-$ $\mathrm{ft}^{\circ} \mathrm{F}$ ) for rocks in petrologic group 8 (including quartzite) (Salomone and Marlowe 1989).

11 These data usually contain site name, latitude, longitude, depth (feet), thermal conductivity (Btu/hr-ft- $\left.{ }^{\circ} \mathrm{F}\right)$, thermal diffusivity ( $\mathrm{ft} 2 /$ day), geologic formation type, elevation, and test contractor. 
than 3 miles apart and have similar depths, GTC values can differ by $70 \%$ when the sites have different lithology.

While available TRT results are limited, thermal conductivity values of rock samples from 68,251 oil and gas wells are available (SMU 2016). The available data also include information on the location and depth of the measurement. Figure 14 shows the location and value of the available rock thermal conductivity data in a national map.

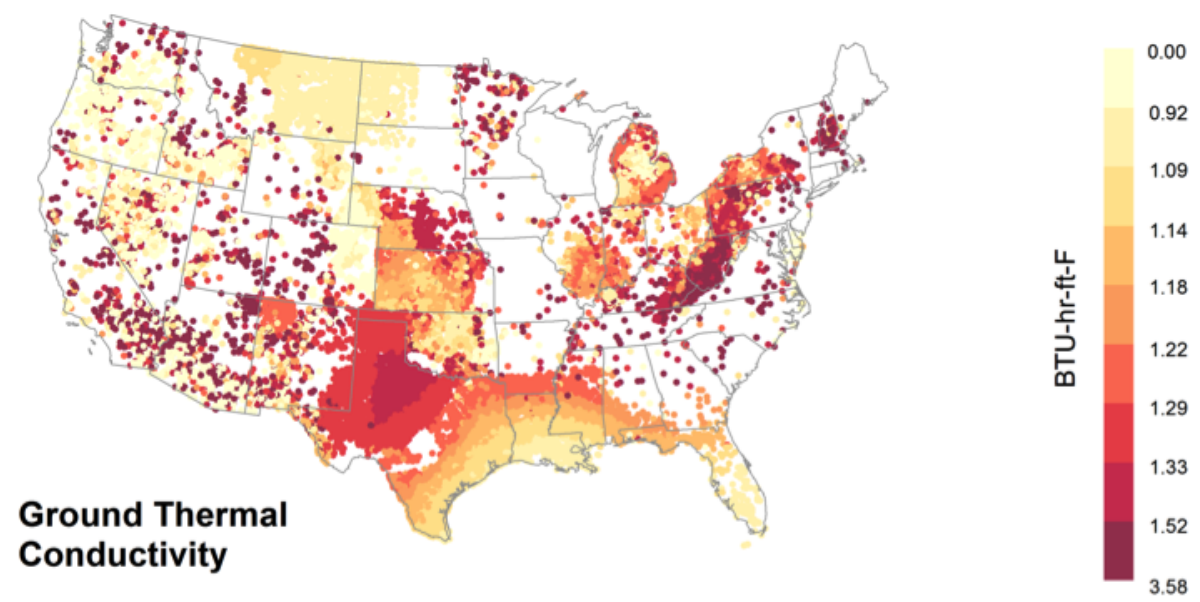

Fig. 14. Location and value of available rock thermal conductivity data (data are adapted from SMU 2016)

GTC values measured from 40 TRTs were compared with the rock thermal conductivity values obtained from oil and gas wells within 25 miles of the TRT sites. Although there are some discrepancies between the two data sets in terms of individual measurement (Fig. 15), the difference in the median value of the two data sets is $-9.2 \%$. It indicates that the available rock thermal conductivity values could be used to approximate the regional average of GTCs.

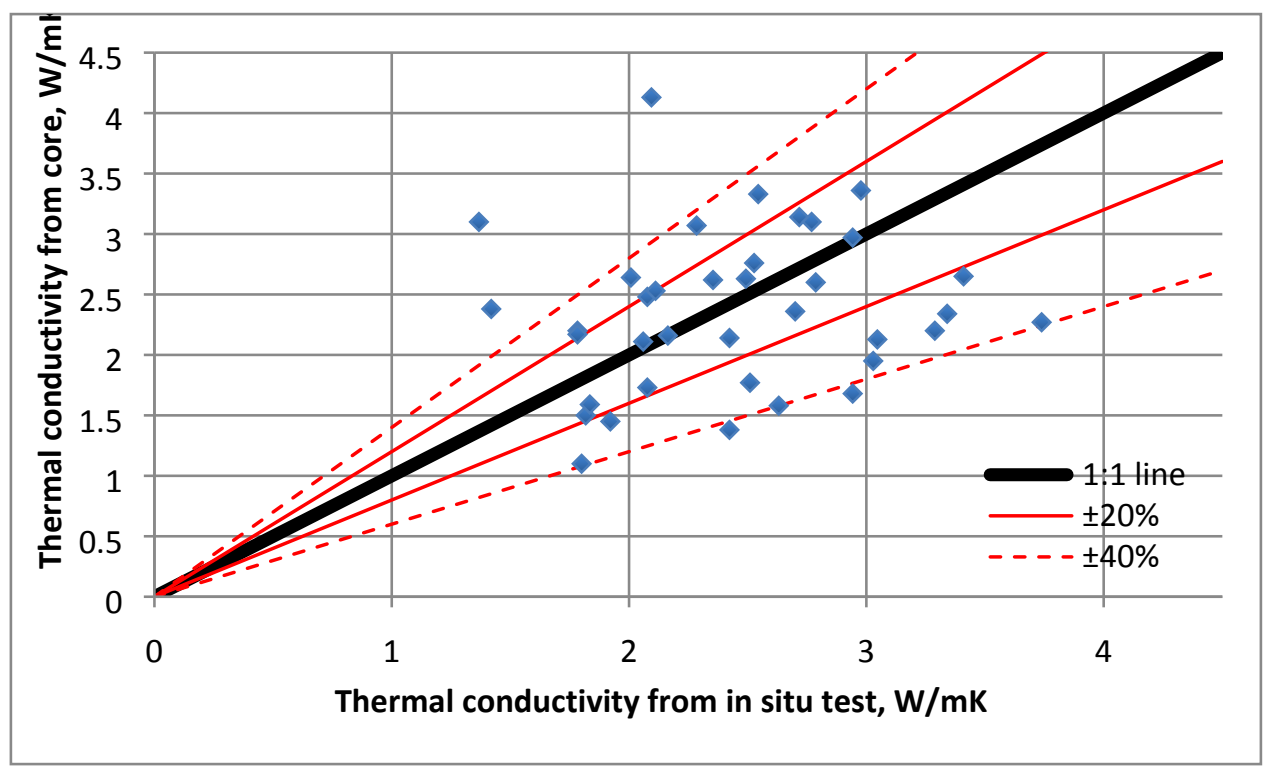

Fig. 15. A comparison between rock thermal conductivity values and ground thermal conductivity values measured with in-situ thermal response tests. 
Figure 16 is a box chart showing the distribution of available rock thermal conductivity values in each climate zone. The median value and the $25^{\text {th }}$ and $75^{\text {th }}$ quartile values of the rock thermal conductivity in each climate zone are used to sample GTC values from and size the GHX for each reference building in the climate zone. Because some states only have limited rock thermal conductivity data, the uncertainty of the estimated mean GTC values in these states would be higher than other states with more data points. A database of GTC values that cover each state with a high resolution (e.g., one data point in each square mile) is desirable to more accurately depict the variances of GTCs.

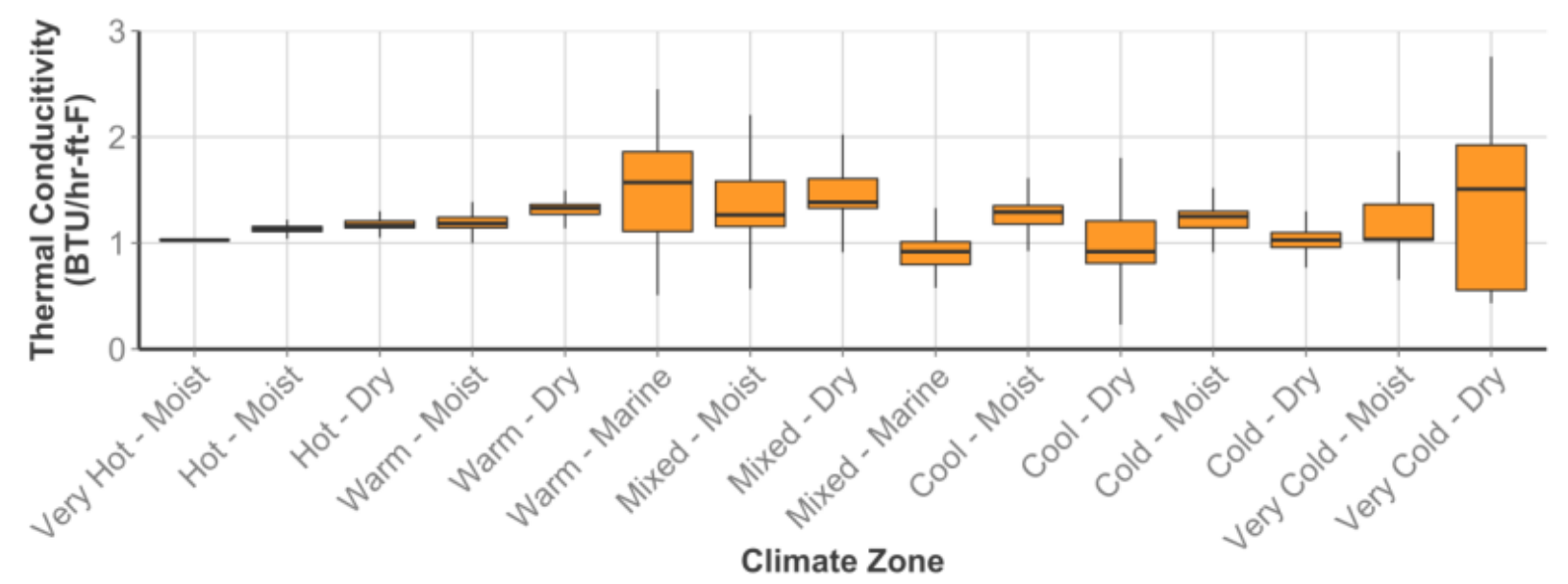

Fig. 16. Statistical distribution of available rock thermal conductivity data in each climate zone.

\subsubsection{Installation and Operation Costs}

\section{Geothermal Heat Pump Systems}

A generic model for the installed cost of GHP systems was developed and used in this study. This model includes prices of the three parts of a GHP system: GHX, GHP equipment, and the balance of the system (BOS).

The GHX price includes all the costs and markups for drilling bores (or trenching), inserting heat exchanger loops, grouting the bores (or backfilling the trenches), and looping to the heat pump. It contributes the most to the overall price of a GHP project. The GHX price $\left(\$_{G H X}\right)$ is calculated based on the average normalized GHX price at a location and the size of the GHX for providing needed capacity with given ground thermal properties, as expressed in Eq. (3).

$$
\$_{G H X}=N G C(i) * N C(x, y) * F S * N G S(x, y) * C G T C(z)
$$

where, $N G C(i)$ is the average normalized price (expressed as dollars per foot of vertical bore) of a vertical closed-loop GHX at location i; $N C(x, y)$ is the normalized capacity of a GHP system (expressed as tons per square foot), which is determined by the computer simulation of a reference building $\mathrm{x}$ at a climate zone y; FS is the floor space of an agent (explained in Section 3.1)represented by the reference building in the climate zone; $N G S(x, y)$ is the normalized GHX size (expressed as the ratio of the total bore length of a vertical loop GHX to the total capacity of the GHP system, in feet per ton), which is determined by the computer simulation of the reference building and with the average GTC value within the climate zone; and $\operatorname{CGTC}(z)$ is a function to adjust the normalized GHX size based on z, which is the ratio of any given GTC to the average GTC. 
The average prices of the vertical closed-loop GHXs by dominant geology conditions in each census region were adapted from a recent study by Battocletti and Glassley (2013) and are listed in Table 5. As shown in this table, prices of vertical closed-loop GHXs vary spatially and are also dependent on the dominant geology. However, due to a lack of the needed subsurface geological data for more granular analysis, dGeo uses the nationwide median value of the GHX price ( $\$ 14 / \mathrm{ft}$ of borehole length) for all geologies. It is assumed that the installed cost of vertical closed-loop GHXs for residential and commercial installations are equal. The installed costs of horizontal closed-loop GHXs are obtained from a major GHP manufacturer in the United States ${ }^{12}$. The installed cost is about $\$ 1,200$ per ton in the Midwest and \$2,500 per ton in the South region. The difference in the installed cost for various types of horizontal loop designs is small and thus neglected in this study.

Table 5. Average prices of vertical closed-loop ground heat exchangers by dominant geology in each census region

\begin{tabular}{c|c|c|c}
\hline Loop Type & Census Region & Dominant Geology & Price (\$/ft) \\
\hline \multirow{4}{*}{ Northeast } & National & Unknown & 14.00 \\
\cline { 3 - 4 } & & Hard rock & 16.50 \\
\cline { 3 - 4 } & & Soft rock & 15.00 \\
\cline { 3 - 4 } & & Sand & 23.00 \\
\cline { 3 - 4 } & \multirow{4}{*}{ Midwest } & Other or unknown & 17.00 \\
\cline { 3 - 4 } & & Hard rock & 13.00 \\
\cline { 3 - 4 } & & Soft rock & 14.00 \\
\cline { 3 - 4 } & & Clay & 10.00 \\
\cline { 3 - 4 } & \multirow{3}{*}{ South } & Other or unknown & 12.00 \\
\cline { 3 - 4 } & & Hard rock & 16.00 \\
\cline { 3 - 4 } & & Clay & 8.00 \\
\cline { 3 - 4 } & & Sand & 7.00 \\
\cline { 3 - 4 } & \multirow{3}{*}{ West } & Other or unknown & 14.50 \\
\cline { 3 - 4 } & & Any & 14.00 \\
\hline
\end{tabular}

The price of GHP equipment includes the capital costs for GHP equipment and the associated installation costs, including material, labor, overhead, and profit. As discussed previously, the modeled commercial GHP systems use multiple small GHP equipment (usually with capacities less than 5 tons) in a distributed configuration. Residential GHP systems usually also have less than 5-ton capacity. The price of GHP equipment $\left(\$_{G H P}\right)$ is calculated with Eq. (4):

$$
\$_{G H P}=N C(x, y) * F S * f(N C) \text {, }
$$

where $f(N C)$ is a correlation between the average size of the GHP equipment used in a representative building and its normalized price (dollars per ton). This correlation is derived from available RSMeans (2016) cost data for 1-, 2-, and 5-ton GHP equipment, as shown by the trend line of the bar chart in Fig.17. For commercial GHP systems, it is assumed in this study that the average size of the GHP equipment is 5 tons.

\footnotetext{
12 Email communications with Bob Brown, the Vice President of WaterFurnace International, on April $27,2017$.
} 


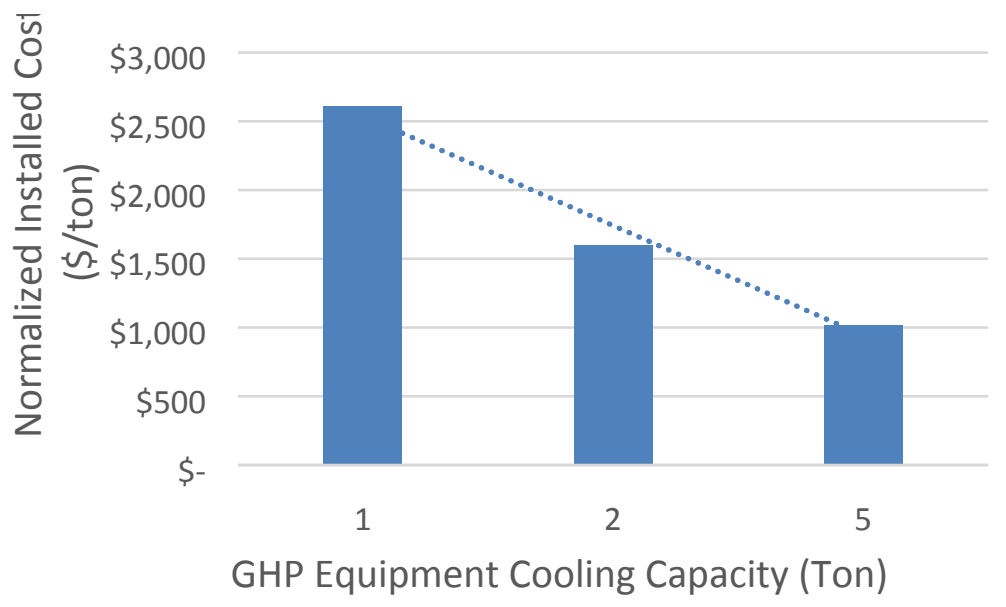

Fig. 17. Installed costs of 1-, 2-, and 5-ton geothermal heat pump equipment (RSMeans 2016).

The BOS price includes the installed costs of all the remaining components other than the GHX and the GHP equipment. These components include ductwork, hydronic piping, circulation pumps, and necessary system-level controls. The BOS price $\left(\$_{B O S}\right)$ is calculated with Eq. (5):

$$
\$_{B O S}=N C(x, y) * F S * D u c t+F S * \text { Piping },
$$

where, Duct is the normalized cost of a multizone ductwork ( $\$ 2,802 /$ ton $)$, which is adopted from RSMeans (2016); and Piping is the normalized cost of a hydronic piping system including circulation pumps $\left(\$ 1.7 / \mathrm{ft}^{2}\right)$, which is the average of the cost data for commercial buildings reported in the literature (TTGeo and GMC 2016).

The central air ductwork that is most commonly used in residential buildings can be used for both GHP and conventional HVAC systems. Therefore, there is no difference in the BOS cost between a GHP system and a baseline HVAC system for both new construction and retrofits. For commercial buildings, if the baseline HVAC system uses multizone ductwork, such as a variable air volume (VAV) system, a new hydronic piping system including circulation pumps would be needed to implement a distributed GHP system.

O\&M cost, which is the total annual cost for operating and maintaining a GHP system, is accounted for in addition to the installed cost. The O\&M cost does not include the energy cost for running these systems, which is calculated separately based on annual energy consumption of the GHP system and the energy price in each year. The O\&M cost is assumed to scale with the size of the system, which is represented by the total floor space (in square feet) served by a GHP system, and is therefore expressed as dollars per square foot per year $\left(\$ / \mathrm{ft}^{2} /\right.$ year). Based on a previous survey by Cane and Garnet (2000), the log-mean of the surveyed total annual maintenance costs of various commercial GHP systems in 1996 was $\$ 0.061 / \mathrm{ft}^{2}$ (base), $\$ 0.074 / \mathrm{ft}^{2}$ (in-house), and $\$ 0.084 / \mathrm{ft}^{2}$ (contractor). The average of these three costs is used as an input to $\mathrm{dGeo}$ after being adjusted with a 3\% inflation rate to get the 2016-dollar value, which is $\$ 0.13 / \mathrm{ft}^{2}$. The O\&M cost for residential GHP systems is negligible (mainly for changing air filters) and the same is assumed for conventional residential HVAC systems.

\section{Baseline Heating Ventilation, and Air-Conditioning Systems}

For residential buildings, three conventional HVAC systems were considered based on RECS (EIA 2013): (1) a packaged air conditioner with a gas-/oil-/propane-fired furnace, (2) a packaged air 
conditioner with electric resistance, and (3) an air-source heat pump with electric resistance. RSMeans (2016) cost data for the heating and cooling equipment of the above three systems are used to derive two correlations between the heating or cooling capacity and the installed costs (as shown in Figs. 18 and 19).

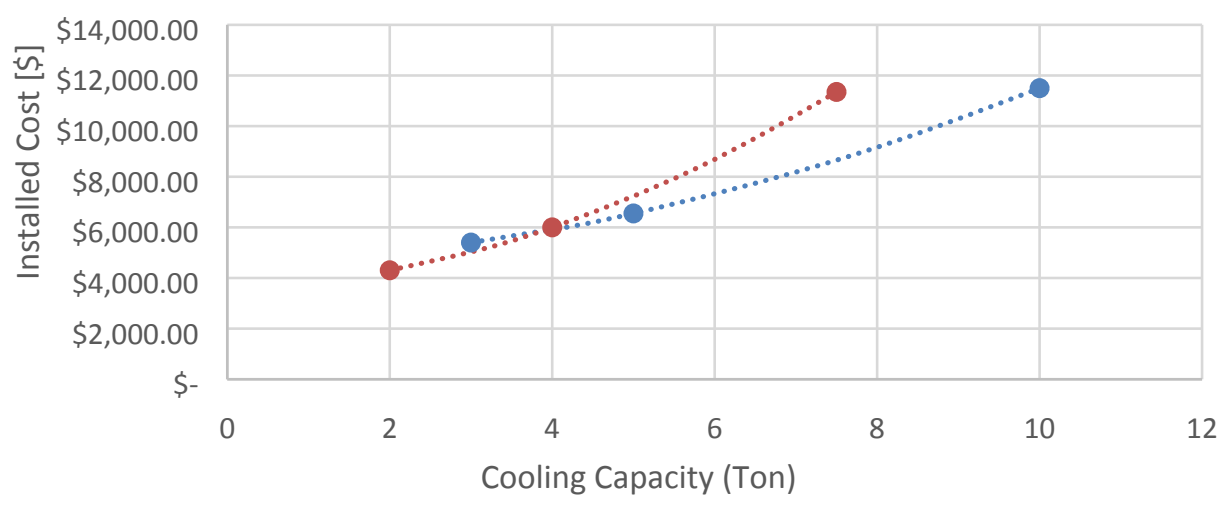

Self-Contained Air-Conditioners, Air cooled, for free blow or duct, not incl. remote condenser

Heat pump, air to air single package

Fig. 18. Installed costs of typical residential space cooling equipment (RSMeans 2016).

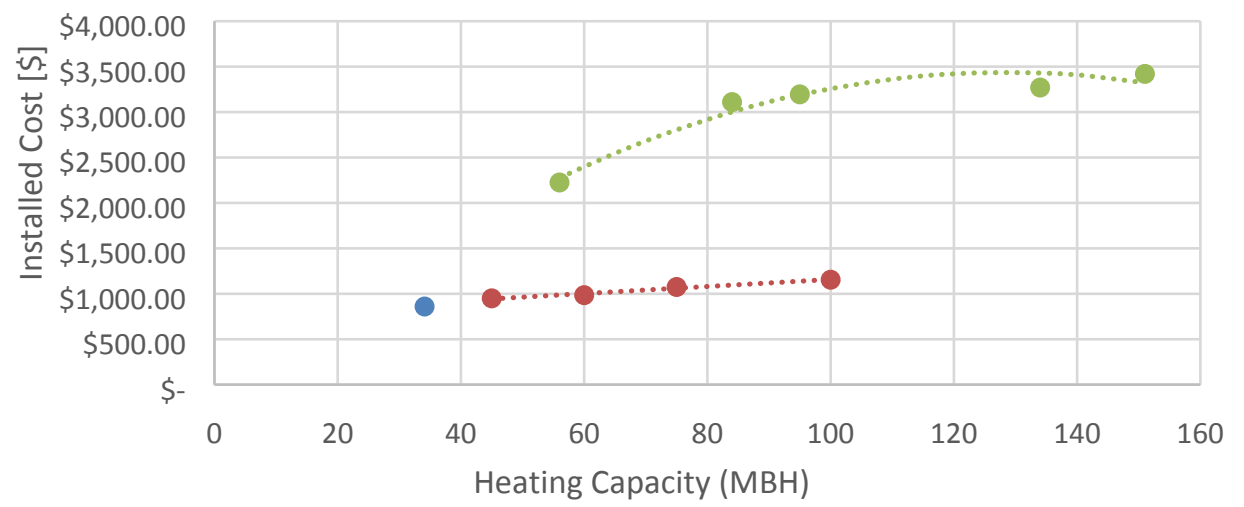

Electric Furnace, hot air, blower, std. controls

Gas-Fired Furnace, AGA certified, upflow, direct drive models

Oil-Fired Furnace, UL listed, atomizing gun type burner

Fig. 19. Installed costs of typical residential space heating equipment (RSMeans 2016).

The price of a baseline HVAC system in a residential building $\left(\$_{R e s-B L}\right)$ is calculated as the sum of the installed cost of the SC and SH equipment and ductwork, as expressed with Eq. (6):

$$
\$_{R e s-B L}=C F_{S C}\left[F S * N C_{S C}(y)\right]+C F_{S H}\left[F S * N C_{S H}(y)\right]+N C_{S C}(y) * F S * D u c t
$$

where $N C_{S C}$ and $N C_{S H}$ are the normalized cooling and heating capacities, respectively, which are determined by the computer simulation of the representative residential building at each climate zone, and 
$C F_{S C}$ and $C F_{S H}$ are the correlations between the installed cost and the capacity of the $\mathrm{SC}$ or $\mathrm{SH}$ equipment.

For commercial buildings, it is assumed that the conventional HVAC system is a packaged VAV system with standard features, including multizone control, electric $\mathrm{SC}$, gas $\mathrm{SH}$, and an air-side economizer. RSMeans (2016) cost data for packaged VAV equipment (the outdoor HVAC equipment only, without ductwork inside the building) with cooling capacities ranging from 15 to 105 tons are used to derive a correlation between cooling capacity and the installed cost of the packaged VAV equipment. Because the cost of the furnace pack used in the packaged VAV equipment is not very sensitive to its capacity, the above correlation is used to estimate the installed cost of packaged VAV equipment based solely on its cooling capacity (between 15 tons and 105 tons). It is assumed that multiple packaged VAV equipment (each with a capacity not larger than 105 tons) is used for systems with larger than 105-ton cooling capacity. For systems with less than 15-ton cooling capacity, the cost is estimated by proportionally decreasing the cost of the 15-ton packaged VAV equipment.

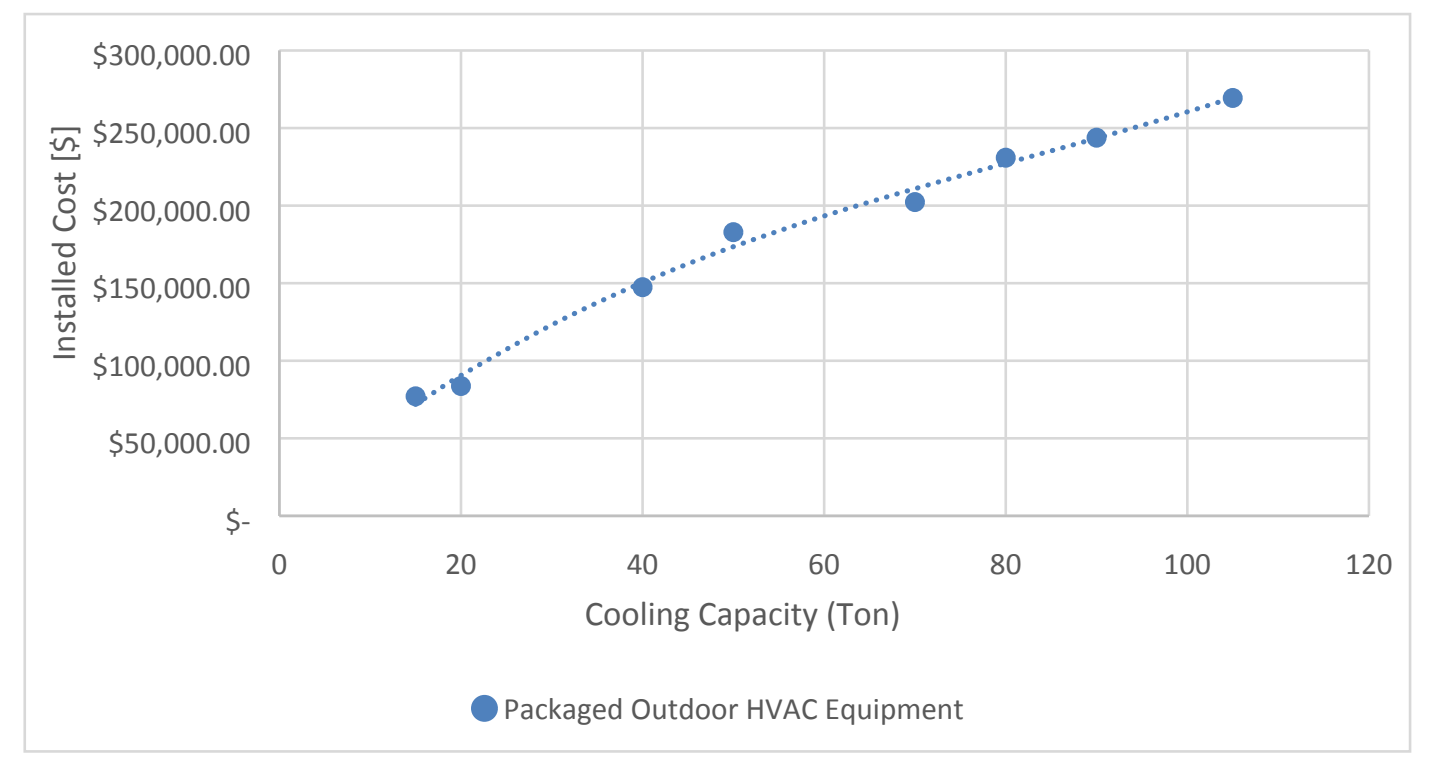

Fig. 20. Installed costs of typical packaged VAV equipment (RSMeans 2016).

The price of a commercial baseline HVAC system $\left(\$_{C o m}-B L\right)$ is calculated as the sum of the installed cost of the packaged VAV equipment and a multizone ductwork, as expressed with Eq. (7):

$$
\$_{C o m-B L}=C F_{S C-P V A V}\left[F S * N C_{S C}(x, y)\right]+N C_{S C}(x, y) * F S * D u c t
$$

where, $C F_{S C-P V A V}$ is the correlation between the installed cost and the capacity of the packaged VAV equipment.

The O\&M cost for a residential baseline HVAC system is negligible as discussed previously. The O\&M cost for a commercial baseline HVAC system is adopted from the results of an ASHRAE study (ASHRAE 1999). The mean annual maintenance cost of a packaged VAV system is estimated as $\$ 0.64 / \mathrm{ft}^{2} /$ year (in 2016 dollars assuming 3\% inflation rate in the past years). 


\subsubsection{Energy Prices}

Within the dGeo framework, agents evaluate the current and anticipated future expenditures associated with the energy consumed for operating both the potential GHP system as well as the baseline HVAC system for SH and SC applications. These energy costs are based on the agents' attributes for current and future energy prices and the site energy consumptions of the GHP and the baseline HVAC system. Energy prices from EIA's 2016 Annual Energy Outlook (AEO; EIA 2016a) report are used in dGeo to represent the price paid to operate the two systems. Figure 21 shows the energy prices (of the Reference Scenario in the 2016 AEO) for the four main fuels modeled in dGeo, electricity, fuel oil, propane, and NG. While Figure 21 shows only the national average energy prices in the residential sector to demonstrate the general temporal trends of the different fuels, dGeo uses region-specific fuel prices for residential and commercial GHP applications, respectively, to improve accuracy of the analysis.

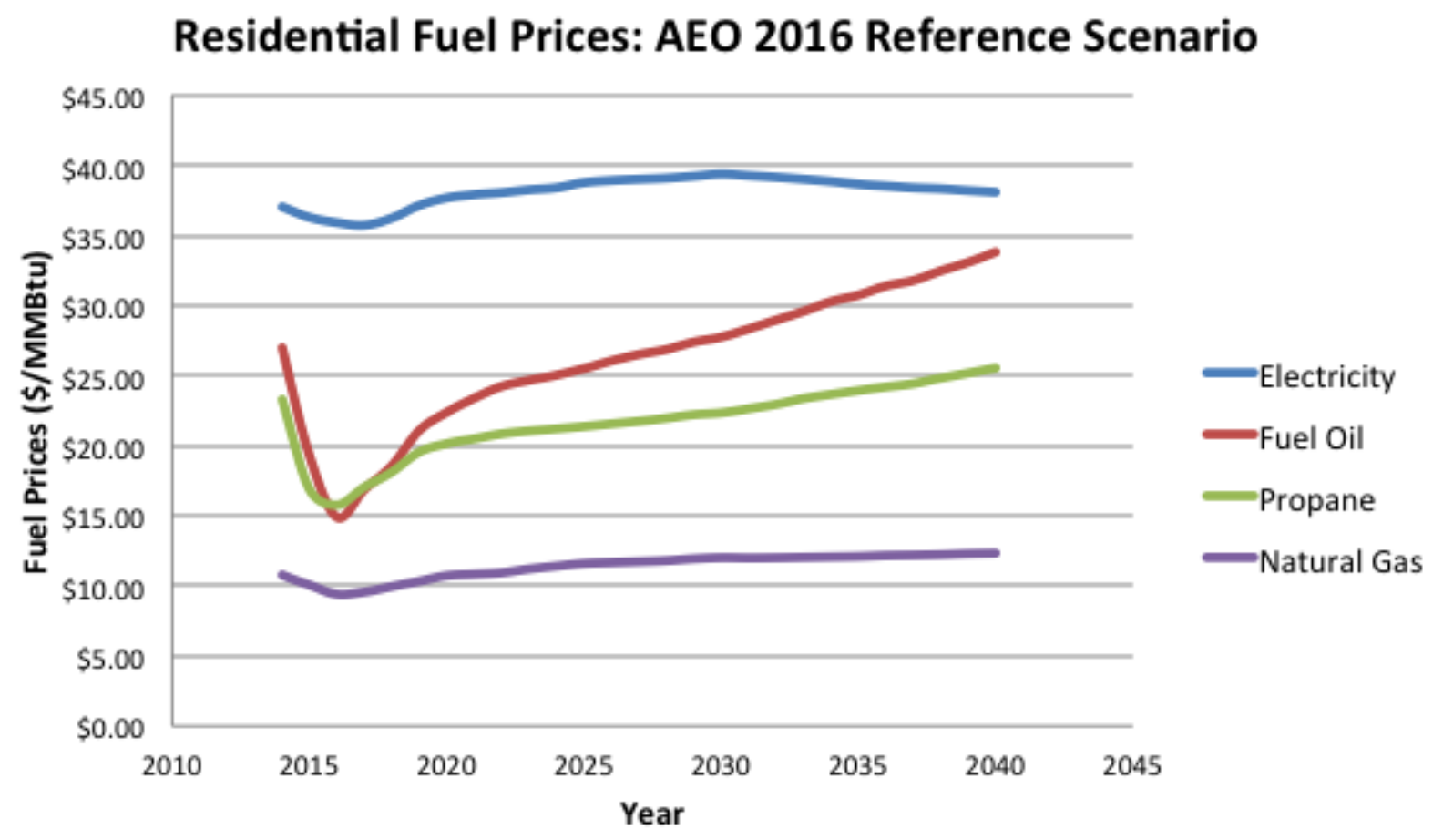

Fig. 21. Projected residential energy prices (EIA 2016a)

\subsubsection{Financial Terms}

The financing portion of dGeo has the following built-in assumptions:

- Every agent in the model has access to the capital required for a GHP system.

- Every agent has access to the same loan terms.

- Inflation is set at $2.5 \% / y e a r$ in all cases.

dGeo can choose financing inputs that are specific to each sector and model year, allowing for potential complex scenario modeling. However, for the purposes of the national adoption modeling in the Geothermal Vision Study, the financing parameters were assumed to remain constant over the entirety of the simulation period (2014-2050). These inputs include parameters such as loan term (15 years), loan rate $(6 \%)$, down payment fraction $(20 \%)$, discount rate $(7 \%)$, and tax rate $(33 \%)$. 
For new construction, the $20 \%$ down payment used in the current scenario study for GHP is reasonable (GHP is an integral part of a new building and thus is financed with it). Currently, TPF programs for GHP retrofits are available (e.g., the GeoSmart program offered by the Electric and Gas Industries

Association ${ }^{13}$ ). These programs are designed to pay for the cost premium of GHP systems with the energy cost savings over a long period (e.g., 20 years).

Per ASHRAE (2011), the median service life of water-to-air heat pumps (i.e., the GHP equipment used in both residential and distributed commercial GHP systems) is longer than 24 years. It is assumed that the service life of GHP equipment is 20 years in this study (to simplify the analysis) and the service life of the closed-loop GHXs, which are buried in the ground without any moving component, is longer than 50 years (DOE 2016).

The service life of major conventional heating and cooling equipment used in baseline HVAC systems is listed below (ASHRAE 2011). To simplify the analysis, service life of all the baseline HVAC equipment is assumed to be 15 years.

- Roof-top air conditioner: 15 years

- Residential air conditioner and air-source heat pump: 15 years

- Chiller: 20-23 years

- Boiler: $15-30$ years

- Furnace: 18 years

\subsection{TECHNICAL POTENTIAL}

The GHP technical potential is assessed based on (1) energy consumption data obtained from the latest survey of energy consumption in residential and commercial buildings, which is conducted by EIA, and (2) energy savings performance data for GHPs compared with existing conventional HVAC systems, which are calculated based on computer simulation results. These computer simulations account for many factors affecting energy savings, including thermal loads (determined by the location, building envelope, and activity of the building), performance of the existing HVAC systems, local geological conditions (i.e., undisturbed ground temperature and ground thermal conductivity), and the performance of GHPs.

Unlike previous studies (Hughes 2008, Liu 2010), which relied on national or census region-level building energy consumption data, this study used a database of county-level site energy consumption data in residential and commercial buildings that was developed by NREL (McCabe et al. 2016). The county-level data for residential buildings were derived by disaggregating regional-level (states, aggregates of states) site energy consumption data for SH, SC, and DWH-reported in EIA's 2009 RECS (EIA 2013) - by the most recent count of housing units in each county, which is extracted from the National Historical Geographic Information System for a 5-year period (2009-2013). The county-level data for commercial buildings were derived by multiplying the total square footage of each type of commercial building in each county_ extracted from the Federal Energy Management Agency's (FEMA) Comprehensive Data Management System (CDMS) - by the average site energy intensities ( $\left.\mathrm{kBtu} / \mathrm{ft}^{2}\right)$ for $\mathrm{SH}, \mathrm{SC}$, and DWH for each particular type of commercial building in the climate zone in which the county is located. The average site energy intensities are provided in the 2009 Buildings Energy Data Book (DOE 2009) by principal building activity and climate zone. The procedure for assessing the technical potential of GHPs is depicted in Fig. 22.

\footnotetext{
${ }^{13}$ https://www.egia.org/geosmart-financing-clearinghouse
} 


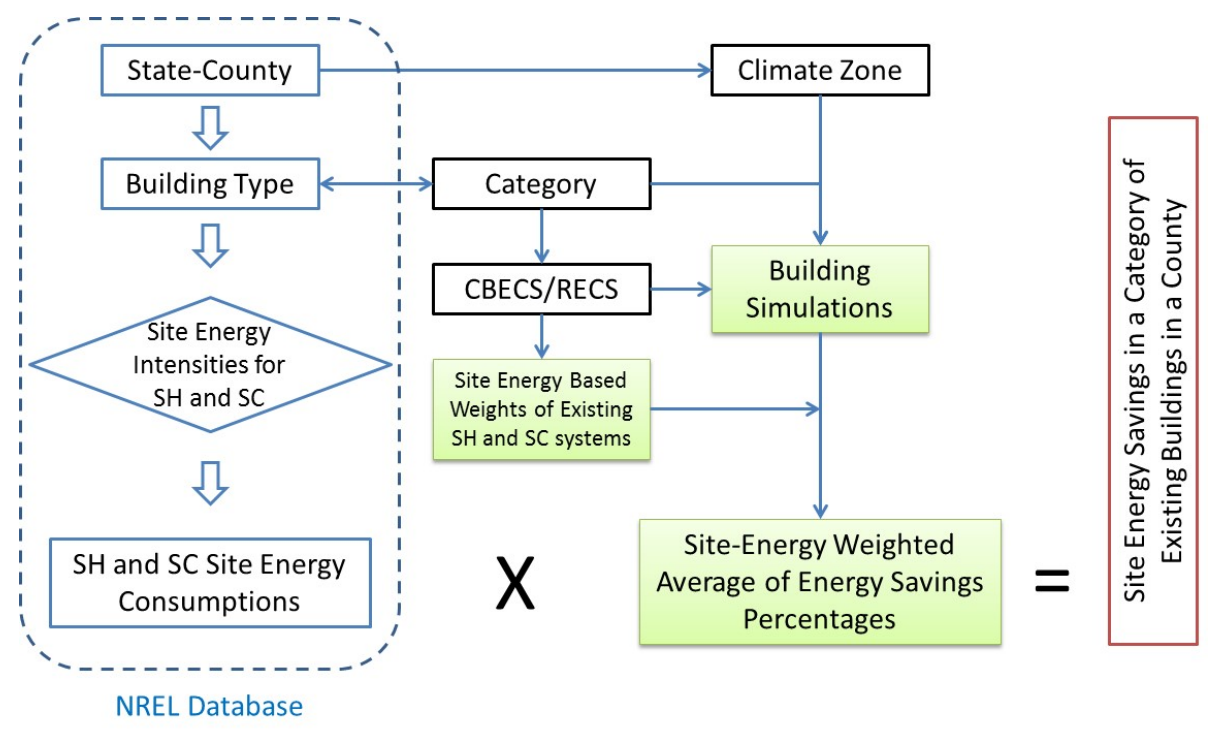

Fig. 22. The process for evaluating the technical potential of energy savings by GHPs in a county.

Because the available county-level energy consumption data do not have information on the contribution of various existing HVAC systems in each county, the national shares of various SH systems (listed in Table 3) are used as weighting factors to account for different existing HVAC systems in each group of buildings. The average site energy saving percentage ( $A v g_{-} E S P c t_{-} S E$ ) resulting from retrofitting existing HVAC systems with GHPs for a given type of building in a particular county is calculated based on the site energy consumption of each existing HVAC system ( $S y s_{-} S E$ ) and the energy saving percentage (ESPct_SE) of the simulated GHP system compared with each existing HVAC system, as expressed with Eq. (8):

$$
A v g_{-} \operatorname{ESPct} \_S E(j, k)=\frac{\sum_{i=1}^{l} S y s_{-} S E(i, j) \cdot E S P c t_{-} S E(i, j, k)}{\sum_{i=1}^{n} S y s_{-} S E(i, j)},
$$

where $i, j$, and $k$ are the indexes of baseline HVAC system, building type, and county, respectively.

The maximum achievable county-level annual site energy savings ( $S E S$ ) from GHP retrofits for a given group of buildings in a county is calculated by multiplying the corresponding total site energy consumption of existing HVAC systems ( $S E$ ) with $A v g_{-} E S P c t_{-} S E$, as expressed with Eq. (9).

$$
\operatorname{SES}(j, k)=S E(j, k) \times A v g_{-} E S P c t \_S E(j, k)
$$

The national annual site energy savings (National_SES ) resulting from retrofitting existing HVAC systems with GHPs in all buildings is calculated with Eq. (10).

$$
\text { National_SES }=\sum_{k=1}^{n} \sum_{j=1}^{m} S E S(j, k)
$$


The savings in primary (source) energy, the reduction in $\mathrm{CO}_{2}$ emissions, and the savings in energy costs are calculated following the same procedure. In these calculations, the annual site energy consumption of each existing HVAC system is replaced with the associated primary energy consumption, $\mathrm{CO}_{2}$ emissions, or energy costs, which are converted from the site energy consumption data using corresponding conversion factors published by NREL (2007) and the 2014 state-level average electricity and NG prices (EIA 2016c, 2016d).

Figure 23 shows the combined source energy savings potential in both residential and commercial buildings in each county of the United States (excluding counties in Alaska and Hawaii). The amount of source energy savings in each county (in trillions of British thermal units) is color-coded as shown in the legend. As Fig. 23 shows, there are substantial energy savings potentials $(>0.4$ trillion Btu) in most counties in the United States, and the northeastern region has more counties with high source energy saving potential ( $>2$ trillion $\mathrm{Btu})$ than other regions.

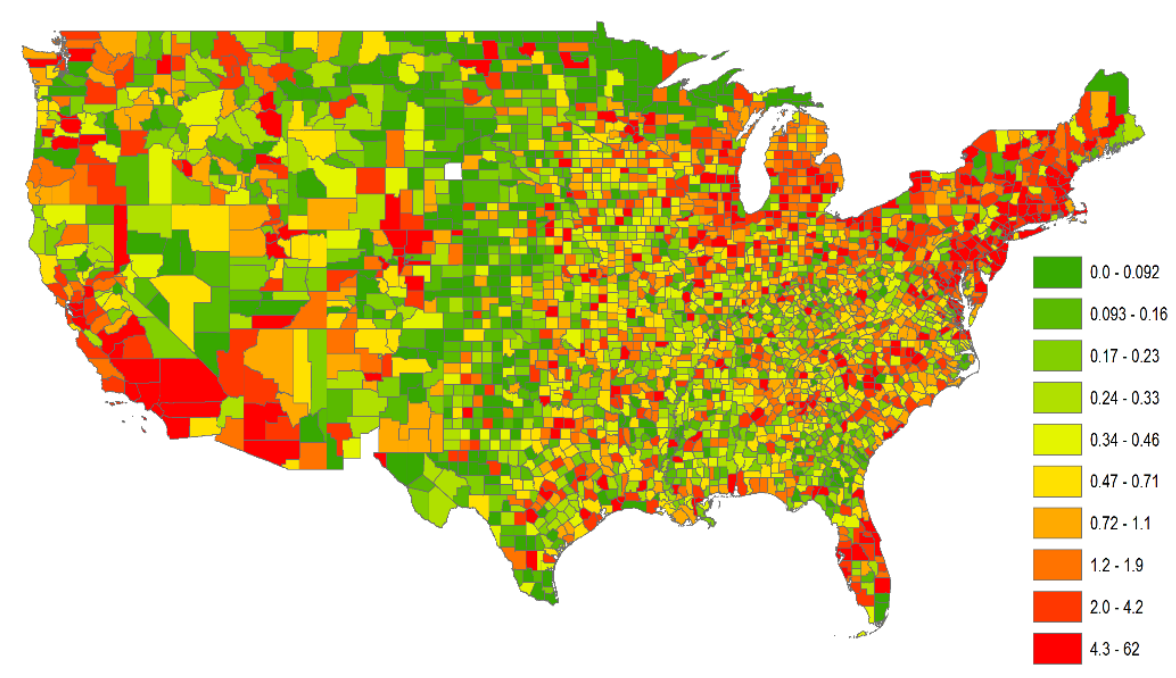

Fig. 23. Source energy savings potential (in trillions of British thermal units) in each county (excluding Alaska and Hawaii) from retrofitting existing HVAC systems in residential and commercial buildings with GHPs.

Table 6 lists the annual site energy savings, source energy savings, carbon emission reductions, and energy cost savings in the residential and commercial sectors, and the sum of the two sectors. As shown in the table, retrofitting the residential sector with GHPs has 3 times more potential than retrofitting the commercial sector. Combining both residential and commercial sectors, GHP retrofits have a potential to save 5.7 quadrillion Btu (quad) of primary energy, avoid 356.3 million $\mathrm{Mt}$ of $\mathrm{CO}_{2}$ emissions, and reduce energy costs by $\$ 49.8$ billion each year. The 2009 Buildings Energy Data Book (DOE 2009) stated that 8.21 and 4.06 quad of primary energy are consumed annually for SH and SC in U.S. buildings in 2010. The 5.7 quad of primary energy savings from GHP retrofits can reduce the national primary energy consumption for SH and SC by $46 \%$ from the 2010 energy consumption level.

Table 6. Technical potential of geothermal heat pump retrofits in the United States

\begin{tabular}{ccccc}
\hline Categories & $\begin{array}{c}\text { Annual site energy } \\
\text { savings } \\
\text { (quadrillion Btu) }\end{array}$ & $\begin{array}{c}\text { Annual source energy } \\
\text { savings } \\
\text { (quadrillion Btu) }\end{array}$ & $\begin{array}{c}\text { Annual carbon emission } \\
\text { reductions } \\
\text { (million Mt) }\end{array}$ & $\begin{array}{c}\text { Annual energy } \\
\text { cost savings } \\
\text { (billion \$) }\end{array}$ \\
\hline Residential & 3.3 & 4.3 & 271.1 & 38.2 \\
\hline Commercial & 1.2 & 1.3 & 85.2 & 11.6 \\
\hline Total & 4.5 & 5.7 & 356.3 & 49.8 \\
\hline
\end{tabular}




\subsection{POTENTIAL TECHNOLOGY IMPROVEMENTS}

This section discusses the potential cost reduction and performance improvement of GHPs under the BAU and BT scenarios through 2050. The inputs under these two scenarios, which are used by dGeo to assess the potential growth of GHPs, are presented below.

\subsubsection{Inputs for Business as Usual Scenario}

In the BAU scenario, it is assumed that there is not any substantial investment in GHP-related R\&D or financial incentives or tax credits for GHPs, and thus the technology advancement is slow. There will not be any cost reductions in GHXs, and there will only be moderate increases in the operational efficiency of GHP systems through 2050. For the baseline (conventional) HVAC systems, it is assumed that there will not be any significant change in the cost and performance during the same period. Therefore, there is only a moderate change in the efficiency difference between GHPs and conventional HVAC systems - $17 \%$ increase by 2050 (Table 7). It is assumed that the incremental cost increase for improving the energy efficiency is offset by improvements in manufacturing efficiency and increased economies of scale. Hence, there is no change in the costs of GHPs and baseline HVAC systems, as well as their service life.

Per a recent study by Kavanaugh et al. (2014), the installed cost (i.e., selling price) of GHXs did not change much in the last decade. The installed cost of GHXs increased 52\% from 1995 through 2012, with an average annual growth rate of $2.65 \%$, which is just slightly higher than the average annual inflation rate during the same period $(2.5 \%)$. Therefore, in the BAU scenario, it is assumed that the installed cost of GHXs does not change, and an annual inflation rate of $2.5 \%$ is used by dGeo to adjust the cost in future years through 2050 .

As discussed previously (Section 3.2.1.3), the GHP equipment efficiency in 2014 (the starting time of this scenario study) is determined based on the type and efficiency level of GHP equipment with the largest volume in the current residential and commercial markets (i.e., for residential, two-stage GHP equipment with 18.2 EER and $4 \mathrm{COP}$ at full-load condition and higher efficiencies at part-load conditions; for commercial, single-stage GHP equipment with 20 EER and 4.2 COP). EIA (2017a) predicts significant increases (45\% in COP and 129\% in EER) in GHP's heating and cooling efficiencies from 2015 through 2050 (Fig. 24). This is technically possible because some high-end GHP equipment currently available on the market (e.g., the GS-IHP discussed in Section 2.1.2) has already reached the efficiency predicted for $2050 .{ }^{14}$ However, EIA's prediction may be too optimistic as the stock average efficiency is usually determined by the minimum energy efficiency standard. Comparing the ASHRAE Standard 90.1 published in 2004 and 2016 (ASHRAE 2004, 2016), the minimum code-compliant efficiency of GHP equipment has not changed much in the last decade (EER increases from 13.4 to 14.1; COP increases from 3.1 to 3.2). Given the likely slow growth of GHP applications due to the predicted low energy prices throughout 2050 (Section 3.2.4), a moderate increase in the stock average efficiency of GHP units, which is between EIA's prediction and a projection based on the slow evolution of ASHRAE standards in the past decade, is considered more realistic for the BAU scenario. In dGeo analysis, the average efficiency of GHP equipment (i.e. the heat pump efficiency improvement factor) will increase $10 \%$ by 2030 and $17 \%$ by 2050 . On the other hand, the efficiency of conventional HVAC equipment (e.g., gas furnace and central air conditioner) has approached the practical limit and will not improve much though 2050 as predicted by EIA (Fig. 25).

\footnotetext{
${ }^{14}$ Per the Air-Conditioning, Heating, and Refrigeration Institute database, currently available maximum efficiency of variablespeed GHP (at full load): $\mathrm{EER}=24.3, \mathrm{COP}=4.1$ (higher efficiency at part-load conditions).
} 
Table 7. Key inputs for the business as usual and breakthrough scenarios

\begin{tabular}{|c|c|c|c|c|}
\hline \multicolumn{5}{|c|}{ Residential } \\
\hline Technology & Input & Year & BAU & Breakthrough \\
\hline \multirow{15}{*}{ Geothermal heat pump } & \multirow{3}{*}{$\begin{array}{l}\text { Ground heat exchanger cost } \\
(\$ / f t)\end{array}$} & 2014 & 14.00 & 14.00 \\
\hline & & 2030 & 14.00 & 11.20 \\
\hline & & 2050 & 14.00 & 9.80 \\
\hline & \multirow{3}{*}{$\begin{array}{l}\text { Heat pump efficiency } \\
\text { improvement } \\
(\%)\end{array}$} & 2014 & 0 & 0 \\
\hline & & 2030 & 10 & 50 \\
\hline & & 2050 & 17 & 50 \\
\hline & \multirow{3}{*}{$\begin{array}{l}\text { Heat pump cost } \\
\text { improvement } \\
(\%)\end{array}$} & 2014 & 0 & 0 \\
\hline & & 2030 & 0 & 0 \\
\hline & & 2050 & 0 & 0 \\
\hline & \multirow{3}{*}{$\begin{array}{l}\text { Fixed O\&M cost } \\
\text { improvement } \\
(\%)\end{array}$} & 2014 & 0 & 0 \\
\hline & & 2030 & 0 & 0 \\
\hline & & 2050 & 0 & 0 \\
\hline & \multirow{3}{*}{$\begin{array}{l}\text { Heat pump lifetime } \\
\text { (years) }\end{array}$} & 2014 & 20 & 20 \\
\hline & & 2030 & 20 & 20 \\
\hline & & 2050 & 20 & 20 \\
\hline
\end{tabular}

\section{Residential Equipment: Stock Average Efficiency}

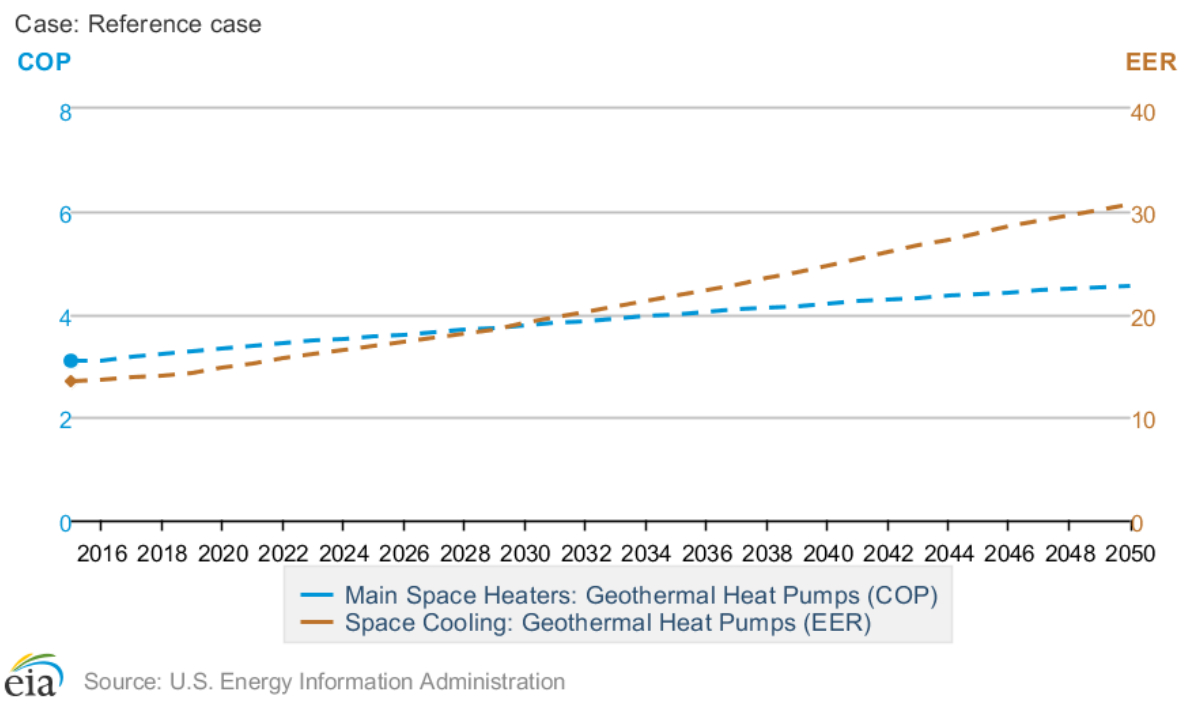

Fig. 24. EIA projected increase of GHP efficiencies from 2015 through 2050 (EIA 2017a) 


\section{Residential Equipment: Stock Average Efficiency}

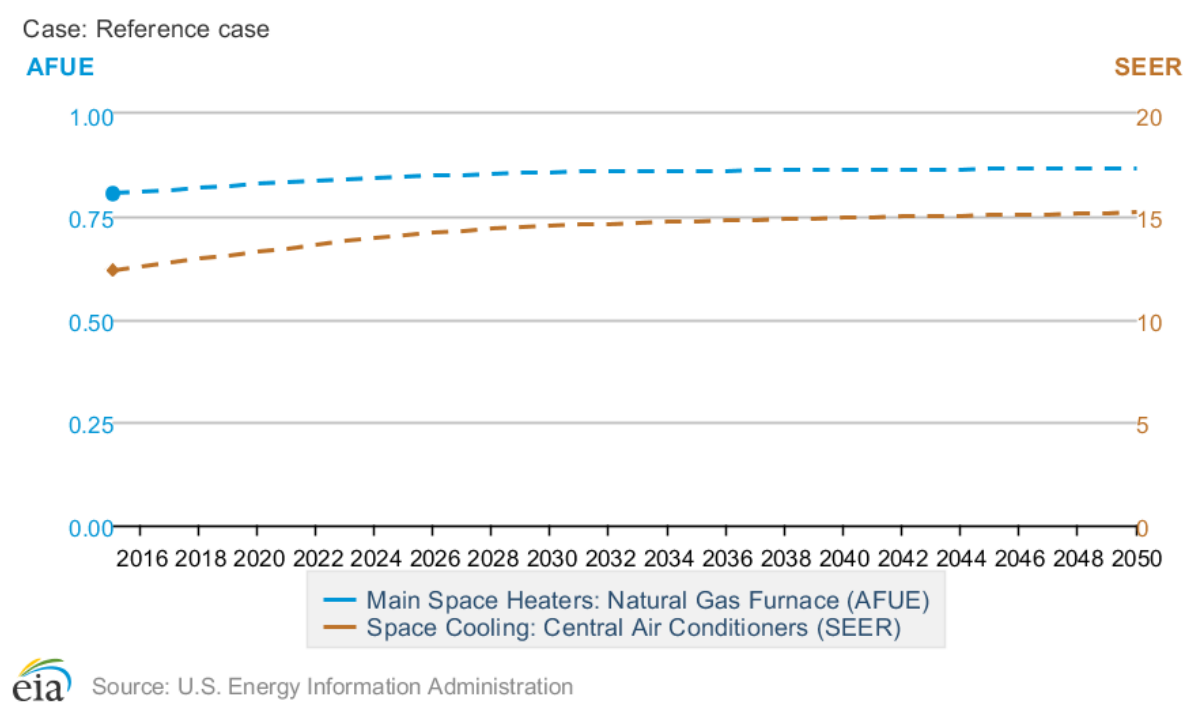

Fig. 25. EIA projected increase in efficiencies of natural gas furnace and central air conditioners from 2015 through 2050 (EIA 2017a).

\subsubsection{Inputs for Breakthrough Scenario}

In the BT scenario, it is assumed that (1) the installed cost of GHXs is reduced from 2012 levels by up to $30 \%$ by 2050 because of technical breakthroughs and increased economies of scale resulting from innovative business modes (e.g., utility-owned GHXs) and (2) the average efficiency of GHP equipment is improved by $50 \%$ relative to 2014 levels by 2030 , with no further improvements through 2050 (Table 7).

The projected cost reduction for GHXs is based on an analysis of the ongoing R\&D worldwide, as discussed in Section 2.5.1. The improvement in operational efficiency of GHP systems comes from both efficiency improvements in heat pumps and other components, as well as the improvements in system designs and controls. For residential GHPs, the 50\% efficiency improvement is from application of advanced GHP equipment such as the GS-IHP, which uses variable speed compressor, pump, and fan, and can provide $100 \%$ DWH and SC simultaneously. The 50\% GHP equipment efficiency gain will result in a 33\% reduction in electricity consumption for providing the same space conditioning service. For commercial GHP systems, the modeled GHP equipment is single-stage; however, based on computer simulations, if the two-stage GHP equipment is used, the annual electricity consumption of GHP systems can be reduced by about 20\%. In addition, as discussed in Section 2.5.4, smart pumping control can cut system power consumption by another $10 \%$. The combination of these two improvements will reduce the system power consumption by $30 \%$, which is approximately equivalent to increasing the GHP equipment efficiency by $50 \%$.

For the same reasons explained in the BAU scenario, it is assumed that there is no change in the costs of GHPs and baseline HVAC equipment, as well as in their service life. 


\subsubsection{Market Adoption}

Different empirical correlations for market adoption are used in each scenario to account for the uncertainty of consumer behavior. Technology adoption is assumed to follow a Bass "S-curve" model. The model is fitted using historic sales data - this defines the shape of the adoption curve. In each year, the maximum market potential, or the fraction of viable GHP systems that would eventually be implemented given the technical and economic conditions, is calculated based on the GHP investment payback period. The market potential of GHPs in each scenario is determined with two different empirical correlations: one is from Navigant (Paidipati et al. 2008) and the other is from NREL (Sigrin and Drury 2014), which is more optimistic and was originally developed based on market adoption data of distributed solar photovoltaics (PV). The Navigant ("BAU Customer Acceptance") and NREL (“Optimistic Customer Acceptance”) correlations are shown in Fig. 26.

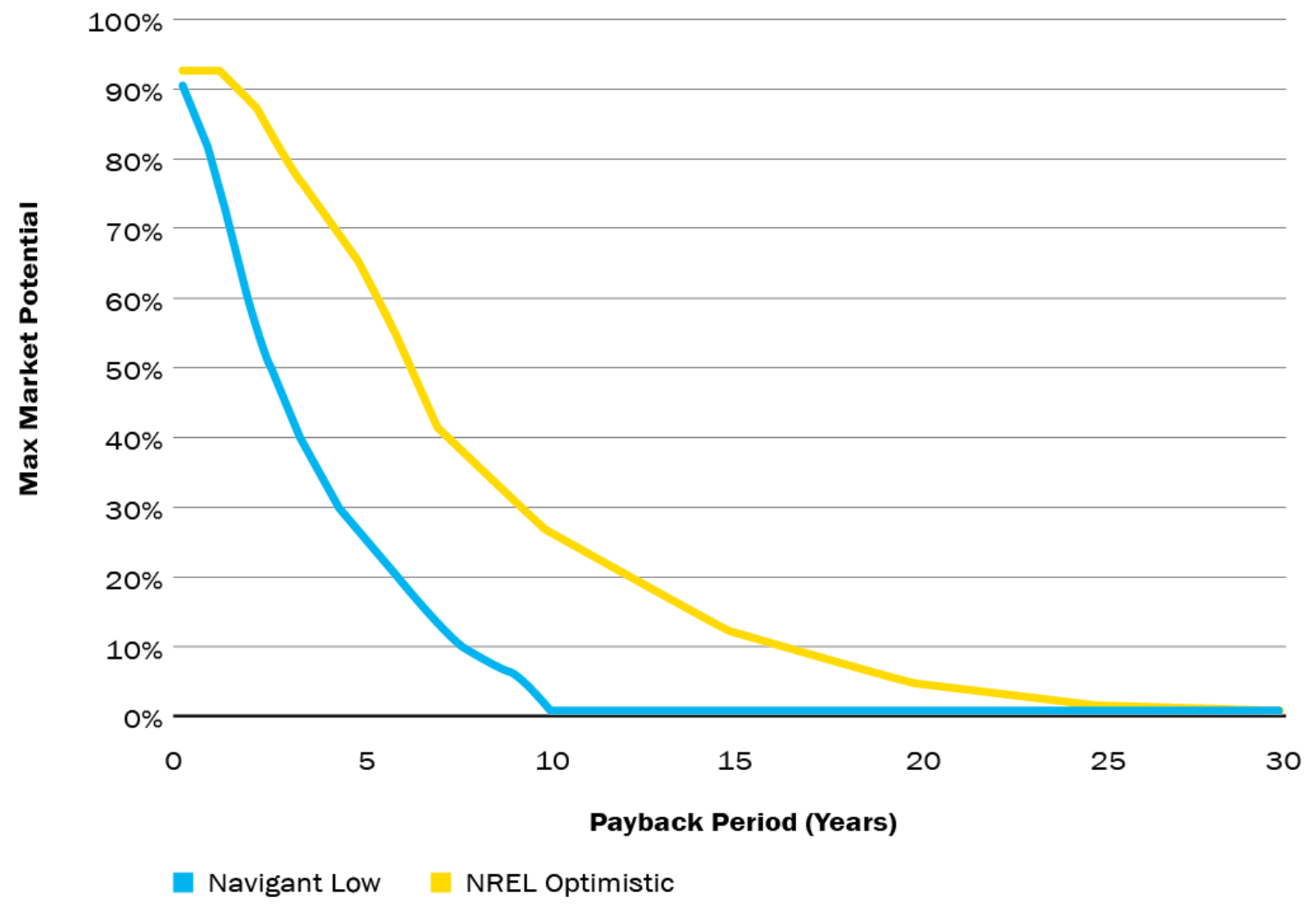

Fig. 26. Two different market adoption curves used in the scenario study

\subsubsection{Future Energy Prices}

An exogenous parameter - fuel price scenario - is used to examine the effect of fuel price projections on GHP adoption. The 2016 AEO published by EIA (2016e) provided fuel price projections under various scenarios, which accounts for low and high levels of economic growth, oil price, oil and gas resources and technology, and various approaches for clean power plan compliance. While the energy prices are lower than the reference case in a few scenarios, the projected energy prices are higher than the reference case 
in others. In this study, two additional scenarios with projected energy prices higher than the reference case were used, including the "High Oil Price" and "Low Oil and Gas Resource and Technology" scenarios. Figure 27 shows the projected prices for NG and electricity in the three scenarios from 2015 through 2050 in the residential sectors. As shown in Fig. 27, the "Low Oil and Gas Resource and Technology" scenario has highest projected energy prices. In this scenario, the NG price keeps increasing through 2050 while the electricity price peaks in about 2030. The projected NG and electricity price in the "Low Oil and Gas Resource and Technology" scenario is about 35\% and 11\% higher than that of the reference case in 2050, respectively. Although not shown in this figure, the projected prices of other fuels, such as distilled fuel oil and propane, as well as the projected energy prices in the commercial sector in the three scenarios, were all accounted for in this study.

\section{Energy Prices: Residential: Electricity}

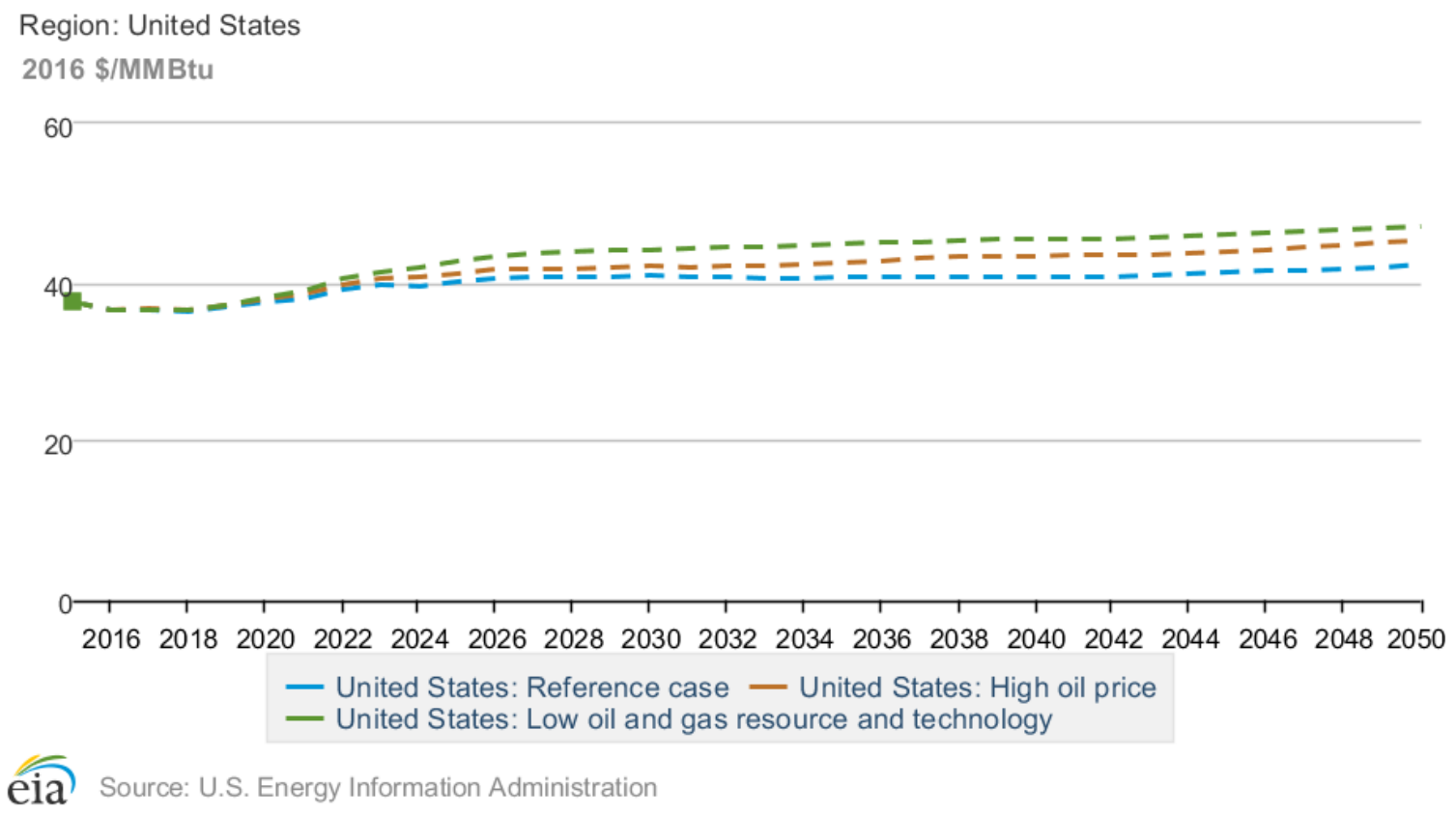

(a) Energy Price: Residential 


\section{Energy Prices: Residential: Natural Gas}

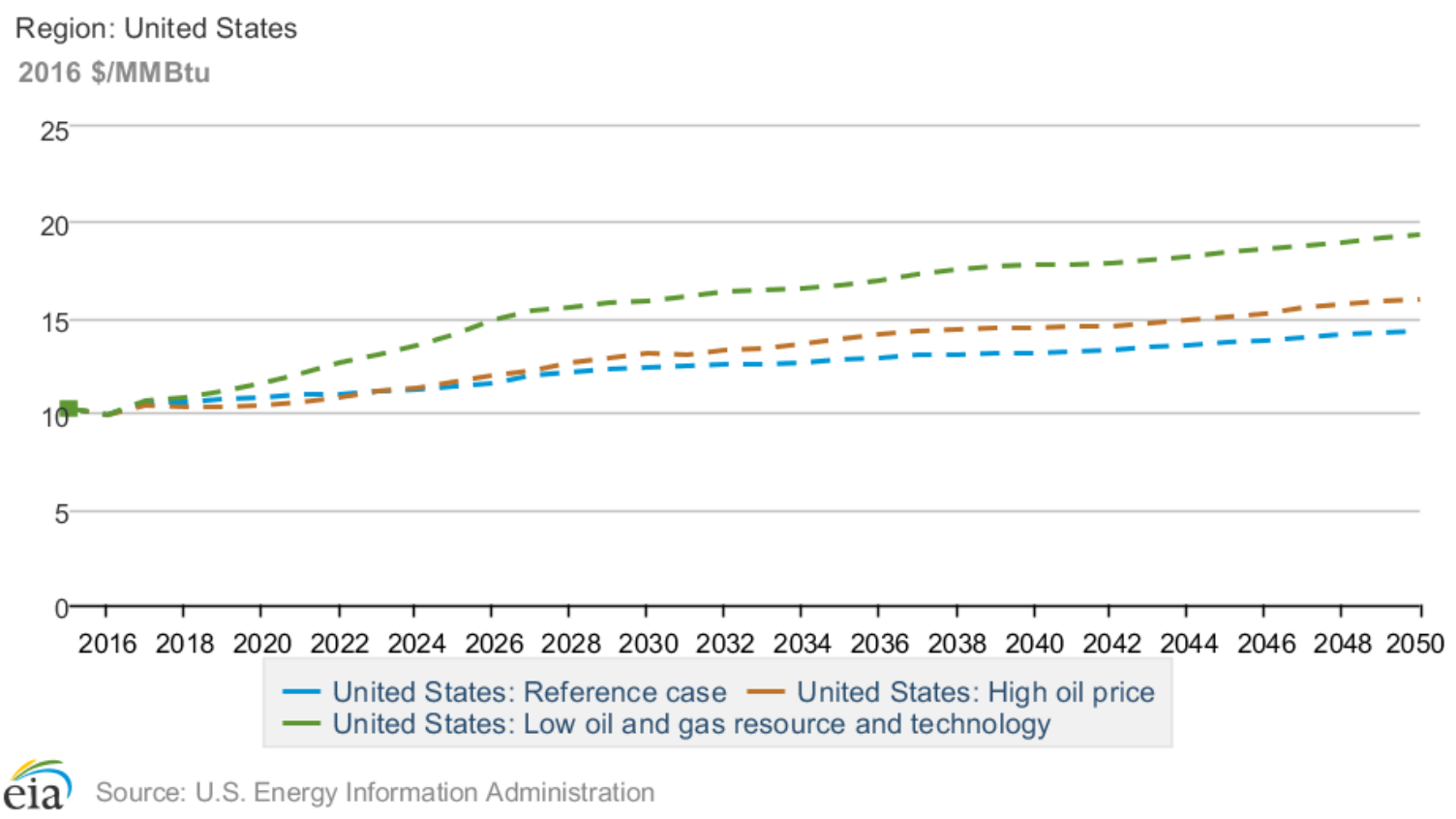

(b) Energy Price: Commercial

Fig. 27. Projected energy prices under various scenarios in the 2016 Annual Energy Outlook (EIA 2016e).

\subsection{RESULTS}

\subsubsection{Economic and Market Potentials}

Figure 28 shows both the maximum market potential and the economic potential in the following four scenarios, along with the total installed GHP capacity in the United States by 2012.

- $\quad$ BT (with Navigant adoption curve and the AEO reference fuel prices)

- BAU (with Navigant adoption curve and the AEO reference fuel prices)

- BT (with NREL adoption curve and the AEO reference fuel prices)

- BAU (with NREL adoption curve and the AEO reference fuel prices)

While the economic potential is not affected by the customer adoption rate, it is significantly affected by the level of technology improvement. With the technology BTs described in Section 3.4.2, the economic potential can reach $582 \mathrm{GW}_{\text {th }}$ by 2050 , which is $30 \%$ higher than that in the BAU scenario $\left(448 \mathrm{GW}_{\text {th }}\right)$. On the other hand, the maximum market potential is affected by both the customer adoption rate and the technology improvement. With a more optimistic customer adoption rate (i.e., the NREL curve), the maximum market potential by 2050 would be $231 \mathrm{GW}_{\text {th }}$ in the BT scenario and $168 \mathrm{GW}_{\text {th }}$ in the BAU scenario. However, with a more conservative customer adoption rate (i.e., the Navigant curve), the maximum market potential by 2050 would be $146 \mathrm{GW}_{\text {th }}$ in the $\mathrm{BT}$ scenario and $104 \mathrm{GW}_{\text {th }}$ in the BAU scenario. With the same level of technology improvement, the economic potential is about 2.5 to 4.3 times the maximum market potential depending on the customer adoption rate. The maximum market potential by 2050 is $8.7-19.3$ times higher than the installed GHP capacity by 2012, which indicates there is significant growth potential for GHPs in the United States. 


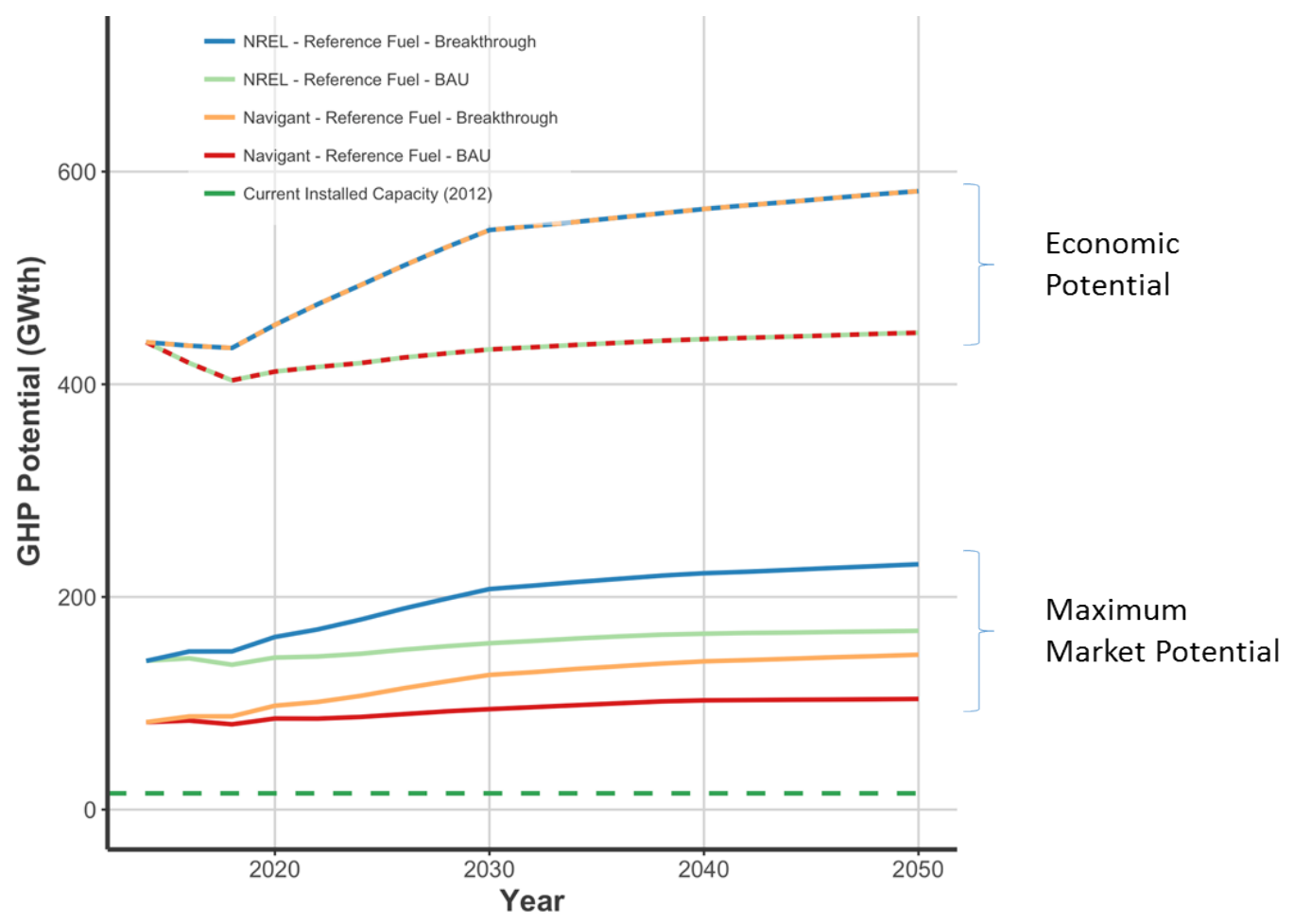

Fig. 28. Projected economic and maximum market potential of GHPs from 2014 through 2050.

Figure 29 shows the economic potential of GHPs in 2050 at two different cases: a conservative case (with low technology development and conservative customer adoption) and an optimistic case (with technology BTs and optimistic customer adoption). In Fig. 29, each county of the continental United States is color-coded based on the normalized economic potential of GHPs in the county, which is the ratio of the economic potential in a county to the total area of the county.

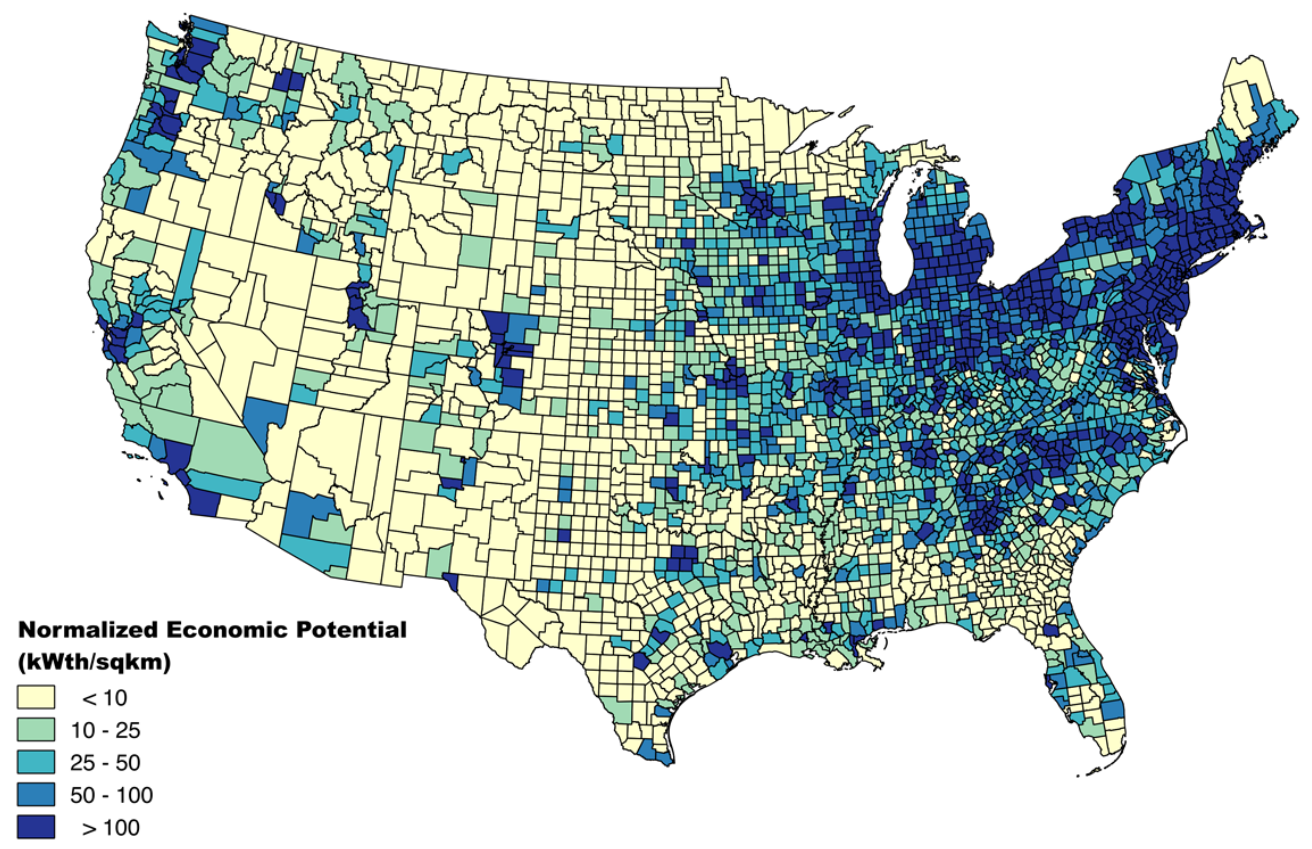




\section{(a) Business as usual with conservative customer adoption}

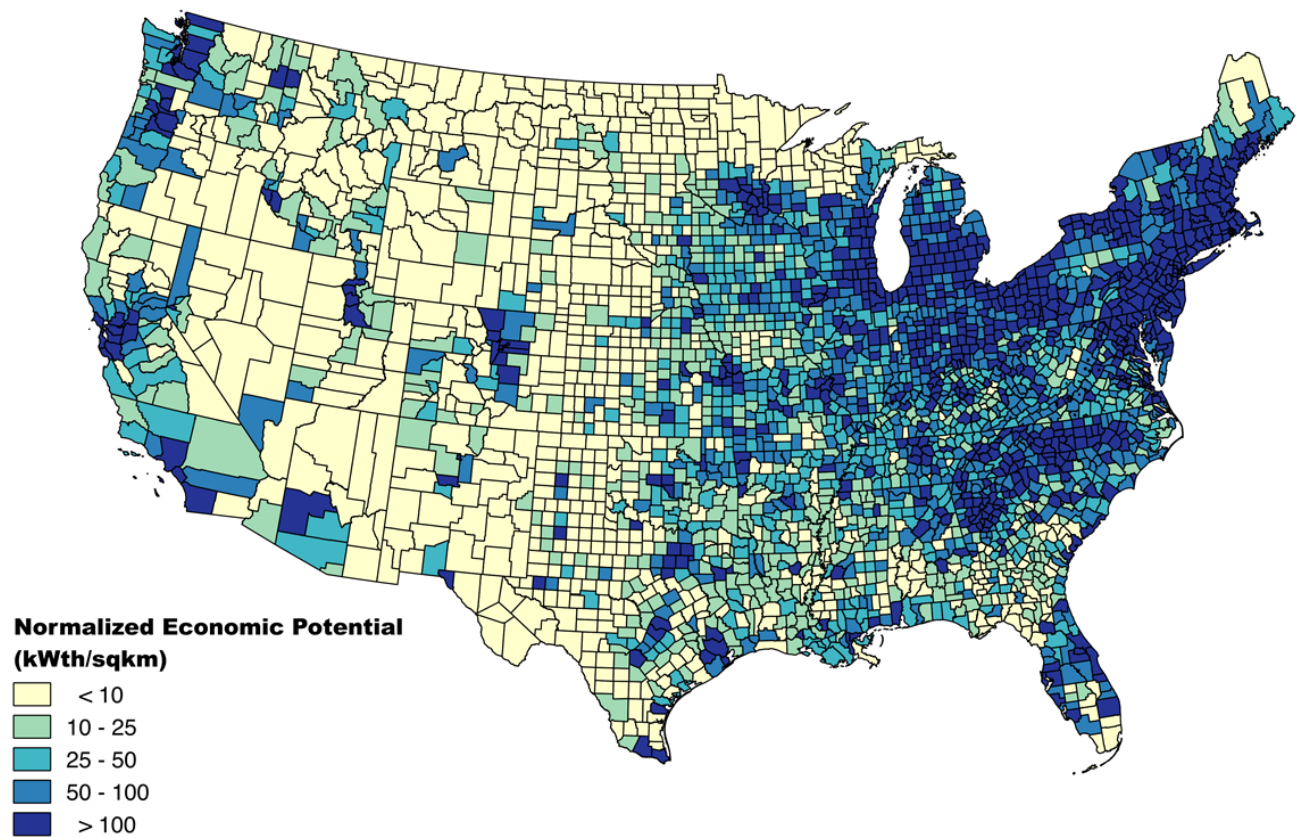

(b) Technology breakthrough with optimistic customer adoption

Fig. 29. Economic potential of GHPs in 2050: (a) conservative case; (b) optimistic case.

As shown in Fig. 29(a), the conservative case, counties in the Northeast and South Atlantic have higher normalized economic potential than other regions. The high economic potential in the Northeast is consistent with the cold climate and high population density in this region. In addition, according to the latest RECS (EIA 2017b), distillate fuel oil consumption for residential heating is high in New England and it is just slightly lower than the NG consumption for residential heating in the same area, and electricity is the primary heating energy source in the South. GHPs are more economically competitive in the Northeast to meet the large heating demands than burning the more expensive heating fuels. The high energy efficiency of GHPs for SC and SH makes them more cost effective in the South when compared with conventional air conditioners and electric resistance heaters. In the optimistic case, almost the entire eastern part of the continental United States, as well as some counties along the West Coast and in the Midwest, has significant economic potential for GHPs (more than $50 \mathrm{~kW}_{\text {th }}$ potential GHP capacity per each square kilometer), as shown in Fig. 29(b).

\subsubsection{Projected Installed Capacity and Market Share of Geothermal Heat Pumps}

Figure 30 shows projections for the cumulative installed GHP capacity, which is the sum of the GHPs expected to be deployed from 2014 through 2050 under the BAU and BT scenarios. As shown in Fig. 30, the installed GHP capacity could reach $151 \mathrm{GW}$ th by 2050 with optimistic customer adoption rate (i.e., the NREL curve) and technology breakthroughs. However, the installed capacity would be $49 \%$ lower (77 GWth) in the case of low technology development and conservative customer adoption rate (i.e., the Navigant curve). With low technology development and the AEO 2016 reference case energy prices, GHP deployment is projected to grow at a low rate, $4.3 \%-5.4 \%$ CAGR, depending on different customer adoption rates. This growth rate is about half of that experienced globally from 2010 through 2015 (8.69\% CAGR) as reported by Lund and Boyd (2016). The main driver of this global growth is thought to 
be the growing awareness and popularity of GHPs. For example, GHPs are becoming a standard for HVAC in NZEBs in China (Xu et al. 2017).

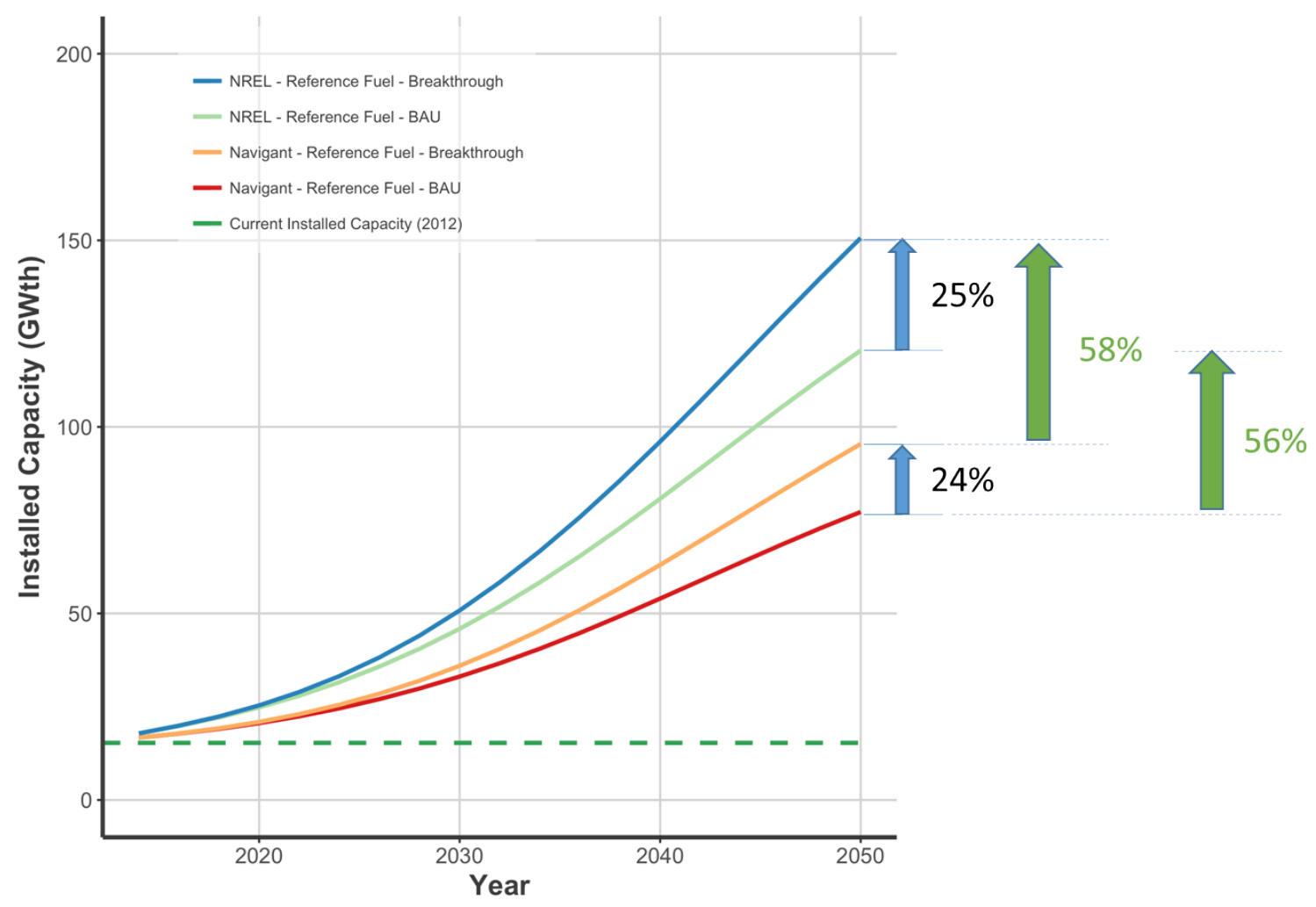

Fig. 30. Projected cumulative installed GHP capacity from 2014 through 2050.

Figure 30 also shows that technology BTs can increase the total installed GHP capacity in 2050 by $24 \%-$ $25 \%$ depending on different customer adoption rates. On the other hand, the customer adoption rate could have a bigger impact than the technology improvement. The optimistic customer adoption (i.e., the NREL curve) can increase the installed GHP capacity in 2050 by $56 \%-58 \%$ depending on different levels of technology development (i.e., low or BT).

Figure 31 shows projections of market shares of GHPs in the commercial and residential sectors under the four scenarios. Note that only the Navigant customer adoption rate is used for determining the market potential of GHPs in the commercial sector due to the lack of data for more optimistic customer adoption rates in the commercial sector. It is predicted that $4 \%-5 \%$ of commercial buildings will be conditioned by GHPs by 2050. For the residential sector, with the reference case energy prices, GHPs can get about $7 \%$ market share in the BAU scenario with conservative customer adoption, but the market share could go up to more than $15 \%$ in the BT scenario with more optimistic customer adoption. 


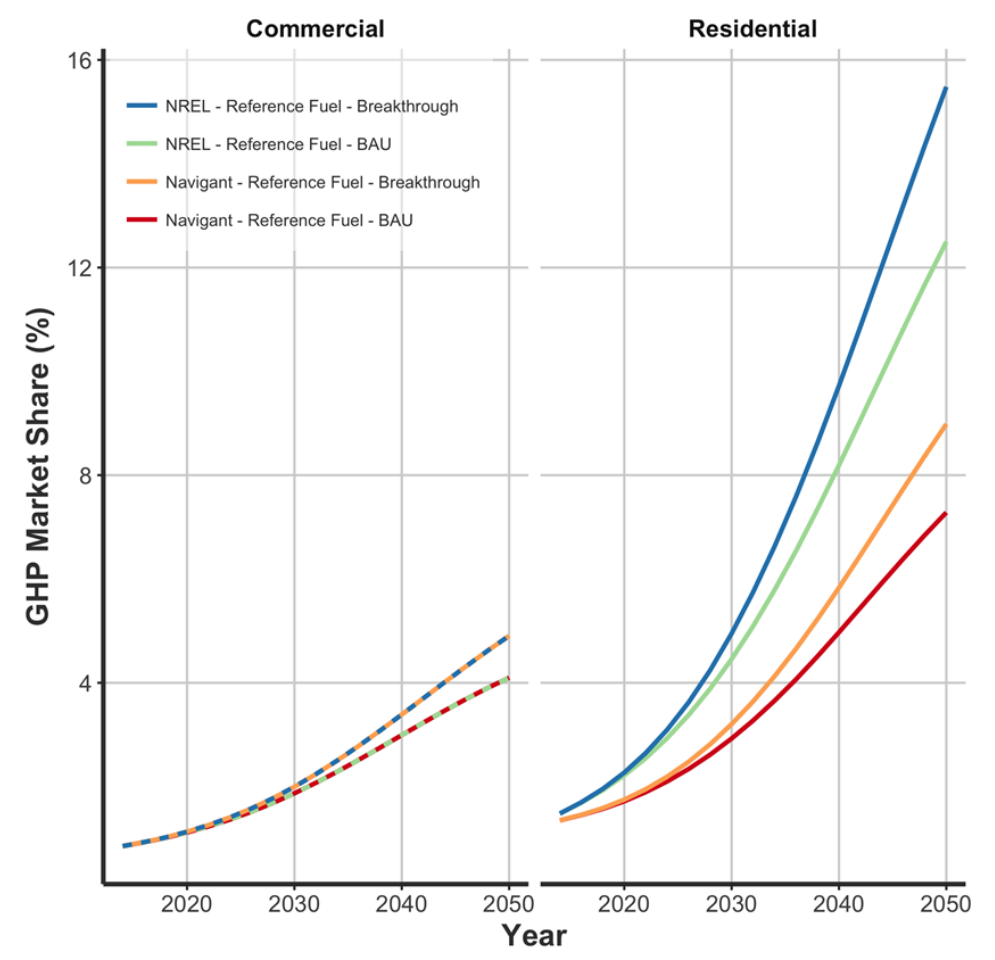

Fig. 31. Projected market share of GHPs in the commercial and residential sectors from 2014 through 2050.

Figure 32 shows the geographical distribution of the normalized installed GHP capacities in 2050. As shown in Fig. 32(a), the conservative case, most counties that have high installed capacity (more than $20 \mathrm{~kW}_{\text {th }}$ installed GHP capacity per each square kilometer) are in the Northeast, especially in New England. As discussed previously, the large heating demands and high heating fuel costs make GHPs more cost effective for SH in this region. In the optimistic case, most counties in the Northeast and South Atlantic have high installed GHP capacity, as shown in Fig. 32(b).

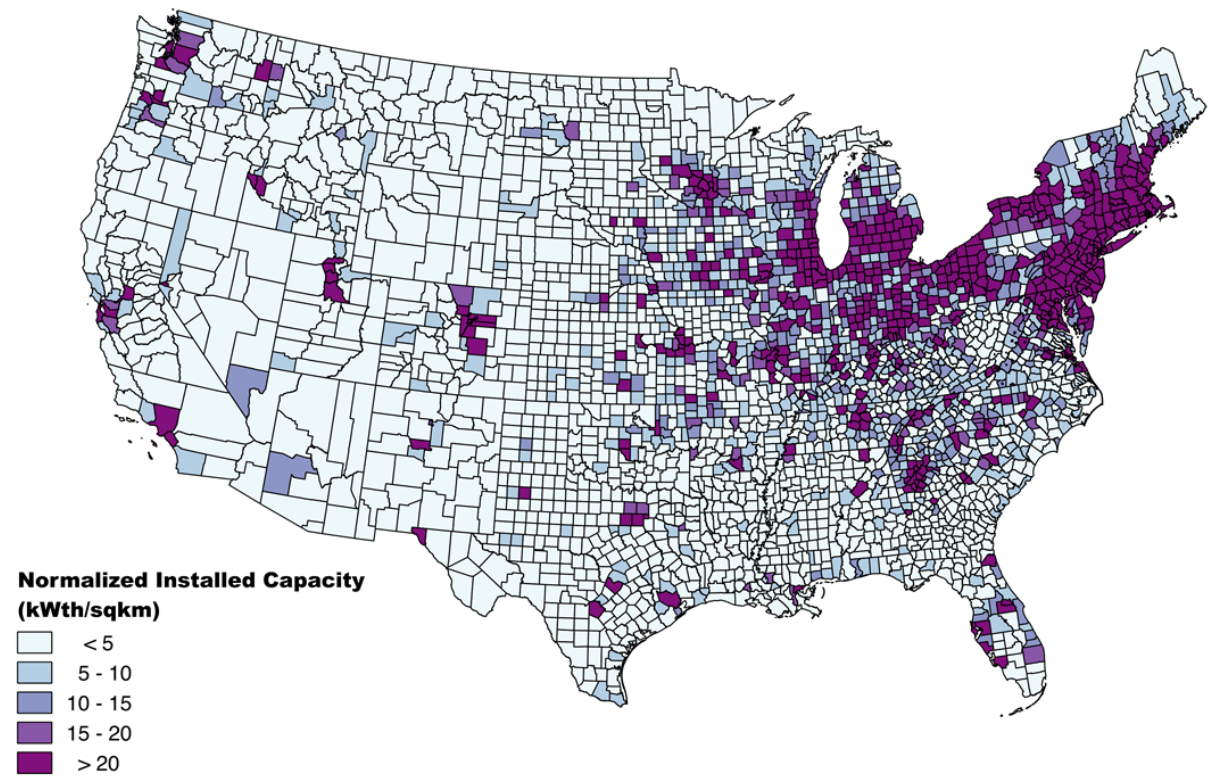

(a) Business as usual with conservative customer adoption 


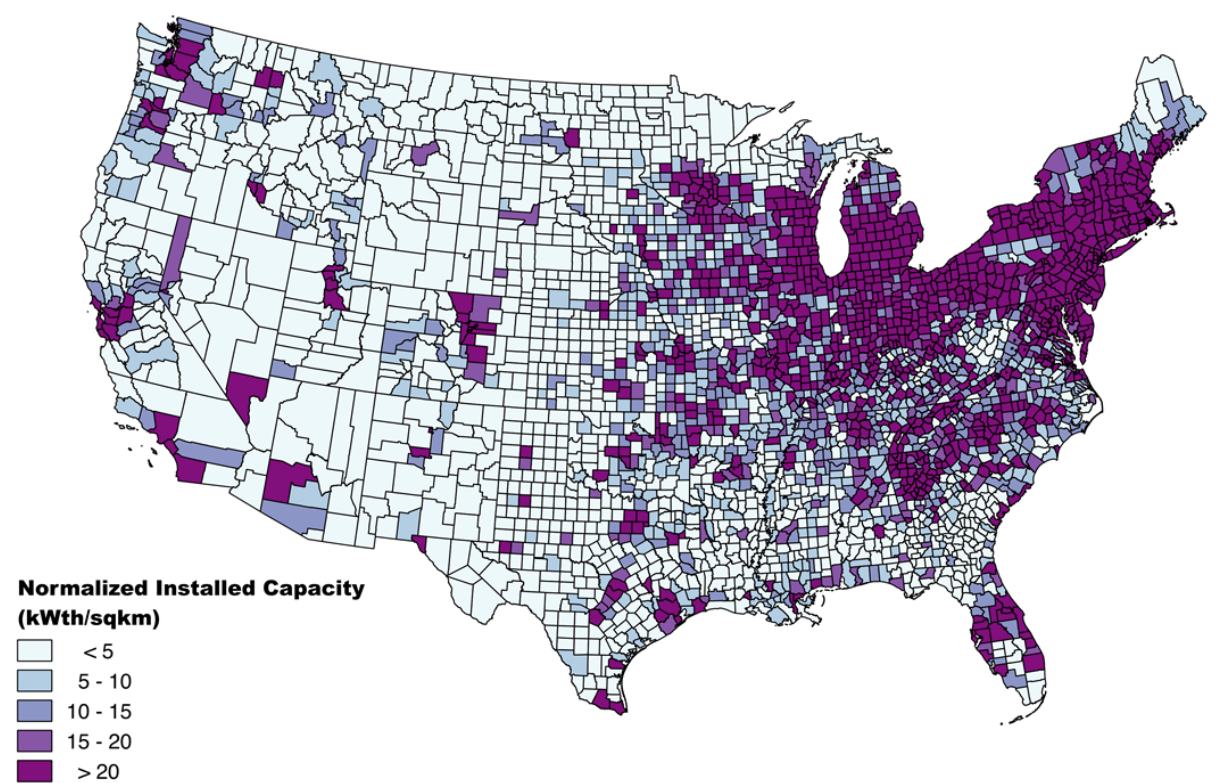

(b) Technology breakthrough with optimistic customer adoption

Fig. 32. Installed GHP capacities in 2050: (a) conservative case; (b) optimistic case.

The color codes in Figs. 32 and 29 indicate that the economic potential could be about 5 times higher than the installed GHP capacity in some counties. As discussed previously (Section 3.1), the installed GHP capacity is determined based on the payback periods of the GHP investments, but the economic potential is determined by NPV of life-cycle costs of GHP systems. To realize the economic potential, innovative financing and business models (such as TPO) are needed to overcome the high initial cost barrier by monetizing the energy savings, as well as other environmental and social benefits, over the life time of GHPs. TPO for GHPs was not investigated in this study due to the lack of supporting data to reliably model customer adoption rates in the case of TPO.

\subsubsection{Impacts of Energy Prices}

Energy prices determine the monetary value of the saved energy and thus affect the economics of the GHP investment. Figure 33 shows the projected installed GHP capacities for the following four scenarios.

- $\quad$ BT (with Navigant adoption curve and the AEO reference fuel prices)

- BAU (with Navigant adoption curve and the AEO low resource fuel prices)

- BT (with NREL adoption curve and the AEO reference fuel prices)

- BAU (with NREL adoption curve and the AEO low resource fuel prices)

The two energy price scenarios, labeled "reference fuel" and "low resource fuel" (i.e., high fuel prices), were discussed previously (Section 3.4.4). As shown in Fig. 33, with the same customer adoption rate, the technology BT scenario has about the same impact on the installed GHP capacity as that of the "low resource fuel" scenario, of which the NG price is $35 \%$ higher than that of the reference case. 


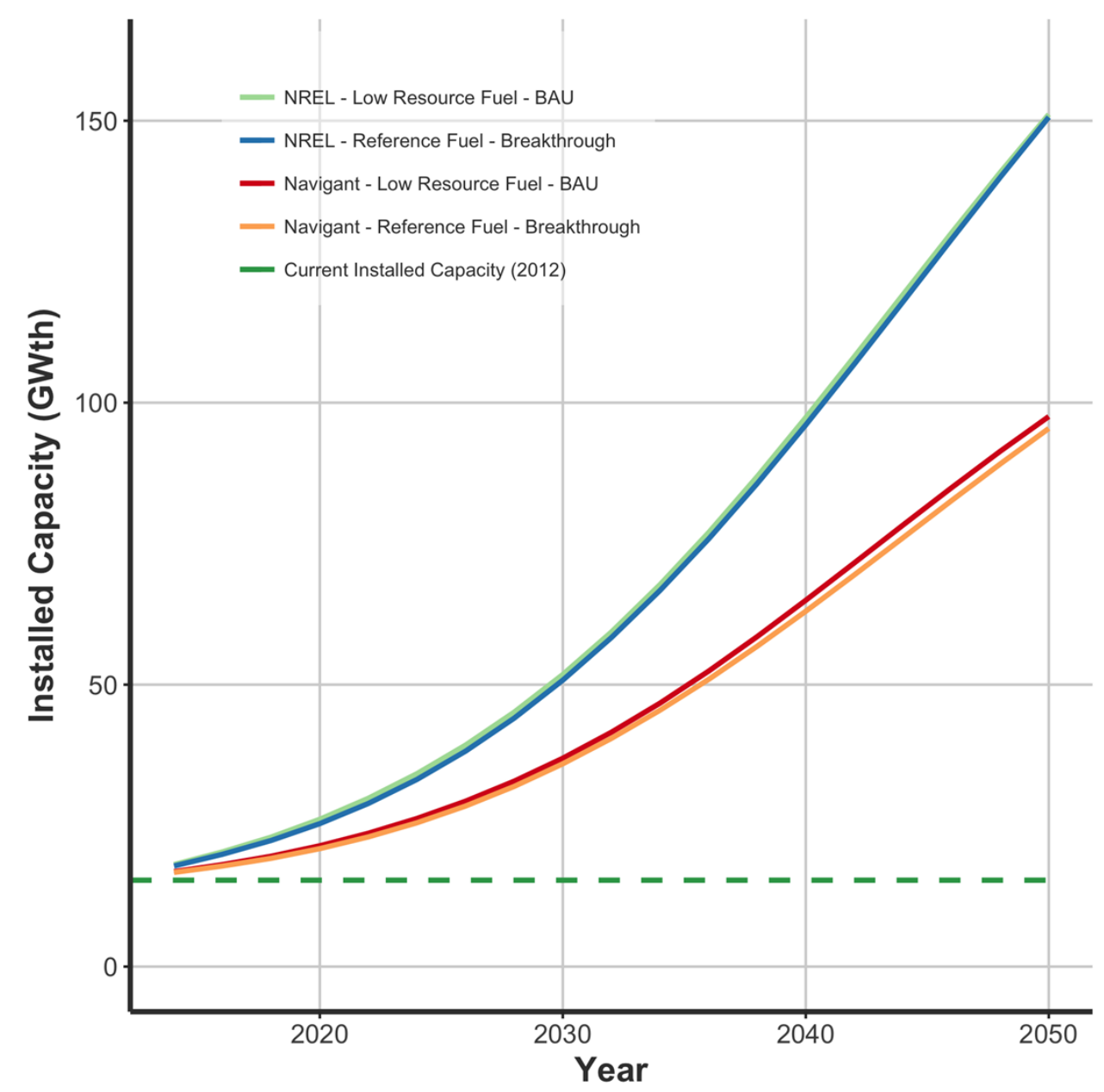

Fig. 33. Impacts of technology development and energy prices on the installed GHP capacity.

\section{CONCLUSIONS AND DISCUSSIONS}

The potential impacts of GHPs could be huge. If all the existing HVAC systems in the residential and commercial sectors were retrofitted with GHPs (i.e., the technical potential of GHPs), in each year, primary energy consumption could be reduced by 5.7 quad, $\mathrm{CO}_{2}$ emissions could be reduced by 356.3 million Mt, and energy costs could be reduced by $\$ 49.8$ billion. The 5.7 quad of primary energy savings from GHP retrofits could reduce national primary energy consumption for SH and SC by $46 \%$ (based on 2010 U.S. building energy end-use data).

The economic potential of GHPs, which is the sum of the potential GHP applications that result in positive NPV, will reach $448 \mathrm{GW}_{\text {th }}$ by 2050 with the $2016 \mathrm{AEO}$ predicted reference case energy prices and low technology development. The economic potential could be increased by $30 \%$ to $582 \mathrm{GW}_{\text {th }}$ in 2050 through technology breakthroughs (i.e., reducing the installed costs of GHXs by $30 \%$ and improving the operational system efficiency of GHPs by $50 \%$ ).

The maximum market potential, which is the total installed capacity of GHPs that have payback periods acceptable to customers, would be $104 \mathrm{GW}_{\text {th }}$ by 2050, assuming a conservative customer adoption rate (i.e., the Navigant curve) and with low technology development. However, with technology breakthroughs and an optimistic customer adoption rate (adopted from residential solar PV installations), the maximum market potential of GHPs would be $231 \mathrm{GW}_{\text {th }}$ by 2050 . 
Given the projected low energy prices throughout 2050, the dGeo analysis predicts that GHP installed capacity will grow at a low rate $(4.3 \%-5.4 \%$ CAGR) if business as usual. This growth rate is about half that experienced globally from 2010 through 2015 (8.69\% CAGR) as reported by Lund and Boyd (2016). With this low CAGR, the total installed GHP capacity will be $77 \mathrm{GW}_{\text {th }}$ by 2050 , which is only about $5 \%$ of the predicted total HVAC market in 2050.

To further increase the deployment of GHPs, substantial investment in R\&D is needed to significantly reduce costs and improve performance of GHPs. With the expected technology breakthroughs, the GHP installed capacity could be increased by $25 \%$ compared with the BAU scenario. The potential technology developments to reduce the cost of GHPs include development of lower cost and performance neutral GHXs (as well as associated techniques/equipment for installation), more cost effective GHP equipment and system configurations, and automated processes for installation and performance evaluation. Nontechnology-related developments could also reduce the cost of GHPs, including volume manufacturing of GHP equipment (e.g., by merging small heat pump manufacturers), large scale GHP applications (e.g., district GHP systems) to take advantage of economies of scale, and a vertically integrated business model - from design, to build, to operate - to improve the efficacy and quality of GHP installations. The energy saving performance of GHPs could be increased though optimal design and integration of GHP systems. The accuracy, flexibility, and accessibility of GHP system design tools (e.g., computer models for various GHXs) and supporting data (e.g., geological characteristics and thermal properties of the shallow ground subsurface) need to be improved to enable optimal design and integration. Currently, ground thermal properties data, which are essential for sizing GHXs, are scarce and in situ measurements of these data are often too expensive for residential GHP projects. More cost-effective testing methods and a national database of high resolution ground thermal property data are highly desirable.

Increasing public awareness of and trust in GHPs is crucial to improve consumer acceptance. The results of this study indicate that the customer adoption rate could have a bigger impact than the technology advancement. Improved customer acceptance has potential to increase the installed GHP capacity in 2050 by $56 \%-58 \%$ depending on different levels of technology development. Individual system design is usually needed for each GHP application and the installation process of a GHP system often involves multiple contractors. Furthermore, it takes more effort to quantify the energy savings benefits of GHPs than just metering the kilowatt-hours generated with a Photovoltaics (PV) system. Streamlining deployment and performance verification are also important and should be an integral part of programs for increasing public awareness and trust in GHPs.

To realize the economic potential of GHPs, which is 2.5 to 4.3 times higher than the maximum market potential, innovative financing (such as TPO) and associated business models are needed to overcome the high initial cost barrier by monetizing the energy savings, as well as other environmental and social benefits, over the lifetime of GHPs. However, TPO for GHPs was not investigated in this study due to the lack of supporting data to reliably model customer adoption for this innovative (early stage) business model. Further study is recommended to understand the challenges and potentials for implementing GHPs with TPO.

Energy prices affect the economics of the GHP investment. If the NG price increases by $35 \%$ as predicted in the 2016 AEO for the "Low oil and gas resource and technology" scenario, the GHP installed capacity could be increased by $26 \%$, which has about the same impact as technology breakthroughs. However, because energy prices are beyond the control of the GHP industry, technology development perhaps is the only certain way to make GHPs more economically competitive in this era of cheap energy. 


\section{REFERENCES}

Acuña, J. 2013. "Distributed Thermal Response Tests-New Insights on U-pipe and Coaxial heat Exchangers in Groundwater-Filled Boreholes.” Doctoral Thesis, KTH.

Acuña, J. 2016. "Deep Borehole Heat Exchangers for Ground-Source Heat Pumps." Retrieved 7/15/2016, from http://effsysexpand.se/p19-djupa-borrhalsvarmevaxlare-for-bergvarmepumpar/.

Andersson, K. 2016. "Best technology for Environment-Friendly Ground Source Heat Pumps." Retrieved 7/15/2016, from http://effsysexpand.se/p24-teknikbarare-basta-teknologi-for-miljovanligbergvarmepump/.

ANSI/CSA C448 Series16. 2016. Design and Installation of Ground Source Heat Pump Systems for Commercial and Residential Buildings.

ARRA. 2009. American Recovery and Reinvestment Act of 2009. Public Law 111-5, 2009.

ASHRAE (American Society of Heating, Refrigerating and Air-conditioning Engineers). 1999. HVAC Maintenance Costs (RP-929). Technical Committee 1.8 final report (draft version 2). Prepared for ASHRAE, Inc., by ADM Associates, Inc.

ASHRAE (American Society of Heating, Refrigerating and Air-Conditioning Engineers). 2004. ASHRAE Standard 90.1-2004 Energy Standard for Buildings Except Low-Rise Residential Buildings. Atlanta, Georgia: ASHRAE, Inc.

ASHRAE (American Society of Heating, Refrigerating and Air-Conditioning Engineers). 2011. ASHRAE Handbook-HVAC Applications. Owning and Operating Costs. Atlanta, Georgia: ASHRAE, Inc.

ASHRAE (American Society of Heating, Refrigerating and Air-Conditioning Engineers). 2015. ASHRAE Handbook - HVAC Applications. Atlanta, Georgia: ASHRAE Inc.

ASHRAE (American Society of Heating, Refrigerating and Air-Conditioning Engineers). 2016. ASHRAE Standard 90.1. 2016. Energy Standard for Buildings Except Low-Rise Residential Buildings. Atlanta, Georgia: ASHRAE, Inc.

Atam, E., and L. Helsen. 2016a. "Ground-Coupled Heat Pumps: Part 1-Literature Review and Research Challenges in Modeling and Optimal Control." Renewable and Sustainable Energy Reviews 54: 16531667.

Atam, E., and L. Helsen. 2016b. "Ground-Coupled Heat Pumps: Part 2-Literature Review and Research Challenges in Optimal Design.” Renewable and Sustainable Energy Reviews 54: 1668-1684.

Bass, F. M. 1969. “A New Product Growth for Model Consumer Durables.” Management Science 18: 215-227.

Battocletti, E. C., and W. E. Glassley. 2013. Measuring the Costs and Benefits of Nationwide Geothermal Heat Pump Deployment. Bob Lawrence \& Associates, Inc. DE-EE0002741. Available online at http://www.osti.gov/geothermal/servlets/purl/1186828. Database available online at https://gdr.openei.org/submissions/180. 
Baxter, V., J. Munk, and A. Gehl. 2016. Field Demonstration of Ground-Source Integrated Heat PumpFinal Report. ORNL/TM-2016/474. Oak Ridge National Laboratory, Oak Ridge, Tennessee.

Brischoux, P., and M. Bernier. 2016. "Coupling PV/T Collectors with a Ground-Source Heat Pump System in a Double U-Tube Borehole." Presented at the 2016 ASHRAE Winter Conference, January 2327, 2016, Orlando, Florida.

Cane, Douglas, and J. Garnet. 2000. "Update on Maintenance and Service Costs of Commercial Building Ground-Source Heat Pump Systems.” ASHRAE Transaction Vol. 106, Pt. 1.

Cecinato, F., and F. A. Loveridge. 2015. "Influences on the thermal efficiency of energy piles." Energy 82: $1021-1033$.

Cheap GSHPs. 2015. "Cheap and Efficient Application of Reliable Ground Source Heat Exchangers and Pumps.” Retrieved July 15, 2016, 2016, from http://cheap-gshp.eu/.

Choi, W., and R. Ooka 2016. "Multi Heat Injection Rate Thermal Response Test and Corresponding Parameter Estimation Method to Determine Performance Dependence in Saturated Porous Formation." Presented at Clima 2016, May 22-25, 2016, Aalborg, Denmark.

Cimmino, M., and M. Bernier. 2014. "A semi-analytical method to generate g-functions for geothermal bore fields." International Journal of Heat and Mass Transfer 70: 641-650.

Corberan, J. M. 2016. "New Trends and Developments in Ground-Source Heat Pumps." Advances in Ground-Source Heat Pump Systems. S. J. Rees. Amsterdam, Woodhead Publishing: 359-386.

Cullin, J. R., J. D. Spitler, C. Montagud, F. Ruiz-Calvo, S. J. Rees, S. S. Naicker, P. Konečný, and L. E. Southard. 2015. "Validation of Vertical Ground Heat Exchanger Design Methodologies. Science and Technology for the Built Environment 21(2): 137-149.

Denholm, P., Drury, E., and Margolis, R. 2009. The Solar Deployment System (SolarDS) Model: Documentation and Sample Results. NREL/TP-6A2-45832. Golden, Colorado: National Renewable Energy Laboratory. Available online at http://www.nrel.gov/docs/fy10osti/45832.pdf.

DOA (US Department of Agriculture). 2007. Food and Energy Security Act of 2007 (H.R. 2419), Section 6108, US Department of Agriculture, Washington, DC, 2007.

DOD (US Department of DefenseDOD). 2007. Report to Congress: Ground-Source Heat Pumps at Department of Defense Facilities. US Department of Defense-Office of the Deputy Under Secretary of Defense, Installations and Environment, Washington, DC.

DOD (US Department of Defense). 2015. Office of the Assistant Secretary of Defense Memorandum. Subject: Submission of Projects for the FY 2017 Energy Conservation Investment Program (ECIP) and Plans for the Remainder of the Future Years Defense Program, October 14, 2015. Available online at http://www.acq.osd.mil/eie/Downloads/IE/FY\%202017\%20ECIP\%20Guidance\%20Signed.pdf.

DOE (US Department of Energy). 1993. The climate change action plan, US Department of Energy, Washington, D.C., October 1993.

DOE (US Department of Energy). 2009. 2009 Buildings Energy Data Book. Washington, DC: U.S. Department of Energy. Available online at http://buildingsdatabook.eren.doe.gov. 
DOE (US Department of Energy). 2012a. Energy Star: Energy Efficiency Requirements for Geothermal Heat Pumps (Effective January 1, 2012). Available online at https://www.energystar.gov/products/heating_cooling/heat_pumps geothermal/key product criteria.

DOE (US Department of Energy). 2012b. DOE's Commercial Reference Buildings. Washington, DC: U.S. Department of Energy.

DOE (US Department of Energy). 2013. Energy Star: Federal Tax Credits for Consumer Energy Efficiency, 2013. Available online at http://www.energystar.gov/index.cfm?c=tax credits.tx index.

DOE (US Department of Energy). 2016. Geothermal Heat Pumps. Available online at https://energy.gov/energysaver/geothermal-heat-pumps.

DOE (US Department of Energy). 2017a. Residential Renewable Energy Tax Credit. Available online at https://energy.gov/savings/residential-renewable-energy-tax-credit.

DOE (US Department of Energy). 2017b. Business Energy Investment Tax Credit (ITC). Available online at https://energy.gov/savings/business-energy-investment-tax-credit-itc.

EIA (US Energy Information Administration). 2004. The Electricity Market Module of the National Energy Modeling Systems: Model Documentation Report. DOE/EIA-M068. Washington, DC: US Department of Energy, Energy Information Administration.

EIA (US Energy Information Administration). 2010. Geothermal Heat Pump Manufacturing Activities 2009. Washington, DC: US Department of EnergyEnergy Information Administration Office of Electricity, Renewable, and Uranium Statistics. Available online at https://www.eia.gov/renewable/annual/geothermal/.

EIA (US Energy Information Administration). 2013. 2009 Residential Energy Consumption Survey (RECS) Preliminary Results. Washington, DC: US Energy Information Administration. Available online at http://www.eia.gov/consumption/residential/data/2009/\#sqft.

EIA (US Energy Information Administration). 2016a. Annual Energy Outlook 2016. Washington, DC: US Department of Energy Energy Information Administration. Available online at https://www.eia.gov/outlooks/archive/aeo16/.

EIA (US Energy Information Administration). 2016b. 2012 Commercial Buildings Energy Consumption Survey (CBECS) Preliminary Results. Washington, DC: US Department of Energy Energy Information Administration. Available online at http://www.eia.gov/consumption/commercial/reports/2012/preliminary/.

EIA (US Energy Information Administration). 2016c. Natural Gas Prices. Available online at http://www.eia.gov/dnav/ng/ng_pri sum_dcu nus m.htm.

EIA (US Energy Information Administration). 2016d. Electricity Prices. Available online at http://www.eia.gov/electricity/data.cfm\#sales.

EIA (US Energy Information Administration). 2016e. Annual Energy Outlook 2016 (Table: Energy Prices by Sector and Source). Washington, DC: US Department of Energy, Energy Information Administration. Available online at https://www.eia.gov/outlooks/aeo. 
EIA (US Energy Information Administration). 2017a. Annual Energy Outlook 2017 (Table: Residential Sector Equipment Stock and Efficiency). Washington, DC: US Department of Energy, Energy Information Administration. Available online at https://www.eia.gov/outlooks/aeo.

EIA (US Energy Information Administration). 2017b. Residential Energy Consumption Survey (Housing characteristics tables). Washington, DC: US Department of Energy, Energy Information Administration. Available online at https:/www.eia.gov/consumption/residential/data/2015/index.php\#sh.

Ellis, D. 2008. "Field Experience with Ground-Source Heat Pumps in Affordable Low Energy Housing." In Proceedings of 9th International Energy Agency Heat Pump Conference, May 20-22, 2008, Zurich, Switzerland.

EOP (Executive Office of the President). 1999. Greening the Government through Efficient Energy Management. Federal Register 64, No. 109, 30851, Executive Order 13123, June 8, 1999.

Gehlin, S. 2016. "Borehole Thermal Energy Storage.” In Advances in Ground-Source Heat Pump Systems. Amsterdam: Woodhead Publishing: 295-327.

Gehlin, S. E. A., J. D. Spitler, and G. Hellström. 2016. "Deep Boreholes for Ground Source Heat Pump Systems-Scandinavian Experience and Future Prospect." Presented at the 2016 ASHRAE Winter Conference, January 23-27. 2016, Orlando, Florida.

Geothermal Exchange Organization (GEO). 2018. Geothermal Heat Pump Tax Credits Reinstated! GEO Industry News, Vol. 5(2). Retrieved Feb. 22, 2018, from https://www.geoexchange.org/wpcontent/uploads/GEO-Industry-News-February-2018.pdf.

GEOTeCH Project. 2016. GEOthermal Technology for Economic Cooling and Heating. Retrieved July 15, 2016, from http://www.geotech-project.eu/.

GHPC (Geothermal Heat Pump Consortium). 2001. Final Report-National Earth Comfort Program. US Department of Energy contract DE-FC07-95ID13347, Geothermal Heat Pump Consortium, 2001.

Hackel, S., G. Nellis, and S. Klein. 2009. “Optimization of Cooling-Dominated Hybrid Ground-Coupled Heat Pump Systems.” ASHRAE Transaction 115 (1).

Hamstra, S. 2014. "Optimum Geothermal Performance via Predictive Modeling and Adaptive Control." Presented at the 2014 ASHRAE Annual Conference, June 28-July 2, Seattle, Washington.

Helsen, L. 2016. “Geothermally Activated Building Structures.” In Advances in Ground-Source Heat Pump Systems. Amsterdam, Woodhead Publishing: 423-452.

Hirsch, J., et al. 2016. eQUEST program. Available at www.doe2.com.

Horwitz-Bennet, B. 2014. “Geothermal: Ready for Prime Time.” Green Builder, September, 2014.

Hughes, P. J. 2008. Geothermal (Ground-Source) Heat Pumps: Market Status, Barriers to Adoption, and Actions to Overcome Barriers. ORNL/TM-2008/232. Oak Ridge, Tennessee: Oak Ridge National Laboratory. 
Hughes, P. J., T. Kaarsberg, and E. Wall. 2011. "Overview and Status of U.S. DOE's New GroundSource Heat Pump Program Initiated in 2009." In Proceedings of the 10th International Energy Agency Heat Pump Conference, May 2011, Tokyo, Japan.

Hughes, P. J., and L. Pratsch. 2002. "Technical and Market Results of Major U.S. Geothermal Heat Pump Programs." In Proceedings of the $7^{\text {th }}$ International Energy Agency Heat Pump Conference, Vol. 1, 325342, May 2002, Beijing, China.

Hughes, P., and J. Shonder. 1998. The Evaluation of a 4000-Home Geothermal Heat Pump Retrofit at Fort Polk, Louisiana. ORNL/CON-460. Oak Ridge, Tennessee: Oak Ridge National Laboratory.

IECC (International Energy Conservation Code). 2009. Climate Zone Map. Available online at https://energycode.pnl.gov/EnergyCodeReqs/.

IGSHPA (International Ground Source Heat Pump Association). 2015. Closed-Loop/Geothermal Heat Pump Systems Design and Installation Standards (2015 Edition).

Im, P., P. Hughes, and X. Liu, 2012. "Demonstration and performance monitoring of foundation heat exchangers (FHX) in ultra-high energy efficient research homes." In Proceedings of the 2012 ACEEE Summer Study on Energy Efficiency in Building, August, Pacific Grove, CA

Javed, S. 2016. "Comparative Experimental Investigation of Performance and Efficiency of Ground Heat Exchangers for Vertical Borehole Applications." Retrieved 7/15/2016, from http://effsysexpand.se/p16komparativ-experimentbaserad-utredning-av-prestanda-och-effektivitet-av-markkollektorer-for-vertikalaborrhalsapplikationer/.

Kastovich, J. C., R. R. Lawrence, R. R. Hoffmann, and C. Pavlak. 1982. Advanced Electric Heat Pump Market and Business Analysis. ORNL/Sub/79-2471/1. Prepared under subcontract for Oak Ridge National Laboratory by Westinghouse Electric Corp. Oak Ridge, Tennessee: Oak Ridge National Laboratory.

Kavanaugh, S., M. Green, and K. Mescher. 2012. "Long-Term Commercial GSHP Performance, Part 4: Installation Costs." ASHRAE Journal 54(10).

Lantz, E., B. Sigrin, M. Gleason, R. Preus, and I. Garing-Gould. 2016. Assessing the Future of Distributed Wind: Opportunities for Behind-the-Meter Projects. NREL/TP-6A20-67337. Golden, Colorado: National Renewable Energy Laboratory. Available online at http://www.nrel.gov/docs/fy17osti/67337.pdf.

Liu, X. 2010. Assessment of National Benefits from Retrofitting Existing Single-Family Homes with Ground Source Hear Pump Systems. ORNL/TM-2010/122. Oak Ridge, Tennessee: Oak Ridge National Laboratory.

Liu, X. 2012. Summary and Analysis of Responses to Surveys on Experience with GHP Installations in Federal Facilities and Minimum Qualifications of GHP-Related Professionals. ORNL/TM-2012/452. Oak Ridge, Tennessee: Oak Ridge National Laboratory.

Liu, X., and G. Hellstrom. 2006. "Enhancements of an Integrated Simulation Tool for Ground-Source Heat Pump System Design and Energy Analysis." In Proceedings of the 10th International Conference on Thermal Energy Storage, May 31-June 2, 2006, Richard Stockton College of New Jersey. 
Liu, X., and J. Munk. 2013. Field Test and Evaluation of Residential Ground Source Heat Pump Systems Using Emerging Ground Coupling Technologies. ORNL/TM-2013/39. Oak Ridge, Tennessee: Oak Ridge National Laboratory.

Liu, X., S. Lu, P. Hughes, and Z. Cai. 2015. "A Comparative Study of the Status of GSHP Applications in the United States and China." Renewable and Sustainable Energy Reviews, Volume 48, August 2015, Pages 558-570.

Liu, X., M. Malhotra, and P. Im. 2017. "Performance Analysis of Ground Source Heat Pump Demonstration Projects in the United States." Presented at the 12th IEA Heat Pump Conference, May 1418, 2017, Rotterdam, the Netherlands.

Loveridge, F., C. G. Olgun, T. Brettmann, and W. Powrie. 2015. "The Thermal Behaviour of Three Different Auger Pressure Grouted Piles Used as Heat Exchangers." Geotechnical and Geological Engineering 33(2): 273-289.

Lund, J. W. 2001. “Geothermal Heat Pumps-An Overview. Geo-Heat Center Quarterly Bulletin 22(1): $1-2$.

Lund, J. W., and T. L. Boyd. 2016. "Direct Utilization of Geothermal Energy 2015 Worldwide Review." Geothermics 60: 66-93.

Madani, H. 2016. "Smart Control Strategies for Heat Pump Systems." Retrieved 7/15/2016, from http://effsysexpand.se/p16-komparativ-experimentbaserad-utredning-av-prestanda-och-effektivitet-avmarkkollektorer-for-vertikala-borrhalsapplikationer/.

McCabe, K., M. Gleason, T. Reber, and K. Young. 2016. "Characterizing U.S. Heat Demand for Potential Application of Geothermal Direct Use." In the Proceedings of the 40th GRC Conference, October 23-26, 2016, Sacramento, California.

Monzó, P., P. Mogensen, J. Acuña, F. Ruiz-Calvo, and C. Montagud. 2015. “A Novel Numerical Approach for Imposing a Temperature Boundary Condition at the Borehole Wall in Borehole Fields." Geothermics 56: 35-44.

Navigant Research. 2013. Geothermal Heat Pumps Residential and Commercial Applications for Geothermal Heat Pumps: Global Market Analysis and Forecasts. Chicago, Illinois: Navigant Consulting, 2013.

NGDS (National Geothermal Data System). 2016. Available online at http://search.geothermaldata.org/dataset.

Millstein, D., S. Jeong, G. Heath, D. Keyser, J. Macknick, J. McCall, and S. Nicholson. 2017. Geothermal Vision Study: Impacts Preview. Impacts Taskforce interim presentation, 7/14/2017.

Niu, F., X. Loiu, and Z. O’Neill. 2016. A Simulation-Based Study on Different Control Strategies for Variable-Speed Pumps in Distributed Ground-Source Heat Pump Systems. ASHRAE Transactions Paper 122(2).

NREL (National Renewable Energy Laboratory). 2007. Source Energy and Emission Factors for Energy Use in Buildings. NREL/TP-550-38617. Golden, Colorado: National Renewable Energy Laboratory. 
NYSERDA (New York State E Research and Development Authority). 2017. Renewable Heating and Cooling Policy Framework. Available online at https://www.nyserda.ny.gov/-

/media/Files/Publications/PPSER/NYSERDA/RHC-Framework.pdf.

Ouzzane, M., P. Eslami-Nejad, M. Badache, and Z. Aidoun. 2015. "New Correlations for the Prediction of the Undisturbed Ground Temperature.” Geothermics 53(0): 379-384.

Paidipati, J., L. Frantzis, H. Sawyer, and A. Kurrasch. 2008. Rooftop Photovoltaics Market Penetration Scenarios. Burlington, Massachusetts: Navigant Consulting. NREL/SR-581-42306.

Palm, B., and M. Ignatowicz. 2016. "Adsorption Corrosion Inhibitors, Green Corrosion Inhibitors and Alternative Secondary Fluids for Indirect Systems.” Retrieved 7/15/2016, from http://effsysexpand.se/p03-adsorberande-korrosionsinhibitorer/.

Priority Metrics Group. 2009. "Global Geothermal Heat Pump Market 2009: Energy Beneath the Backyard.” Business Wire, 2009.

R. W. Beck Inc. 2009. Distributed Renewable Energy Operating Impacts and Valuation Study. Seattle, Washington: Prepared by R. W. Beck Inc. for Arizona Public Service. Available on line at http://files.meetup.com/1073632/RW-Beck-Report.pdf.

Raymond, J., L. Lamarche, and M. Malo. 2015. "Field Demonstration of a First Thermal Response Test with a Low Power Source.” Applied Energy 147(0): 30-39.

Remund, C., and R. Carda. 2009. Ground Source Heat Pump Residential and Light Commercial Design and Installation Guide. Oklahoma State University: International Ground Source Heat Pump Association.

RHC-Platform. 2011. Common Vision for the Renewable Heating and Cooling Sector in Europe: 20202030-2050. Luxembourg: Publications Office of the European Union, 48p.

RHC-Platform. 2013. Stategic Research and Innovation Agenda for Renewable Heating and Cooling. Brussels, 87p.

Rice, C. K., V. Baxter, S. Hern, T. McDowell, J. Munk and B. Shen. 2013. "Development of a

Residential Ground-Source Integrated Heat Pump.” ASHRAE Transactions 2013: 119(1): p1-8.

Rogers, Everett M. 2003. Diffusion of Innovations, 5th ed. New York: Free Press.

Rouleau, J., L. Gosselin, and J. Raymond. 2016. "New Concept of Combined Hydro-Thermal Response Tests (H/TRTS) for Ground Heat Exchangers." Geothermics 62: 103-114.

RSMeans. 2016. Building Construction Cost Data. Available online at https://www.rsmeans.com/products/online/building-construction-cost-data-online.aspx.

Sachs, H. 2002. “Geology and Drilling Methods for Ground-Source Heat Pump Installations.” ASHRAE, Atlanta, 2002.

Salomone, L. A., and J. I. Marlowe. 1989. Soil Rock Classification According to Thermal Conductivity. EPRI CU-6482. Palo Alto, California: Electric Power Research Institute. 
Sigrin, B., and E. Drury. 2014. "Diffusion into New Markets: Economic Returns Required by Households to Adopt Rooftop Photovoltaics." Presented at the AAAI 2014 Fall Symposium on Energy Market Prediction, November 13-15, 2014, Washington, DC.

Sigrin, B., M. Gleason, R. Preus, I. Baring-Gould, and R. Margolis. 2016. The Distributed Generation Market Demand Model (dGen): Documentation. NREL/TP-6A20-65231. Golden, Colorado: National Renewable Energy Laboratory. Available online at http://www.nrel.gov/docs/fy16osti/65231.pdf.

SMU (Southern Methodist UniversitySMU). 2016. Geothermal Laboratory Thermal Conductivity Observation. Available online at http://159.87.39.4/dataset/smu-geothermal-laboratory-thermalconductivity-observation.

Southard, L. E., X. Liu, and J. D. Spitler. 2014. "Performance of HVAC Systems at ASHRAE HQPart 1." ASHRAE Journal 56: 14-24.

Spitler, J., S. Javed, and R. Grundmann. 2016. "Calculation Tool for Effective Borehole Thermal Resistance.” Presented at Clima 2016, May 22-25, 2016, Aalborg, Denmark.

Spitler, J., L. Southard, and X. Liu.2017. Technical Support for GeoVision Study. (Internal Document.)

Stignor, C. H. 2016. "Further Developments of Heat Pump Systems for NZEB." Retrieved 7/15/2016, from http://effsysexpand.se/p06-vidareutveckling-av-varmepumpssystem-for-nara-noll-energi-hus/.

Su, L., X. Liu, and R. Clemenzi. 2017. "Dynamic Determination of Ground Thermal Conductivity and Minimum Thermal Response Test Duration Using the Line Source Model." Presented at the 12th IEA Heat Pump Conference, May 15-18, 2017, Rotterdam, the Netherlands.

Thygesen, R. 2016. "Low Energy Buildings Equipped with Heat Pumps for High Self-Consumption of Photovoltaic Electricity.” Doctoral Thesis, Mälardalen University, Sweden.

TTGeo and GMC (Tuya Terra Geo Corp. and Geothermal Managemetn Company Inc.) 2016. The Roadmap for Development of Geothermal Direct-Use Projects in British Columbia, Canada. Geoscience BC Report 2016-07 Section B. Vancouver, British Columbia: Geoscience BC.

Verdecchia, A., D. Brunelli, F. Tinti, A. Barbaresi, P. Tassinari, and L. Benini. 2016. "Low-Cost MicroThermal Response Test System for Characterizing Very Shallow Geothermal Energy." Presented at the 2016 IEEE Workshop on Environmental, Energy, and Structural Monitoring Systems, June 13-14, 2016, Bari, Italy.

Wang, S, X. Liu, and S. Gates. 2015. "Comparative Study of Control Strategies for Hybrid GSHP System in the Cooling Dominated Climate." Energy and Buildings 89: 222-230.

Wemhoener, C. 2016. “IEA HPP Annex 40-Switzerland Participation.” Retrieved July 23, 2016, from https://www.annex40.net/index.php?id=11581.

Xing, L. 2014. "Estimations of Undisturbed Ground Temperatures using Numerical and Analytical Modeling." Doctoral Thesis, Oklahoma State University.

Xu, W. 2013. Report on the Situation of China Ground-Source Heat Pump. Beijing: China Architecture and Building Press. 
Xu, W., H. Li, J. Wu, Z. Yu, and L. Yang. 2017. "Application of GSHP in Nearly Zero Energy Building (NZEB)." Presented at the 12th IEA Heat Pump Conference, May 15-18, 2017, Rotterdam, the Netherlands 